\title{
Synthesis, Inhibitory Activity, and In Silico Modeling of Selective COX-1 Inhibitors with Quinazoline Core
}

Marcela Dvorakova ${ }^{a, *}$, Lenka Langhansova ${ }^{a}$, Veronika Temml ${ }^{b}$, Antonio Pavicic ${ }^{a}$, Tomas Vanek ${ }^{a}$, Premysl Landa ${ }^{a}$

a Laboratory of Plant Biotechnologies, Czech Academy of Sciences, Institute of Experimental Botany, Rozvojova 263, 16502 Prague 6 - Lysolaje, Czech Republic

${ }^{\mathrm{b}}$ Department of Pharmaceutical and Medicinal Chemistry, Paracelsus Medical University of Salzburg, Strubergasse 21, 5020 Salzburg, Austria

\section{Supporting Information}

\section{Table of Contents}

${ }^{1} \mathrm{H}-\mathrm{NMR}$ and ${ }^{13} \mathrm{C}-\mathrm{NMR}$ spectra of compounds 3a-v.

${ }^{1} \mathrm{H}-\mathrm{NMR}$ and ${ }^{13} \mathrm{C}-\mathrm{NMR}$ spectra of compounds $\mathbf{5 a - b}$.

${ }^{1} \mathrm{H}-\mathrm{NMR}$ and ${ }^{13} \mathrm{C}-\mathrm{NMR}$ spectra of compounds 6a-e. $. \mathrm{S} 26-\mathrm{S} 30$

${ }^{1} \mathrm{H}-\mathrm{NMR}$ and ${ }^{13} \mathrm{C}-\mathrm{NMR}$ spectra of compounds 7a-o. $.531-545$

${ }^{1} \mathrm{H}-\mathrm{NMR}$ and ${ }^{13} \mathrm{C}-\mathrm{NMR}$ spectra of compounds 8a-b. $.546-547$

${ }^{1} \mathrm{H}-\mathrm{NMR}$ and ${ }^{13} \mathrm{C}-\mathrm{NMR}$ spectra of compounds $9 \mathrm{a}-\mathbf{b}$. S48-S49

Table 1S. Percentual inhibition of COX-1 and COX-2 isoenzymes by tested compounds at $20 \mu \mathrm{M}$....S50 Table 2 S. COX-1 inhibition by compound $\mathbf{9 b}$ and Ibuprofen at different substrate concentrations...S50 Graph 1S. COX-1 inhibitory activity in \% vs. $\log$ (concentration of the most active compounds) .551 UPLC/UV-VIS chromatogram_Blanks S51-S52 UPLC/UV-VIS chromatograms of the active compounds. S52-S57 


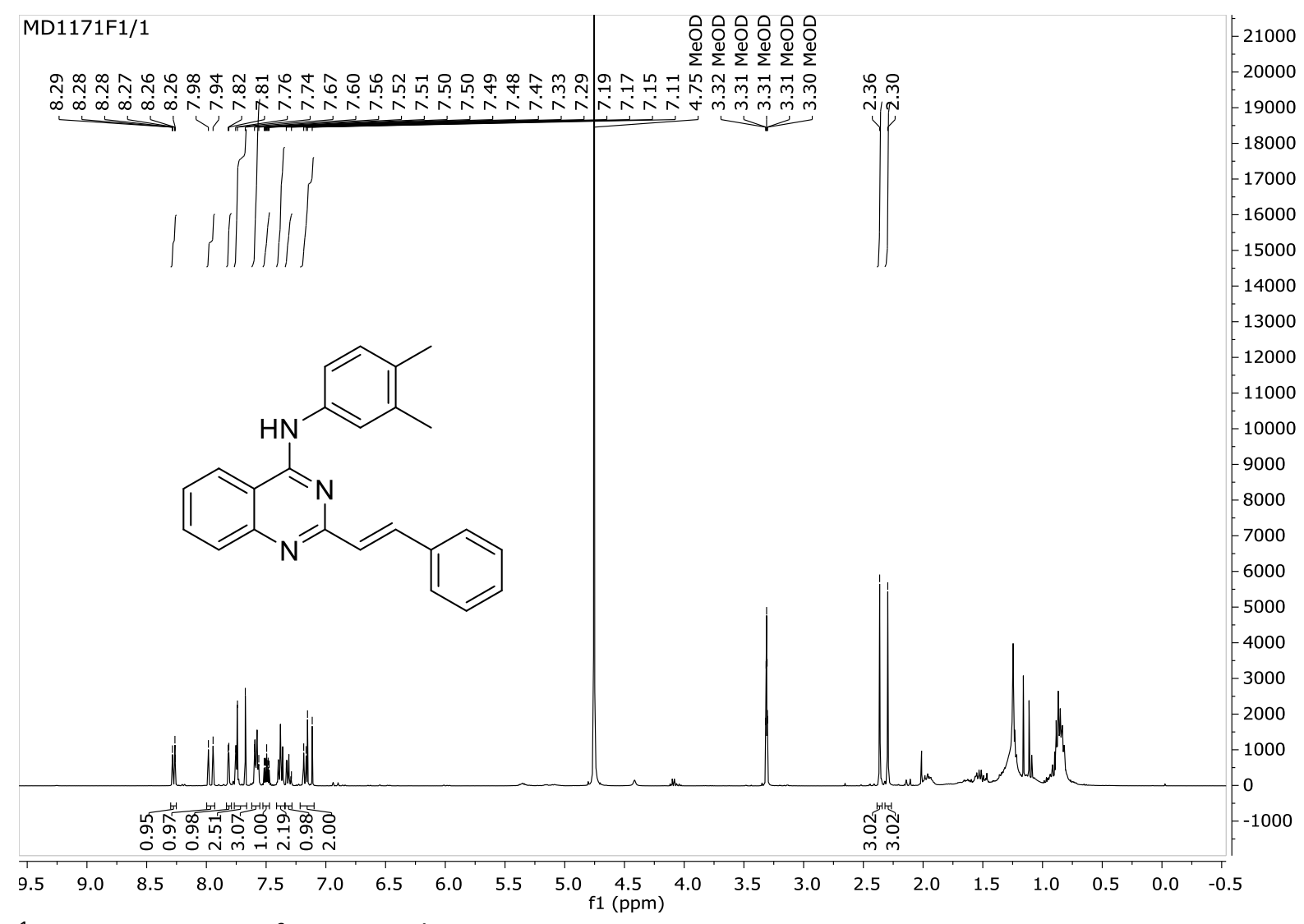

${ }^{1} \mathrm{H}-\mathrm{NMR}$ spectrum of compound $3 \mathrm{a}$

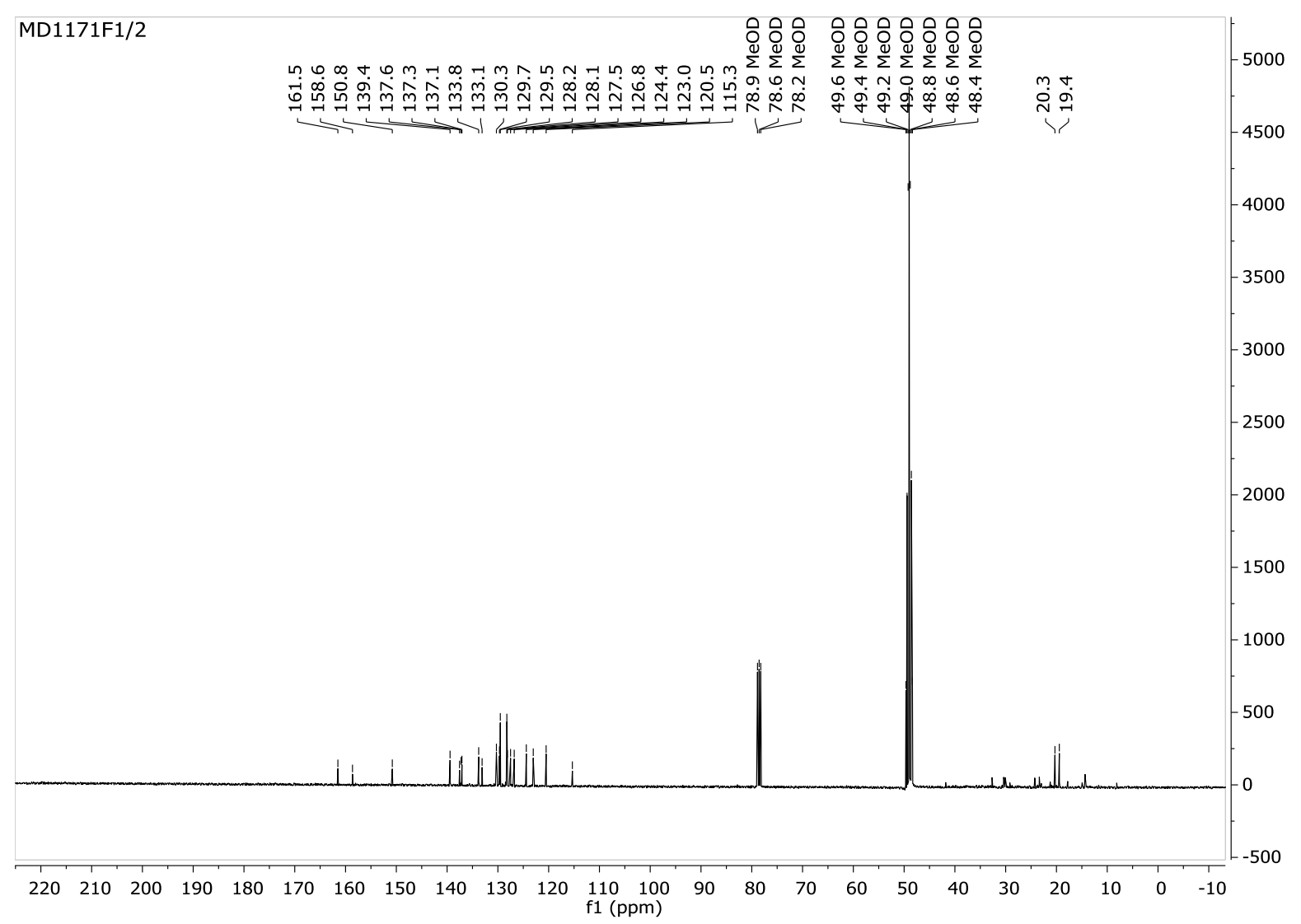

${ }^{13} \mathrm{C}-\mathrm{NMR}$ spectrum of compound $\mathbf{3 a}$ 


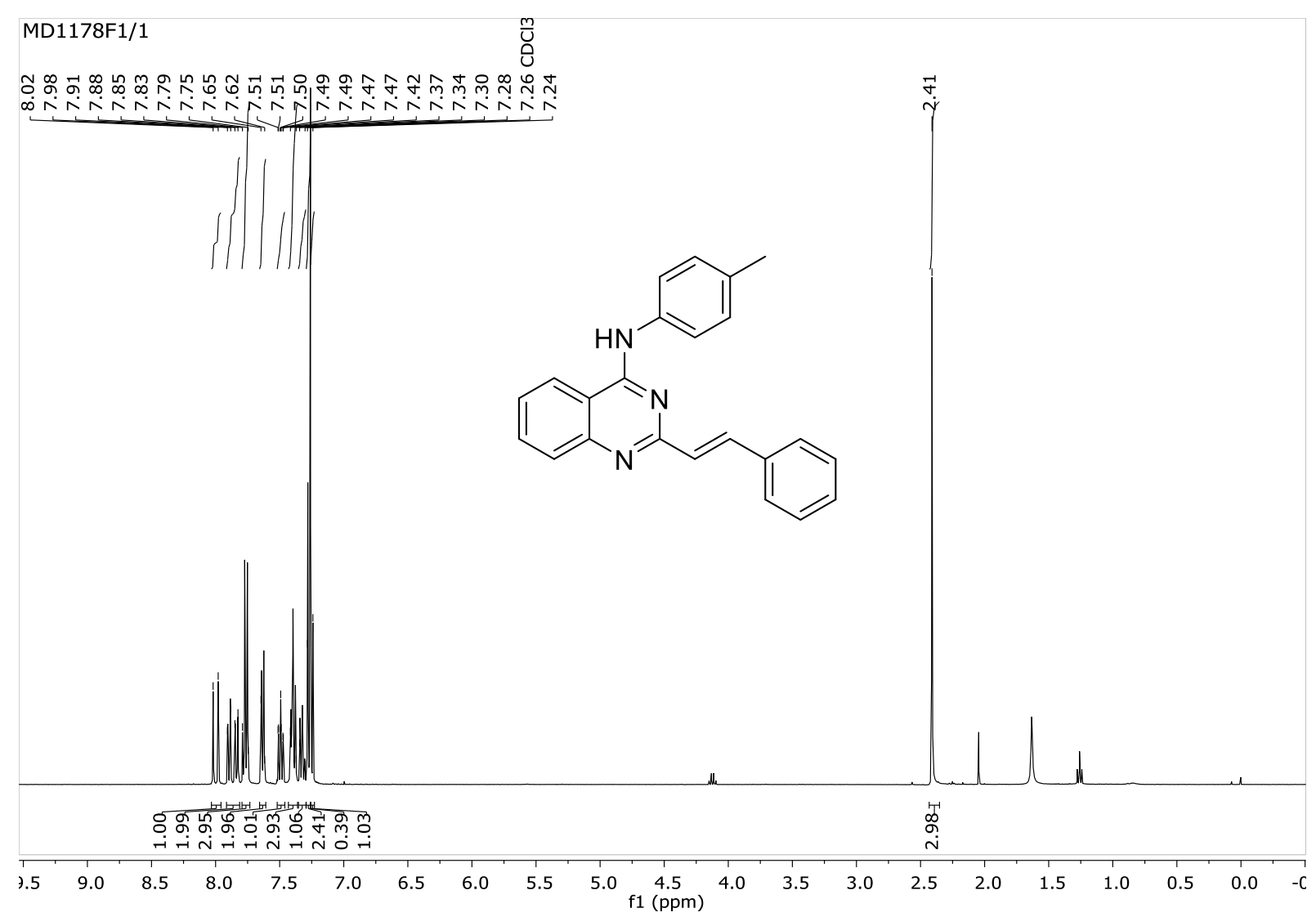

${ }^{1} \mathrm{H}-\mathrm{NMR}$ spectrum of compound $\mathbf{3 b}$

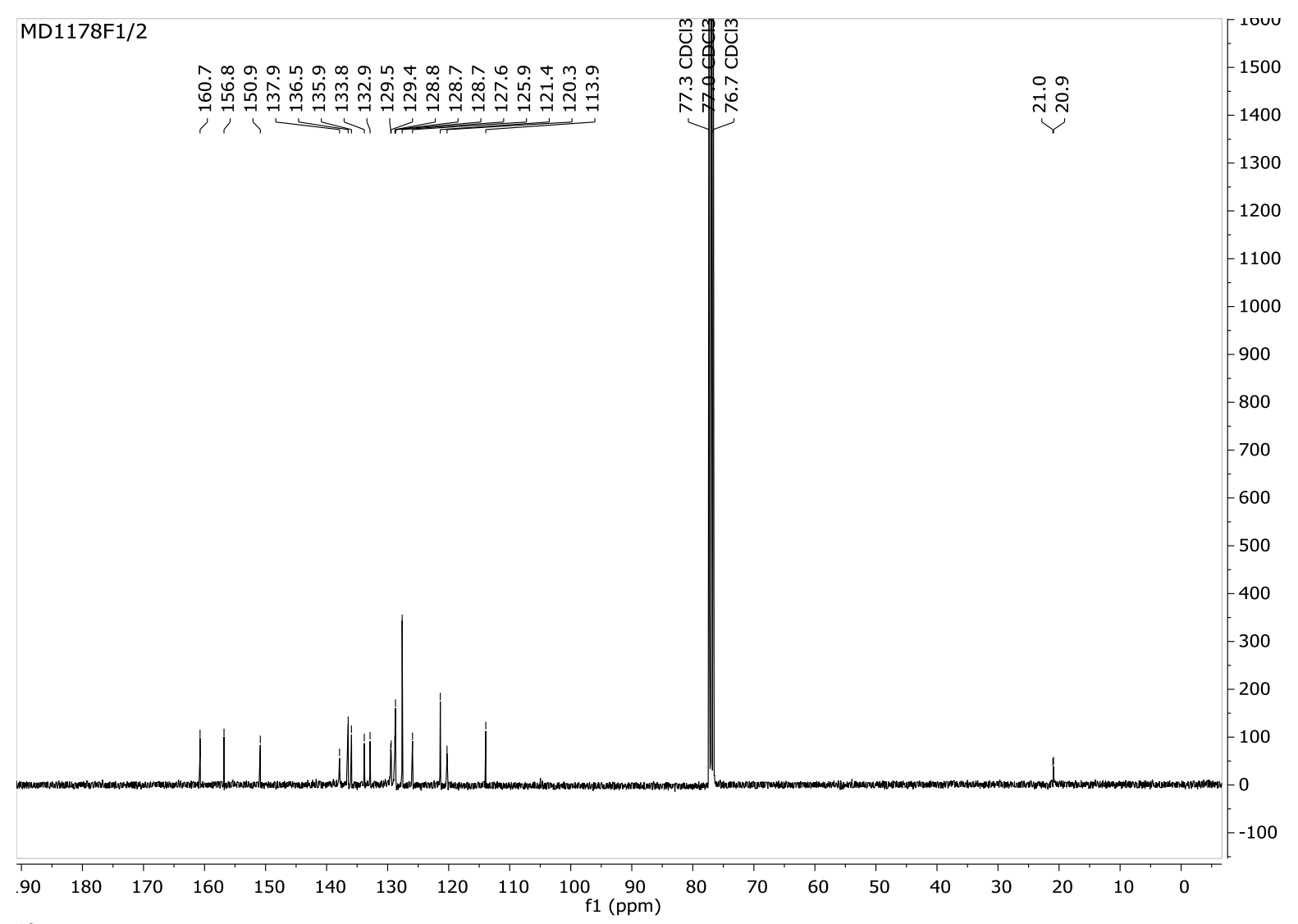

${ }^{13} \mathrm{C}$-NMR spectrum of compound $\mathbf{3 b}$ 


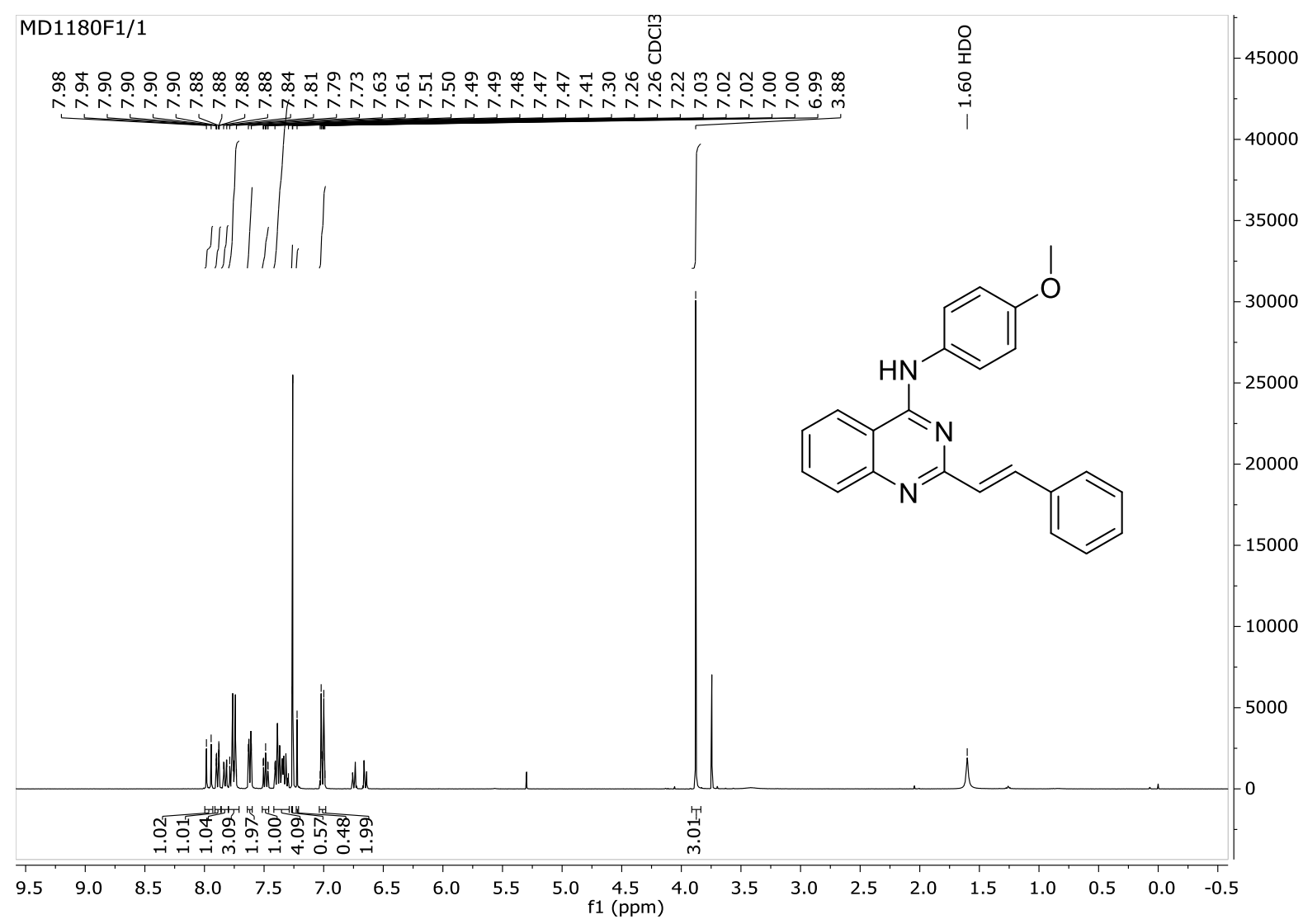

${ }^{1} \mathrm{H}-\mathrm{NMR}$ spectrum of compound $\mathbf{3 c}$

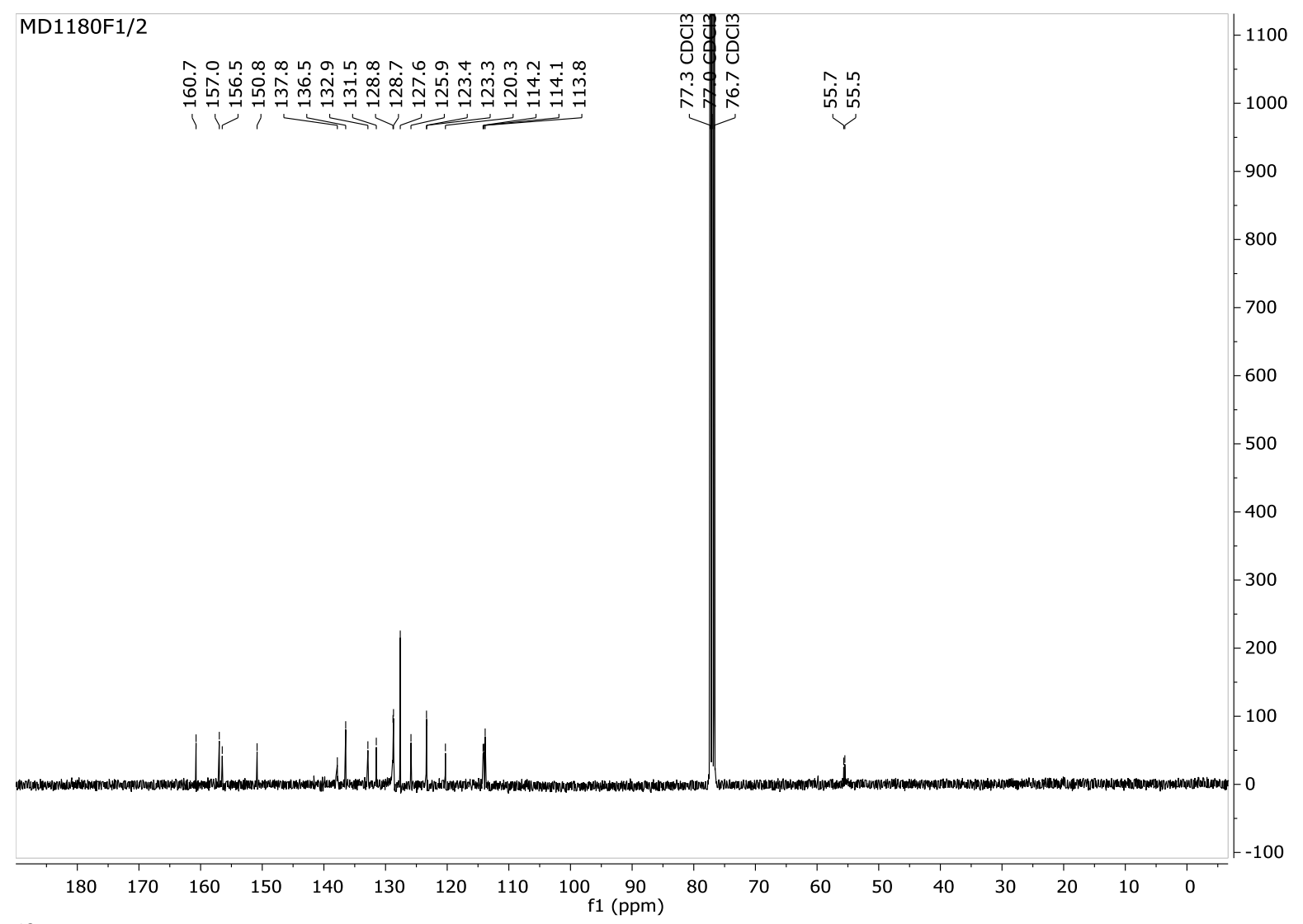

${ }^{13} \mathrm{C}-\mathrm{NMR}$ spectrum of compound $\mathbf{3 c}$ 


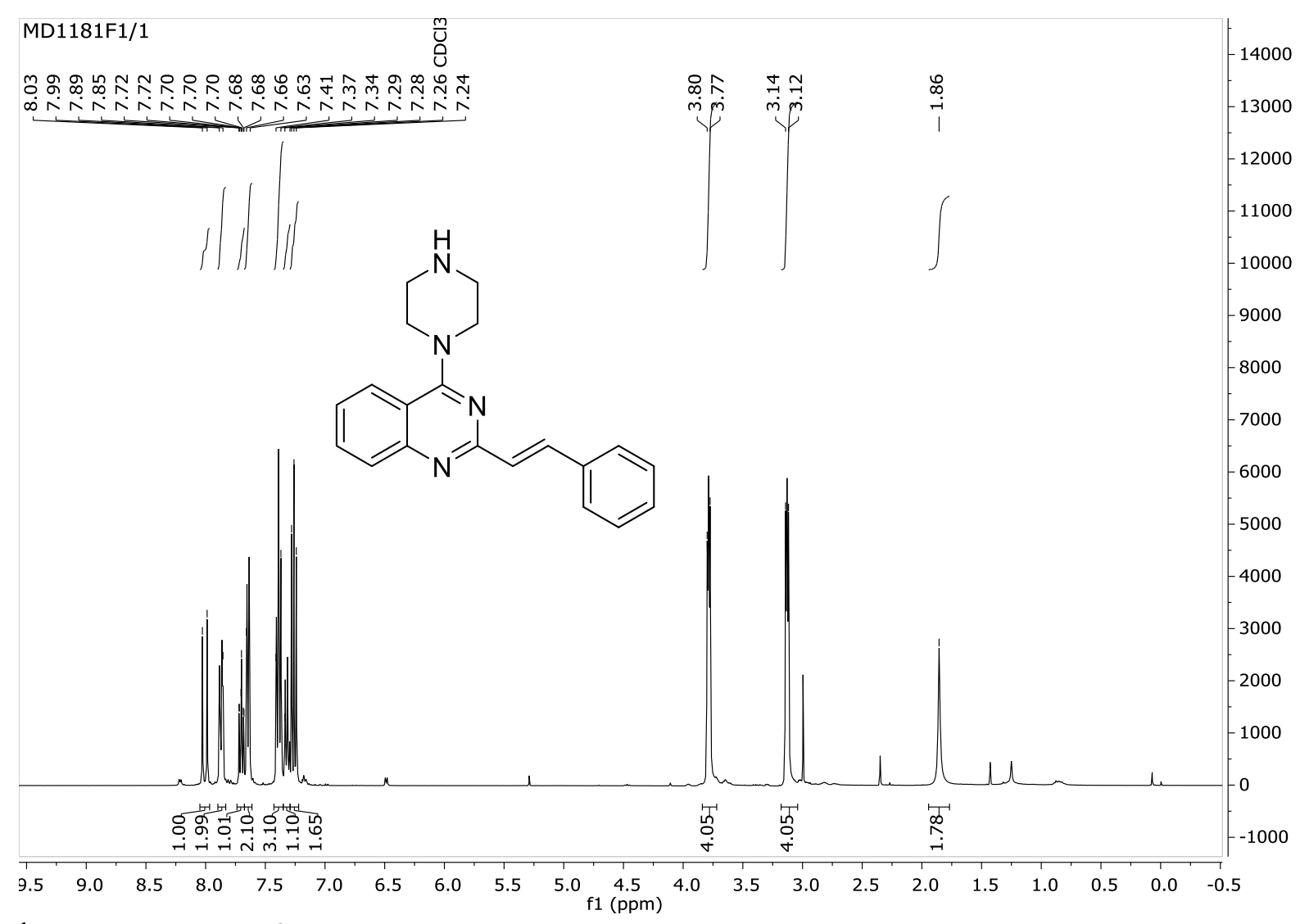

${ }^{1} \mathrm{H}-\mathrm{NMR}$ spectrum of compound $\mathbf{3 d}$

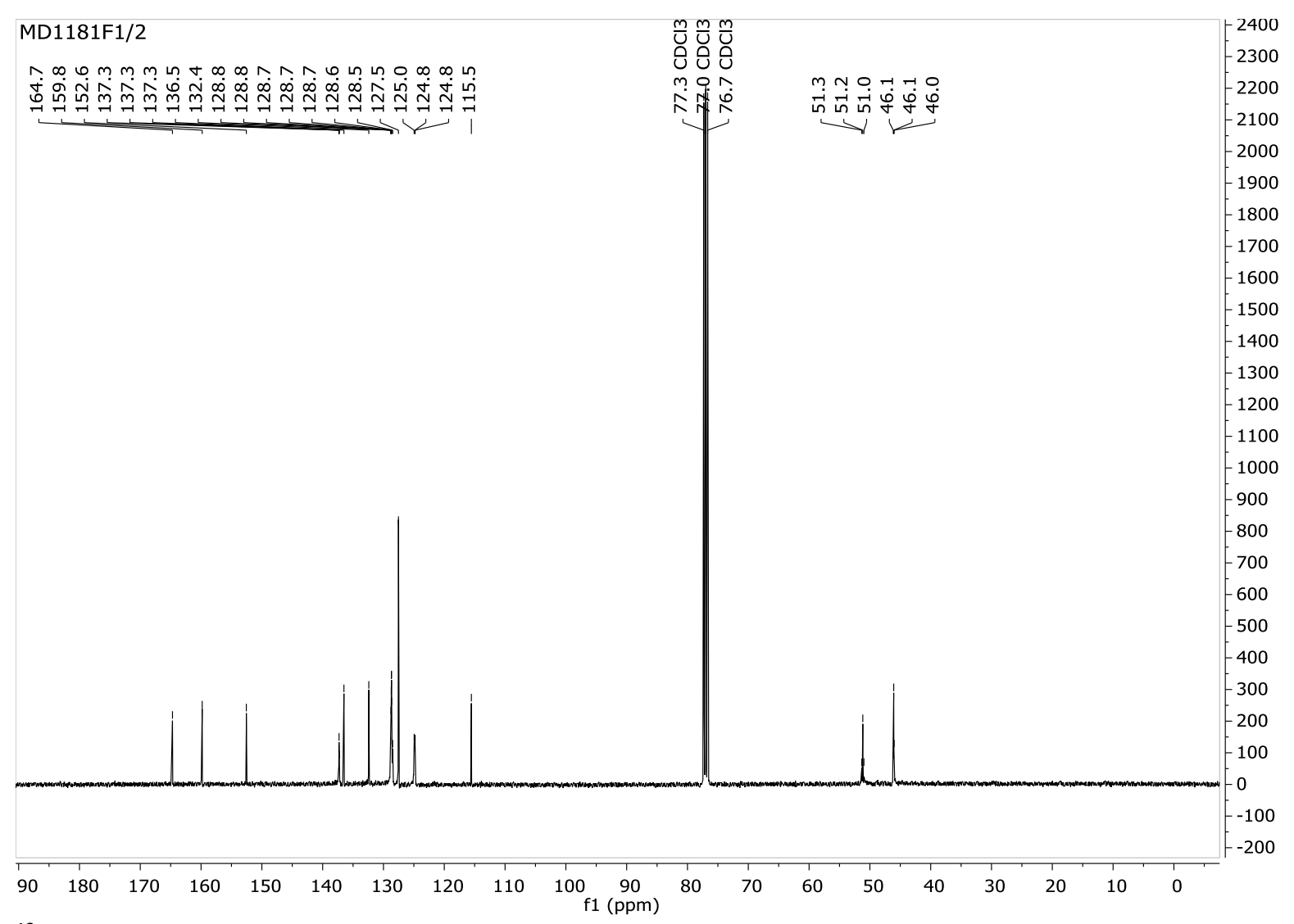

${ }^{13} \mathrm{C}$-NMR spectrum of compound $\mathbf{3 d}$ 


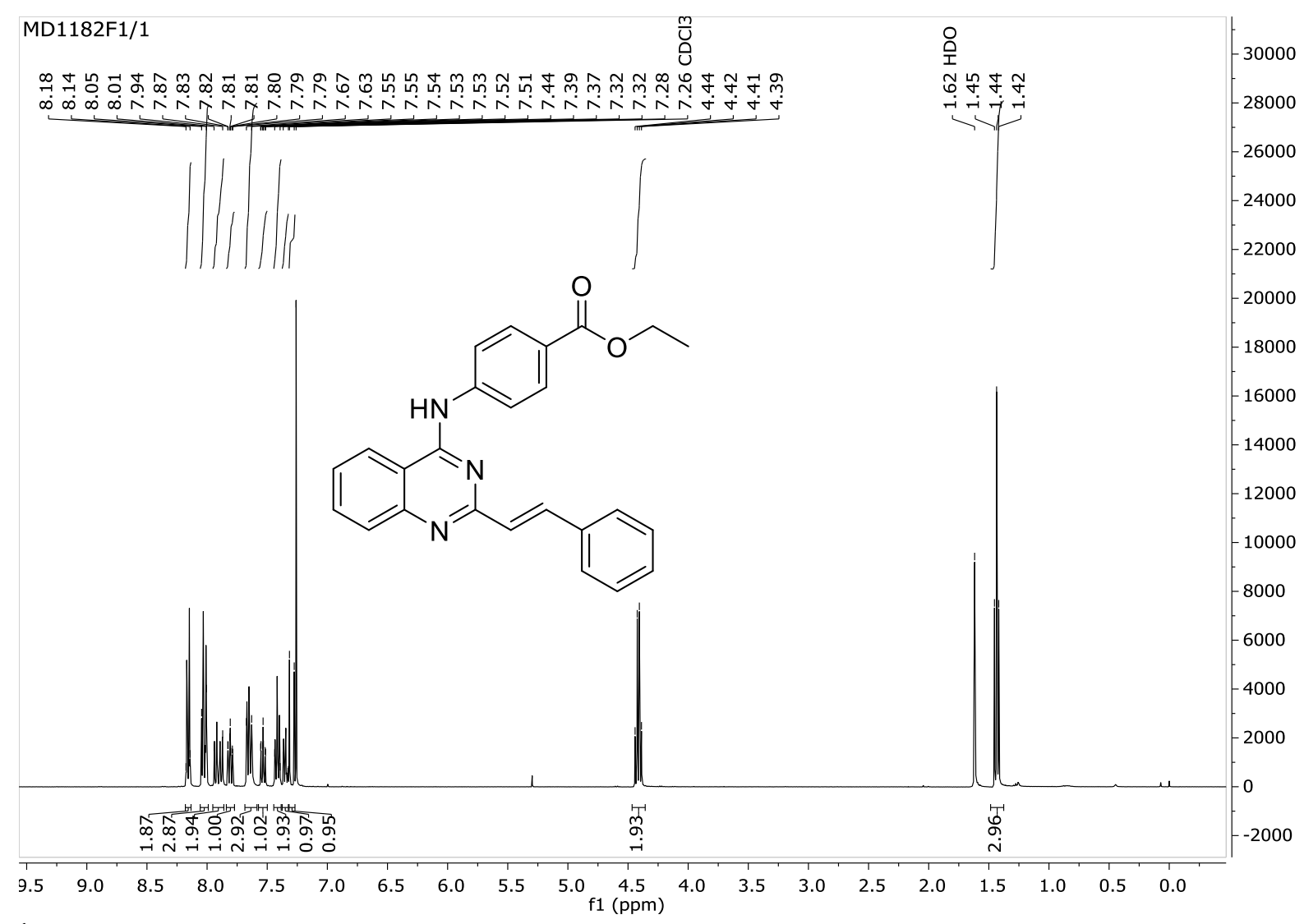

${ }^{1} \mathrm{H}-\mathrm{NMR}$ spectrum of compound $\mathbf{3 e}$

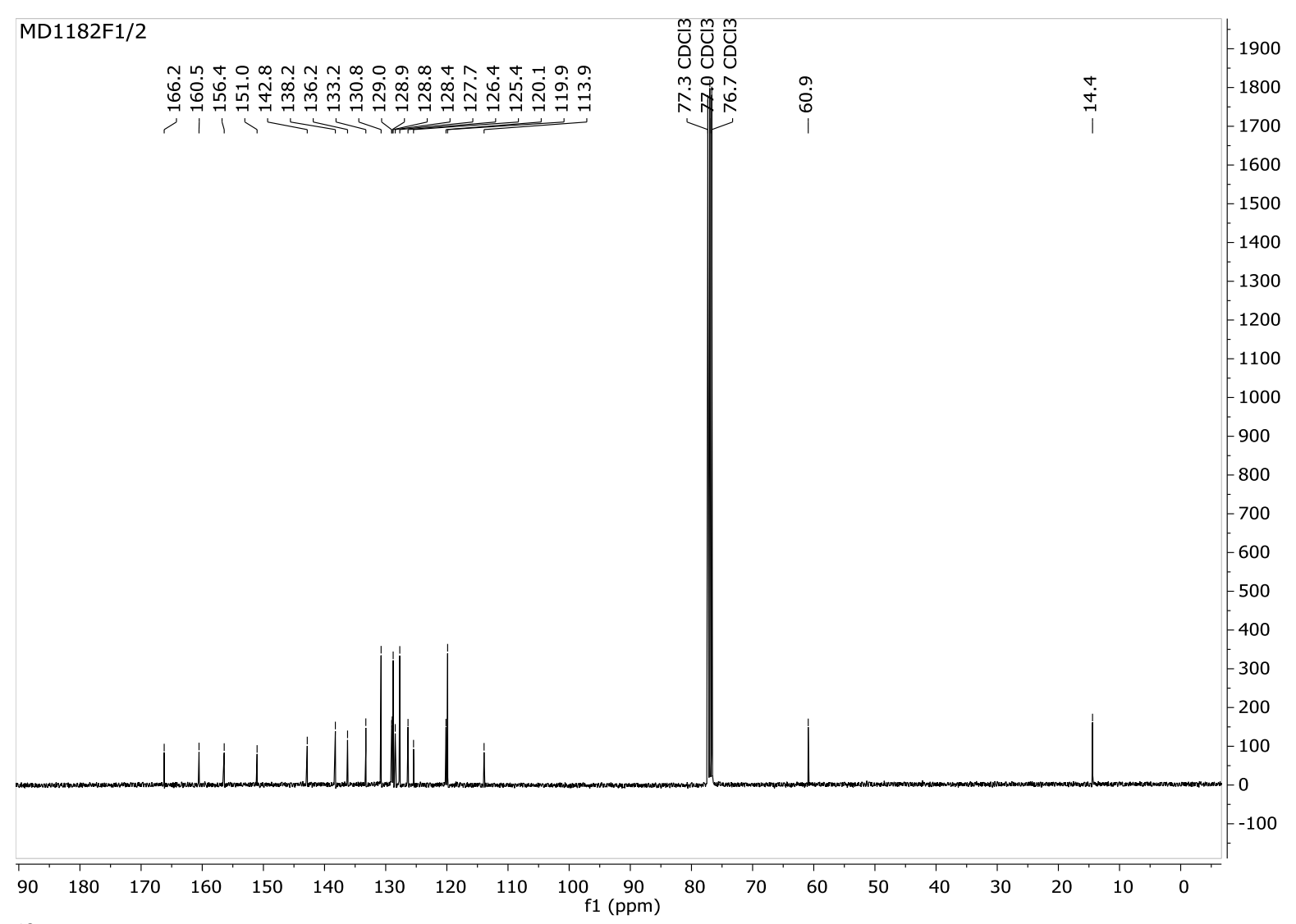

${ }^{13} \mathrm{C}-\mathrm{NMR}$ spectrum of compound $\mathbf{3 e}$ 


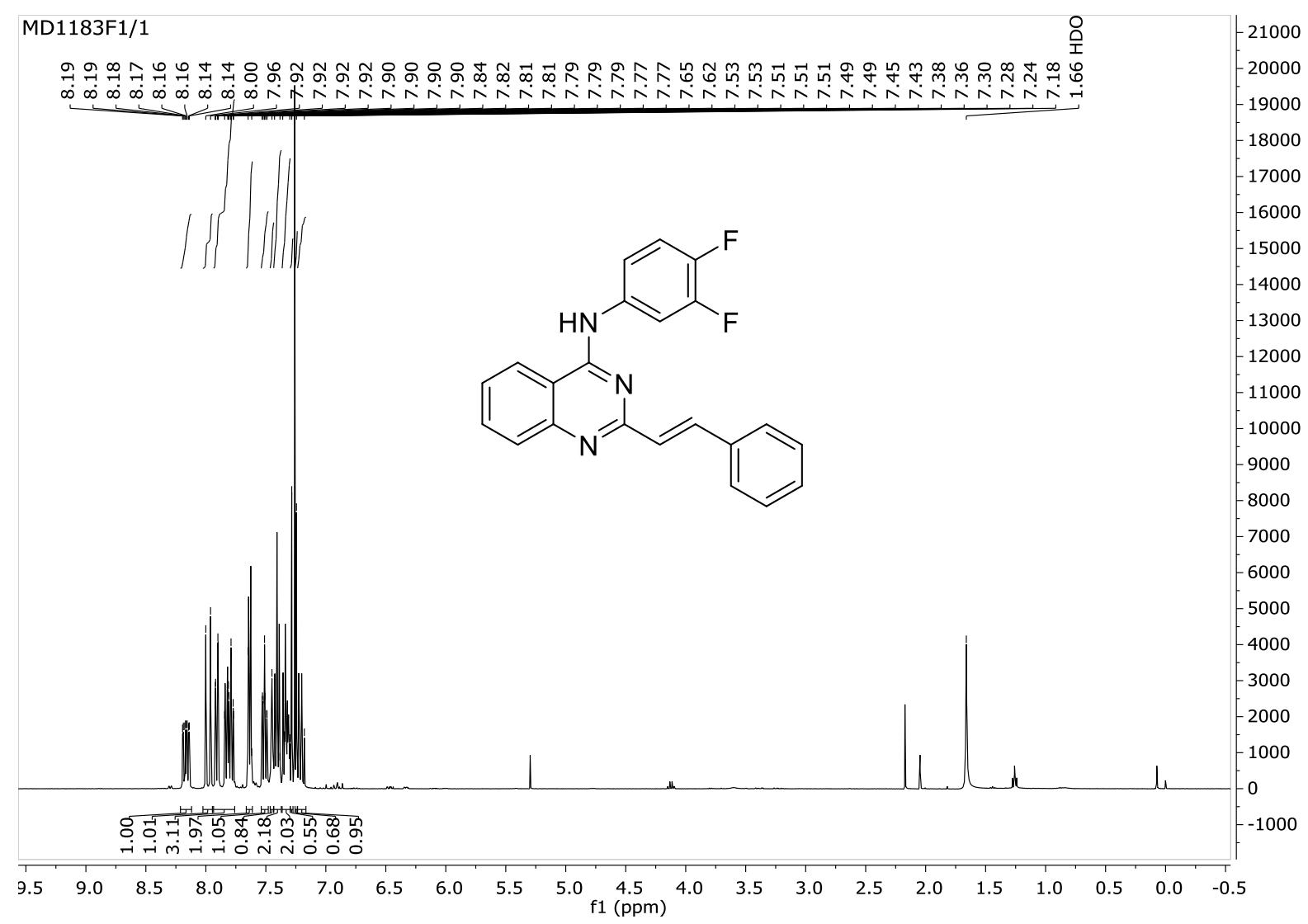

${ }^{1} \mathrm{H}-\mathrm{NMR}$ spectrum of compound $\mathbf{3 f}$

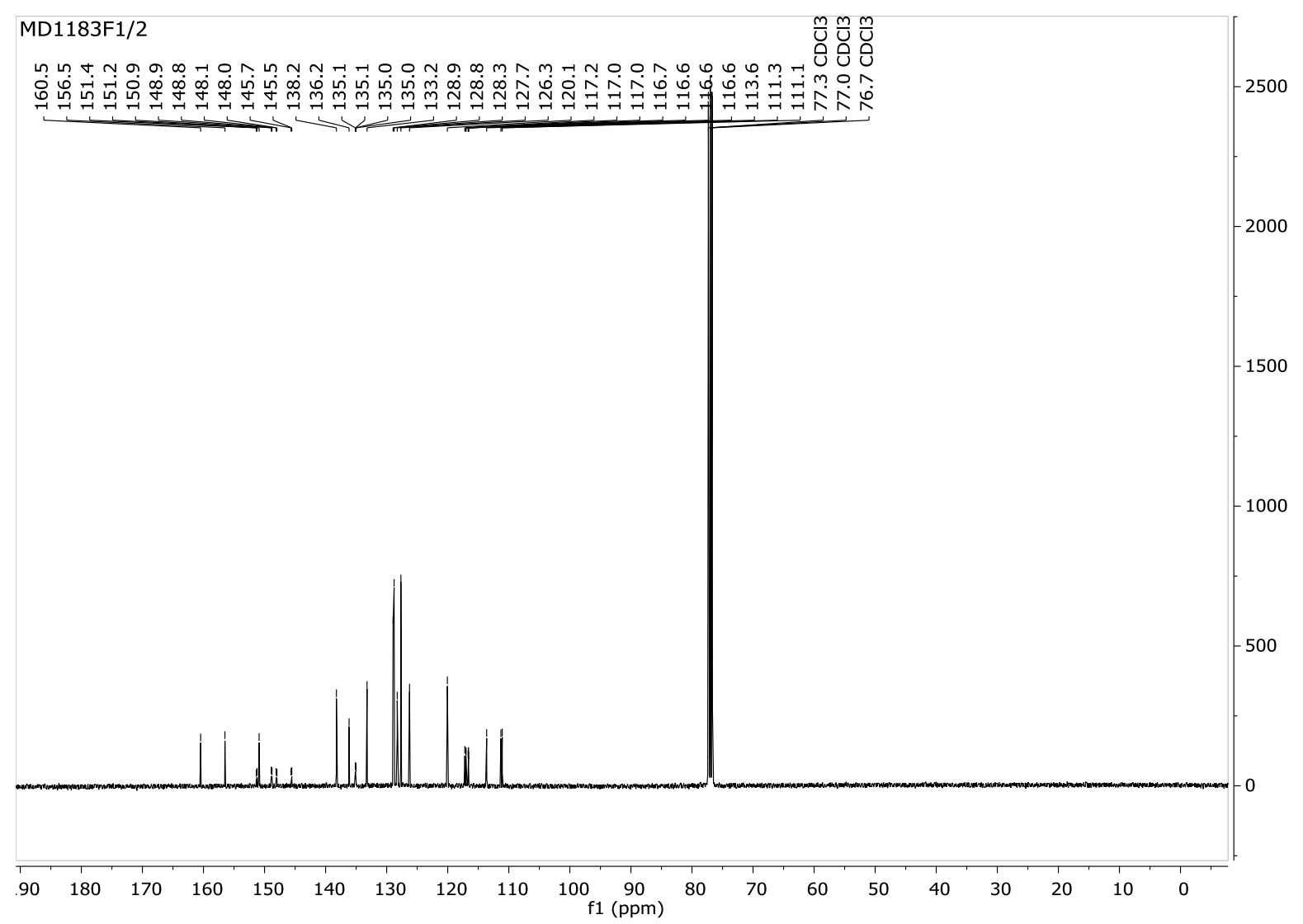

${ }^{13} \mathrm{C}-\mathrm{NMR}$ spectrum of compound $\mathbf{3 f}$ 


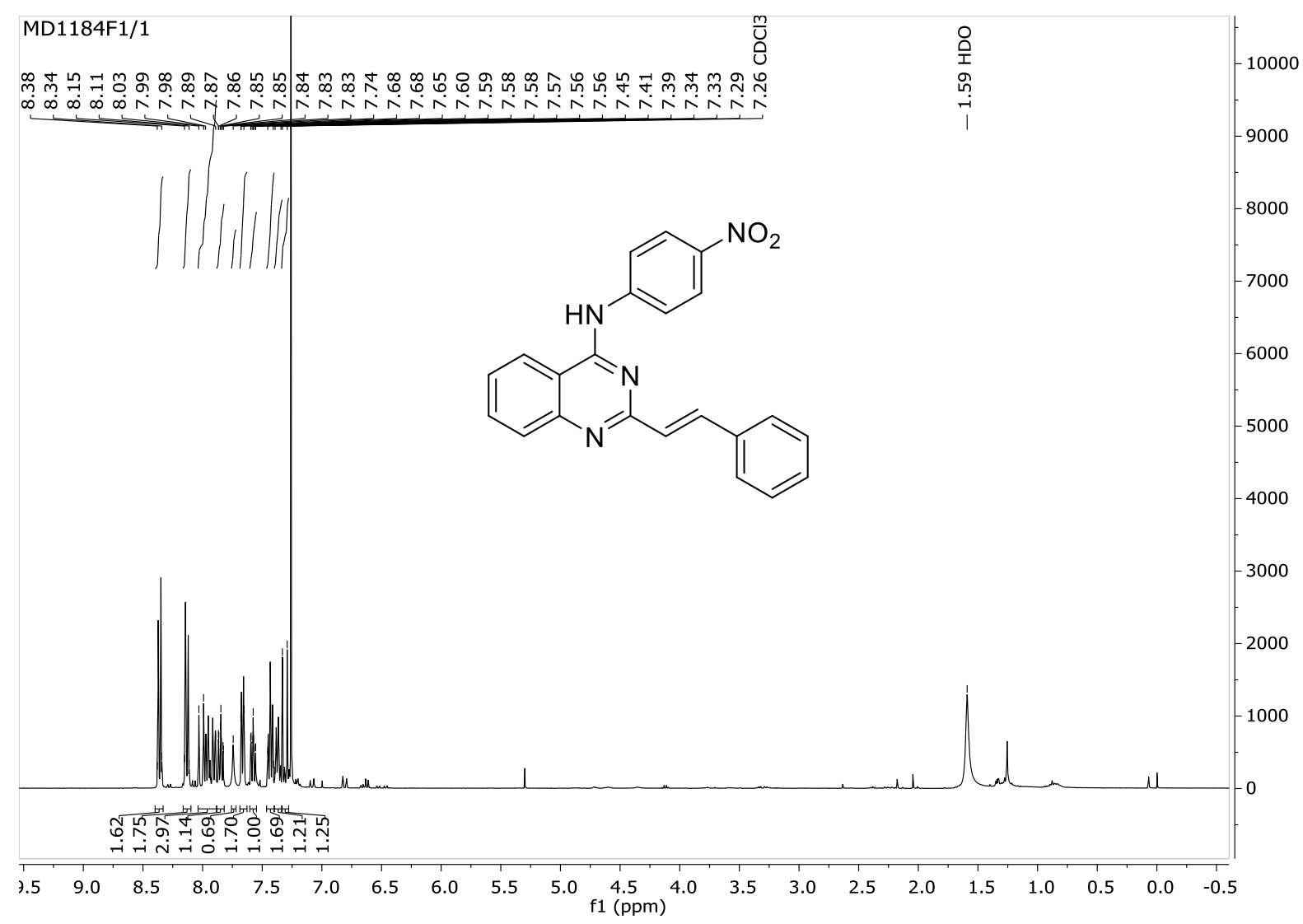

${ }^{1} \mathrm{H}-\mathrm{NMR}$ spectrum of compound $\mathbf{3 g}$

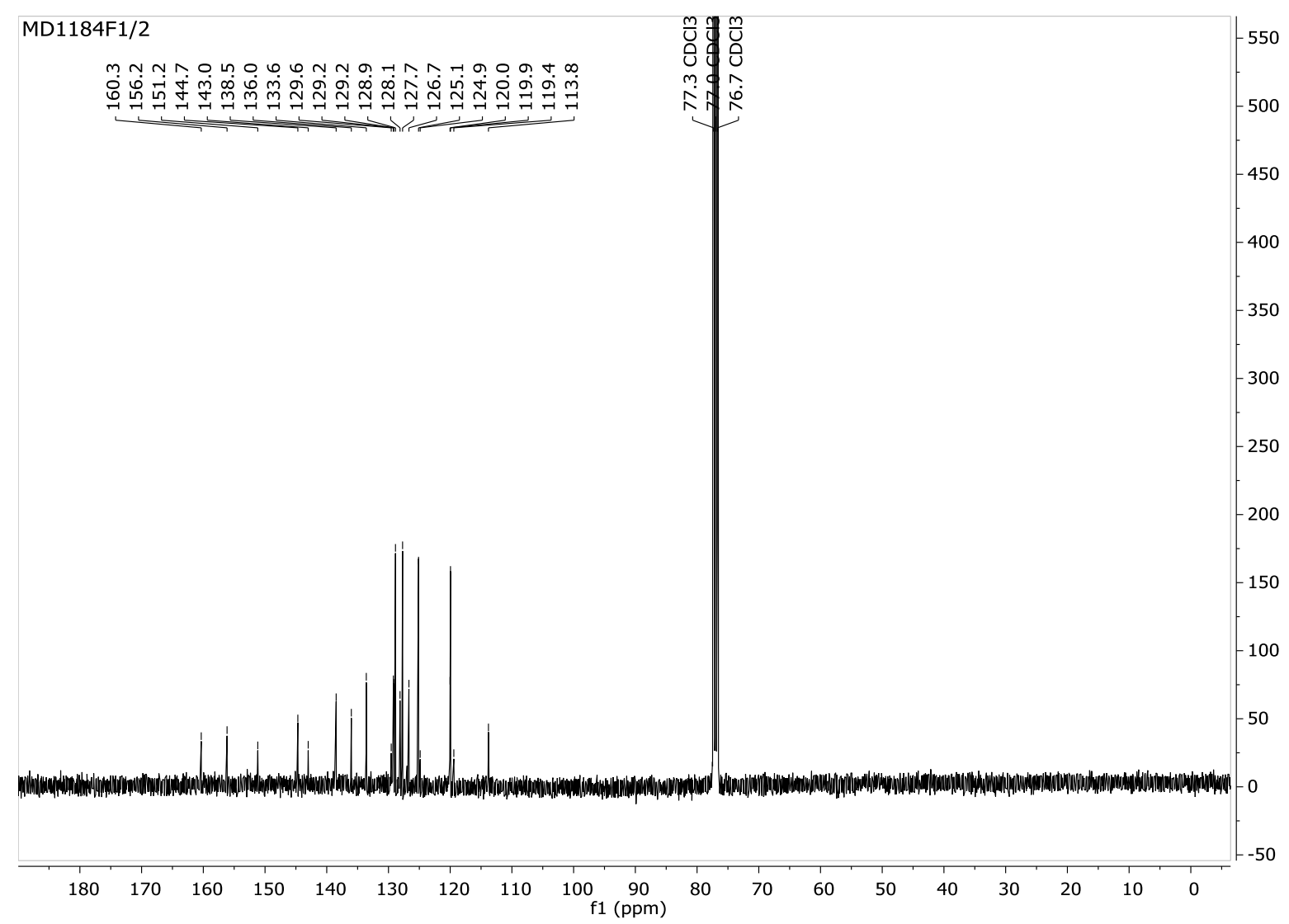

${ }^{1} \mathrm{H}-\mathrm{NMR}$ spectrum of compound $\mathbf{3 g}$ 


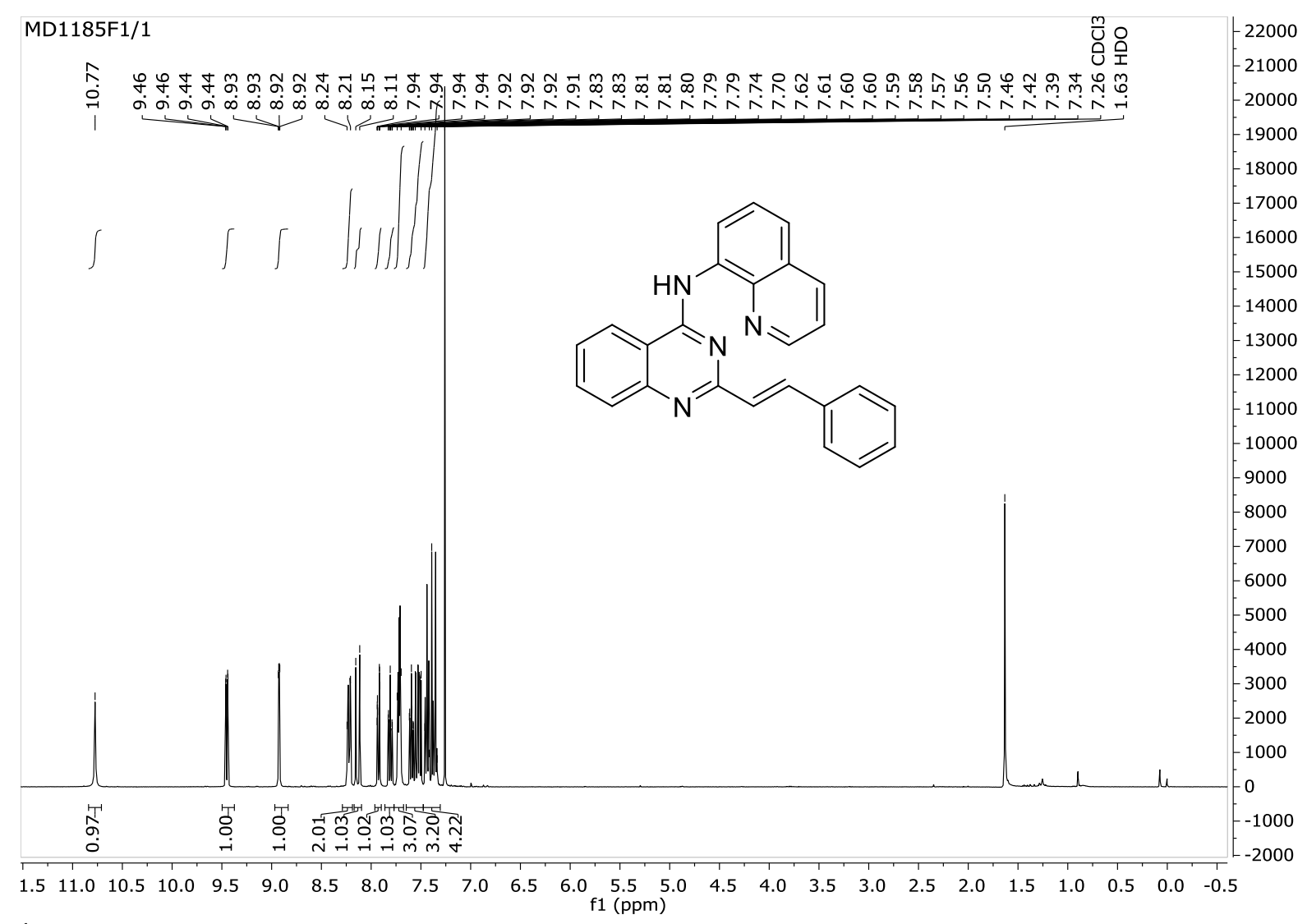

${ }^{1} \mathrm{H}-\mathrm{NMR}$ spectrum of compound $\mathbf{3 h}$

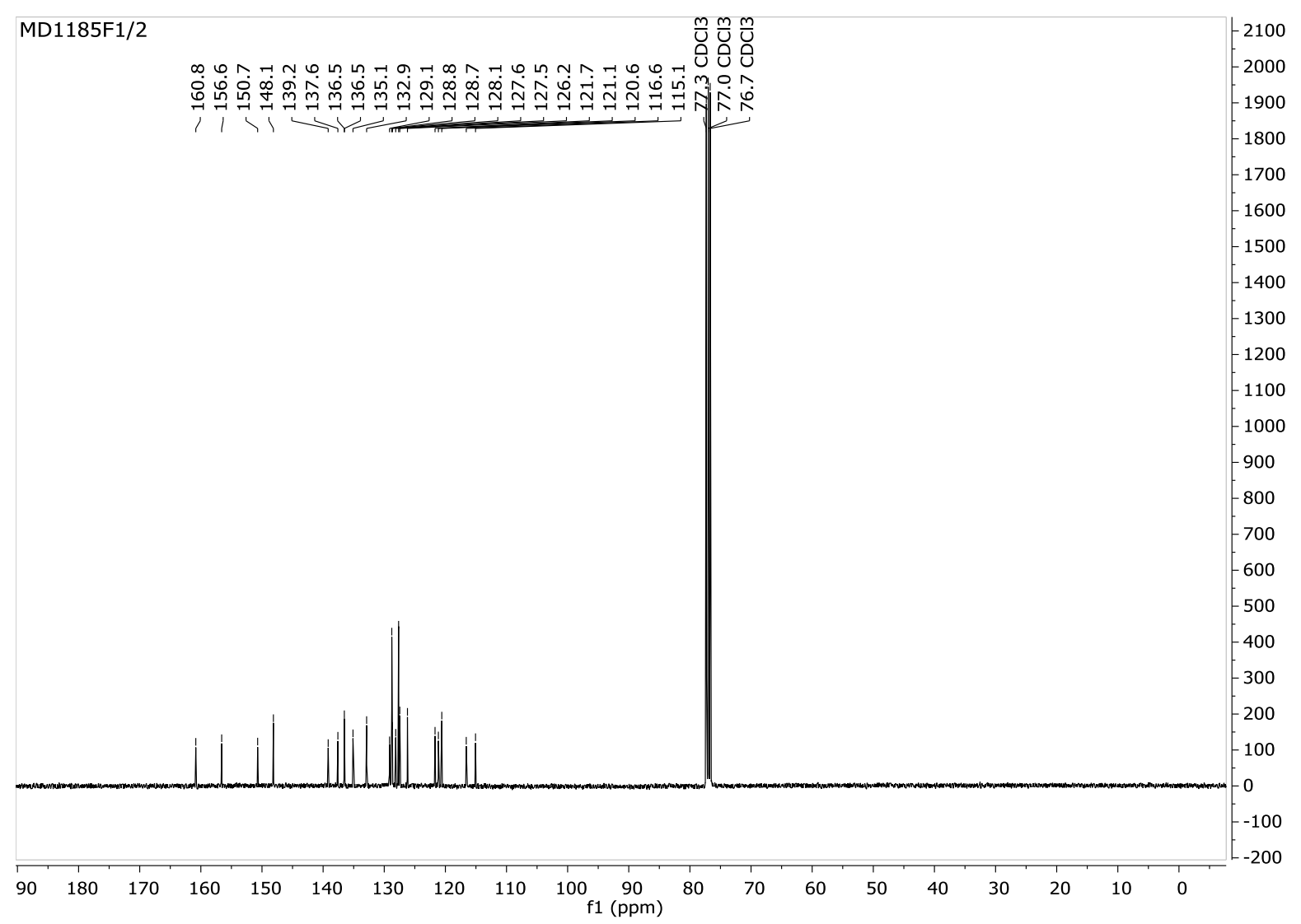

${ }^{13} \mathrm{C}-\mathrm{NMR}$ spectrum of compound $3 \mathrm{~h}$ 


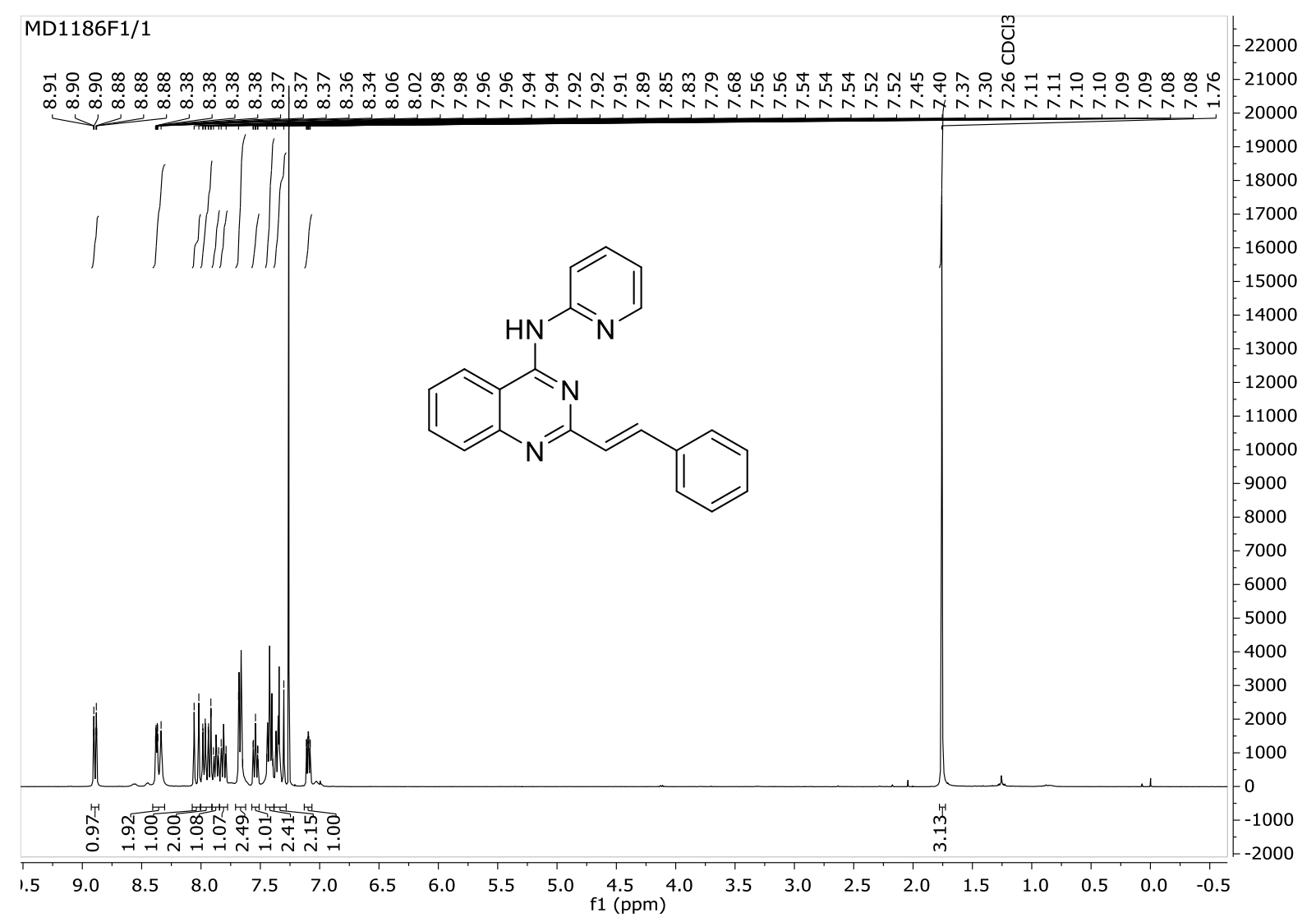

${ }^{1} \mathrm{H}-\mathrm{NMR}$ spectrum of compound $\mathbf{3 i}$

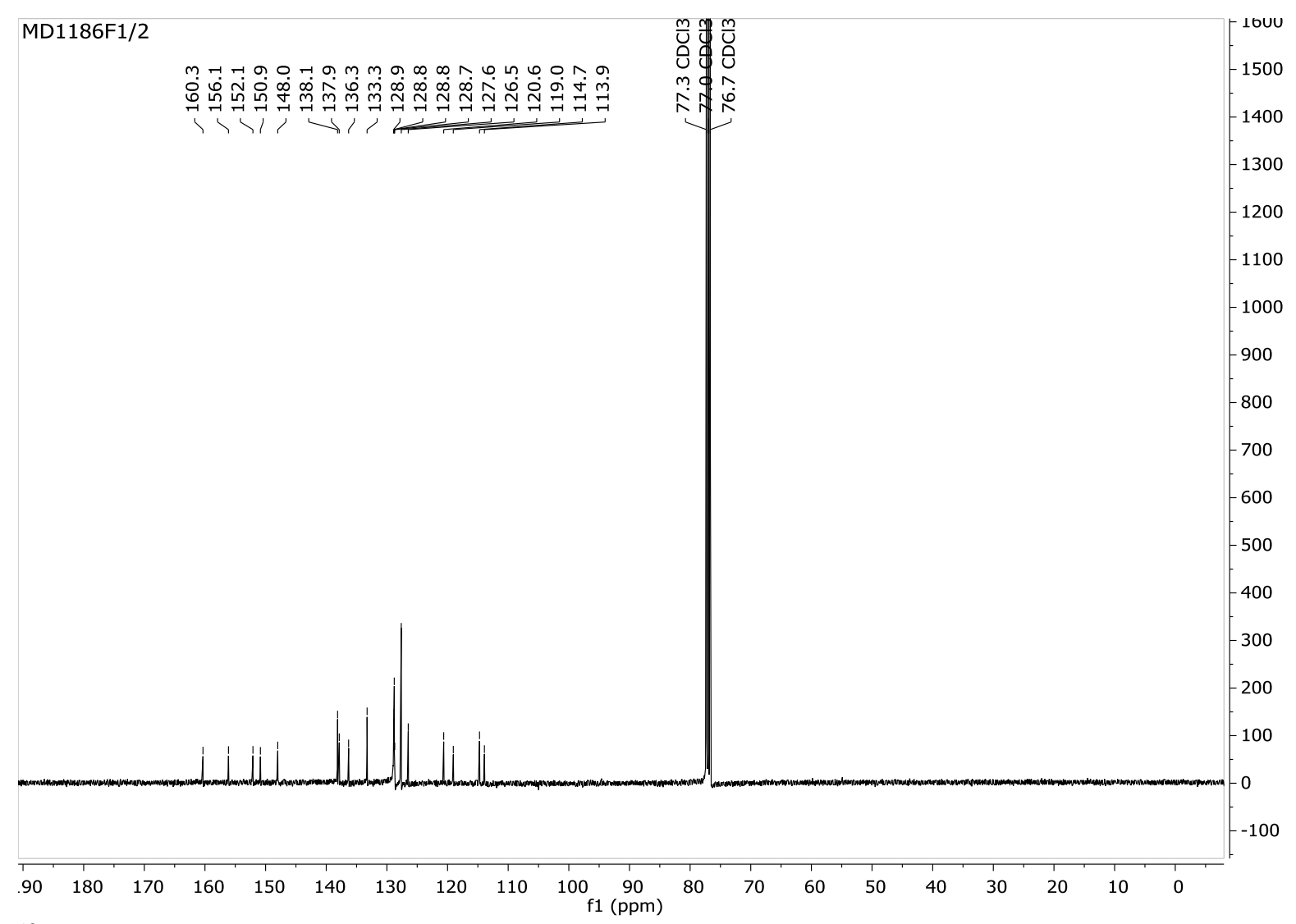

${ }^{13} \mathrm{C}-\mathrm{NMR}$ spectrum of compound $\mathbf{3 i}$ 


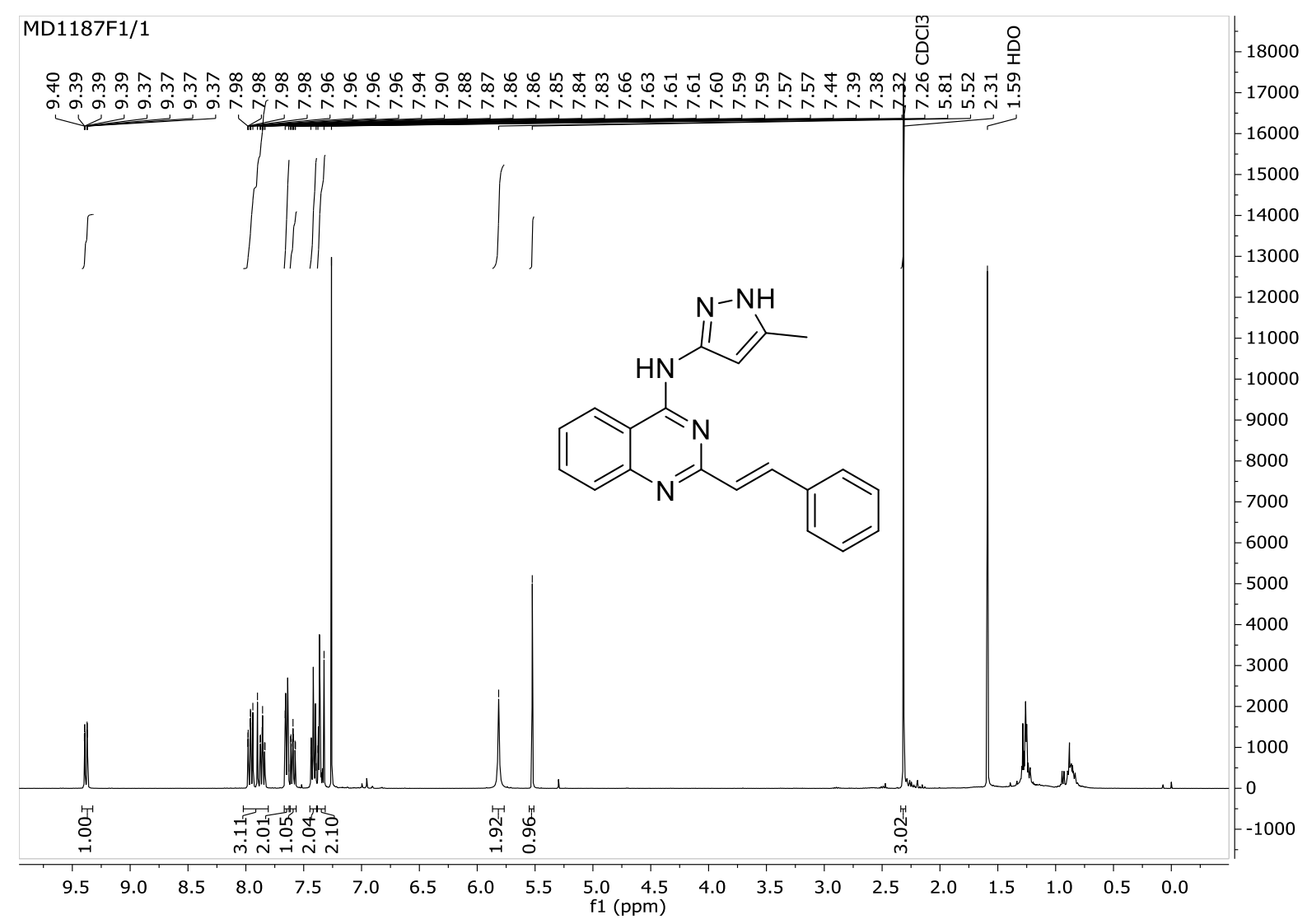

${ }^{1} \mathrm{H}-\mathrm{NMR}$ spectrum of compound $\mathbf{3 j}$

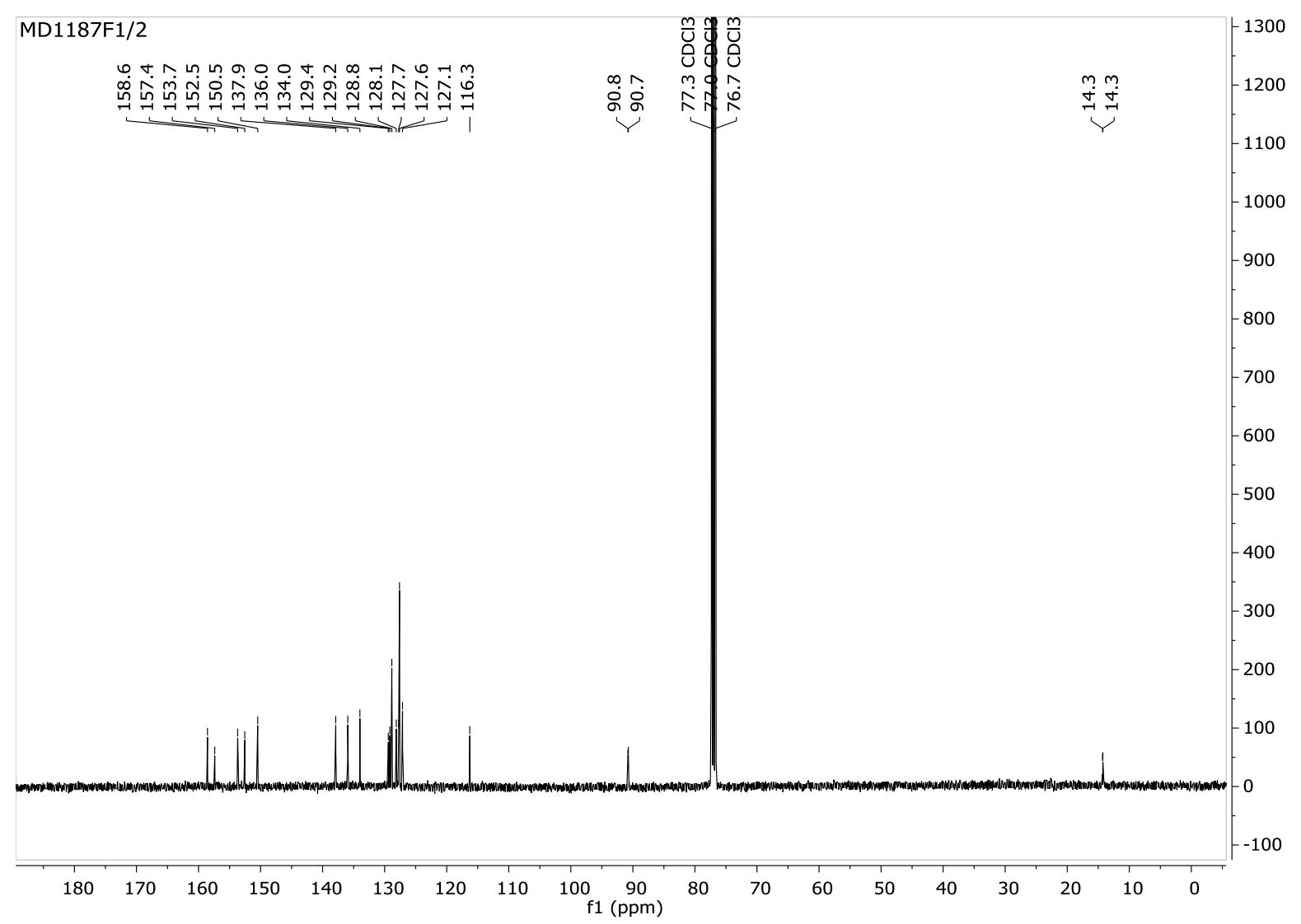

${ }^{13} \mathrm{C}-\mathrm{NMR}$ spectrum of compound $\mathbf{3 j}$ 


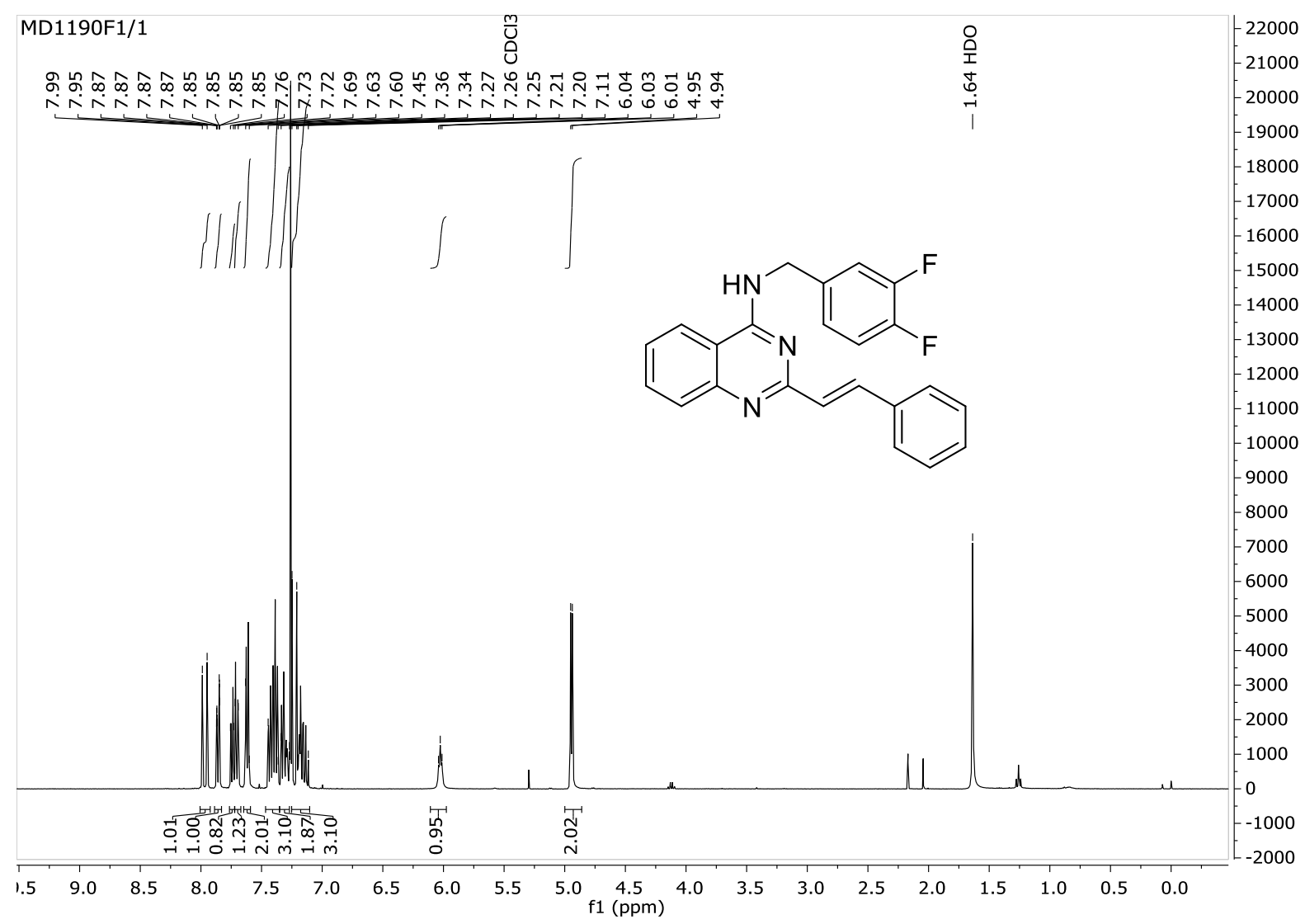

${ }^{1} \mathrm{H}-\mathrm{NMR}$ spectrum of compound $\mathbf{3 k}$

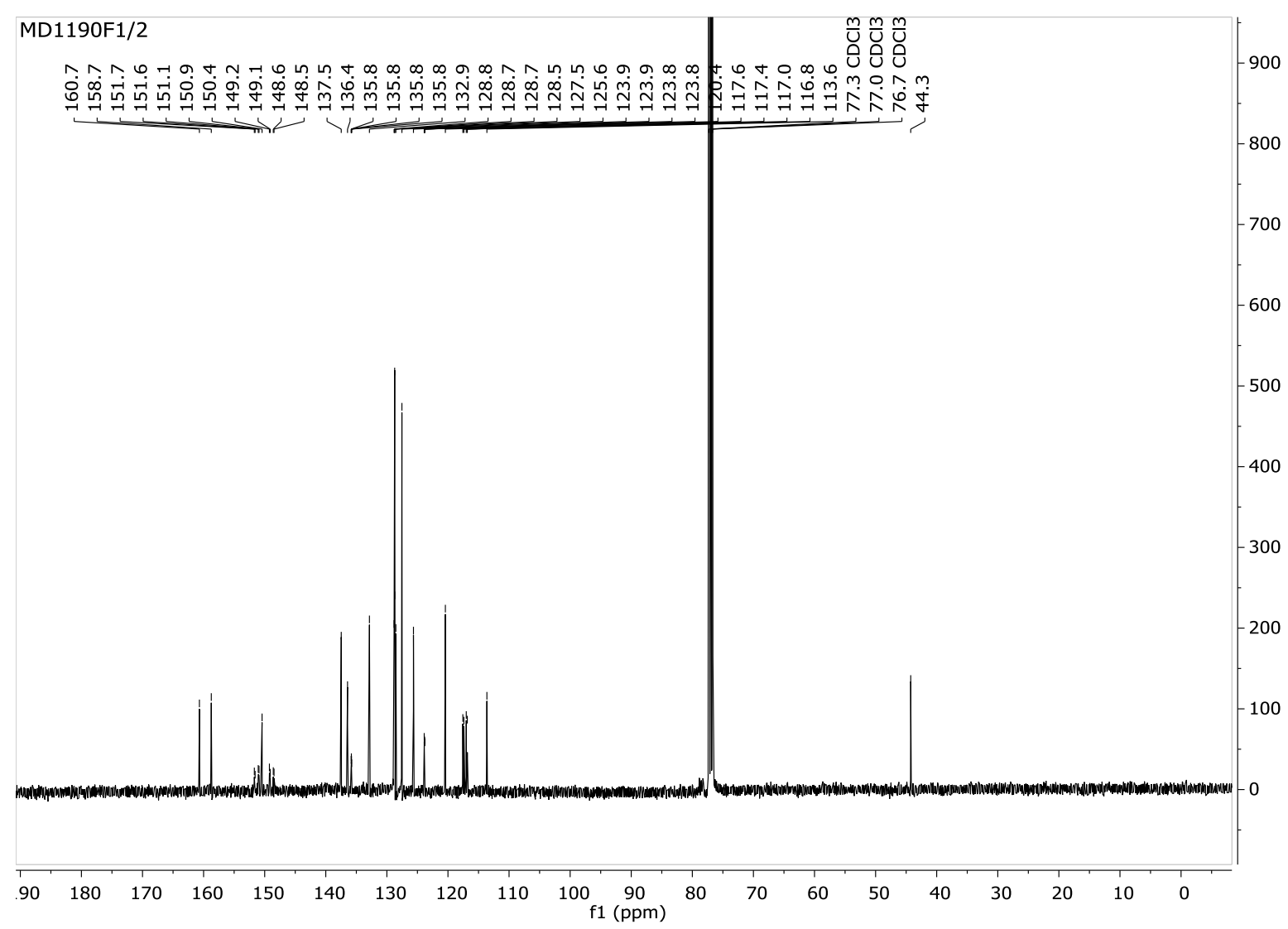

${ }^{13} \mathrm{C}-\mathrm{NMR}$ spectrum of compound $\mathbf{3 k}$ 


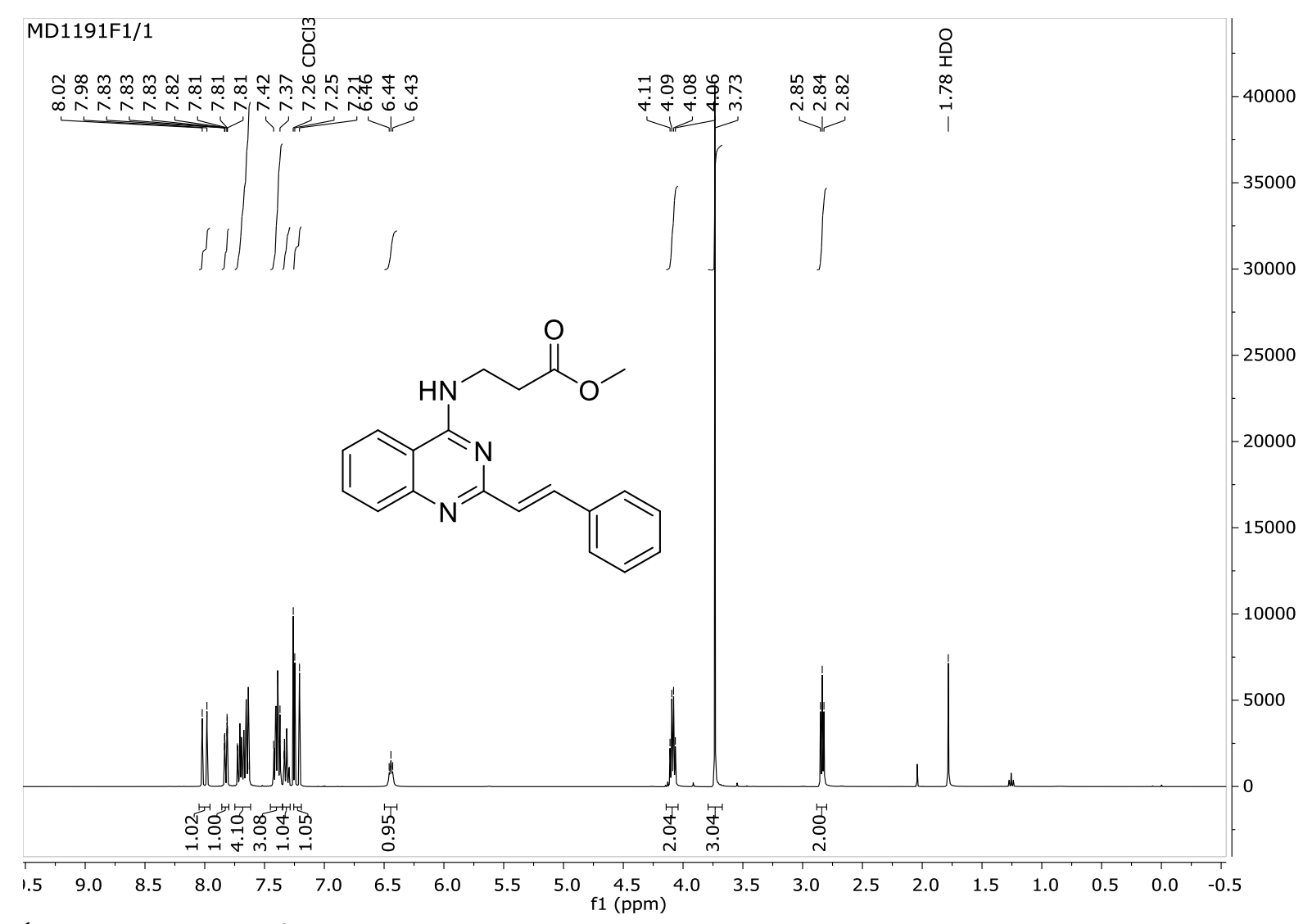

${ }^{1} \mathrm{H}-\mathrm{NMR}$ spectrum of compound $\mathbf{3}$ I

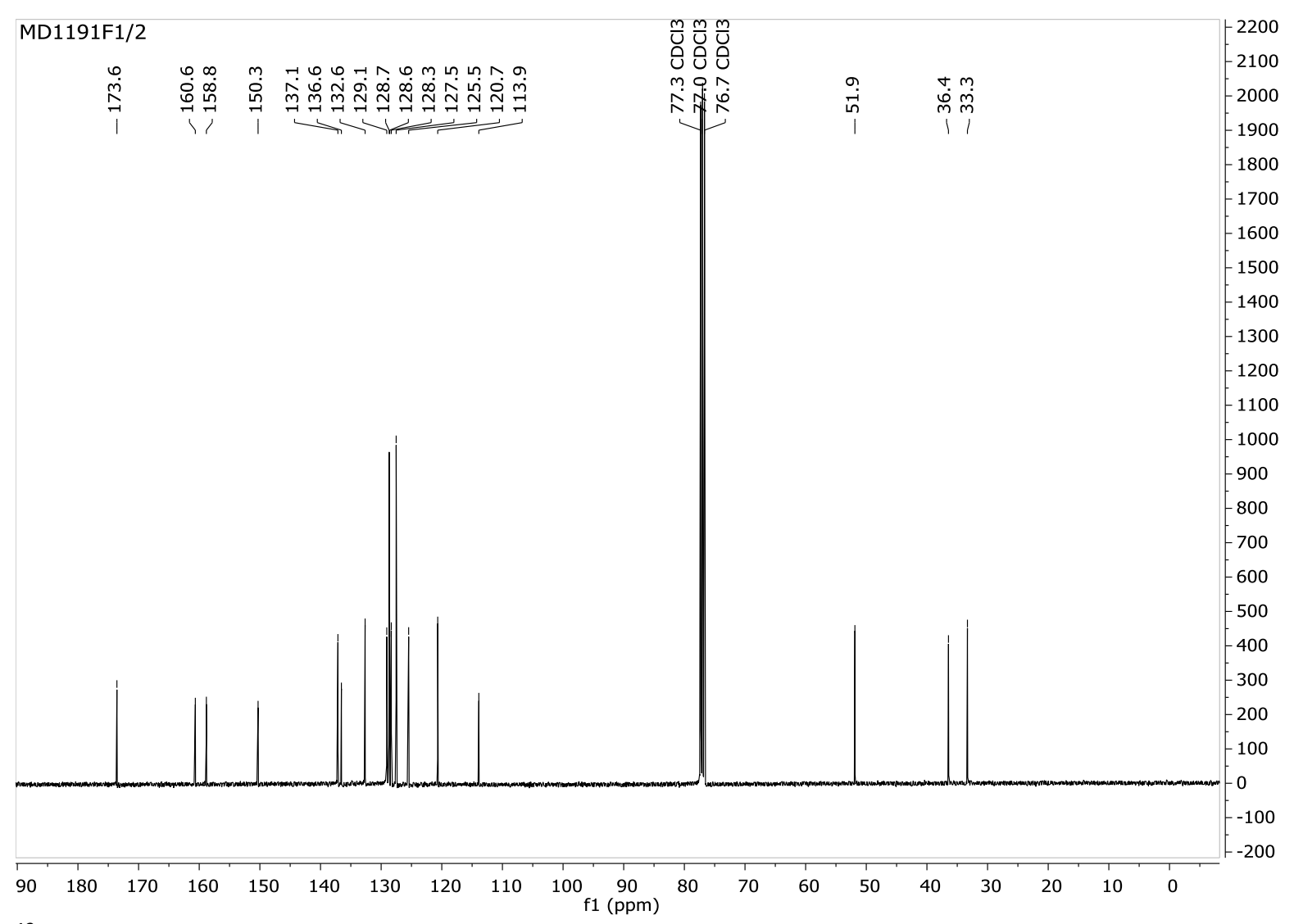

${ }^{13} \mathrm{C}-\mathrm{NMR}$ spectrum of compound $\mathbf{3}$ | 


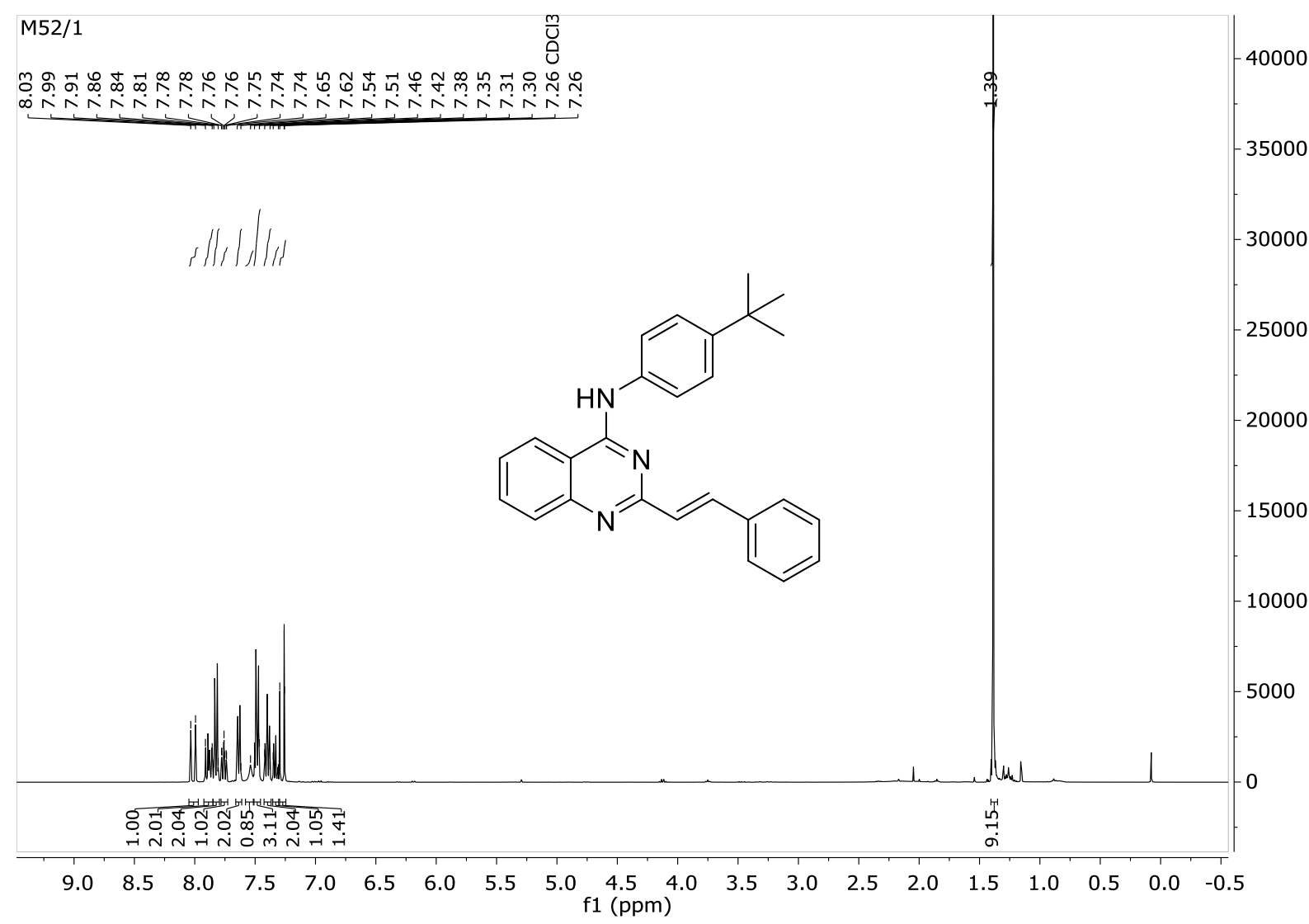

${ }^{1} \mathrm{H}-\mathrm{NMR}$ spectrum of compound $\mathbf{3 m}$

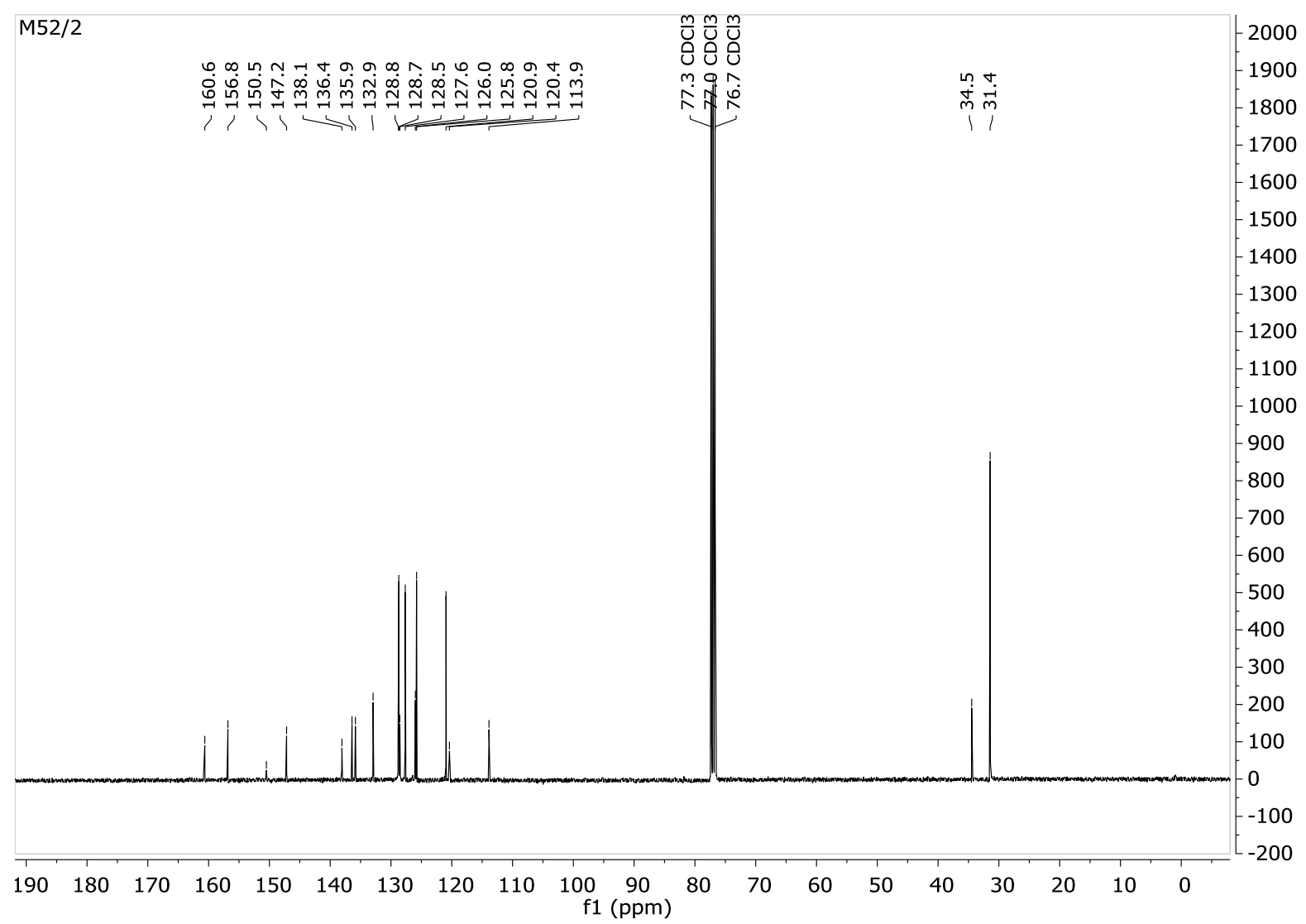

${ }^{13} \mathrm{C}-\mathrm{NMR}$ spectrum of compound $\mathbf{3 m}$ 


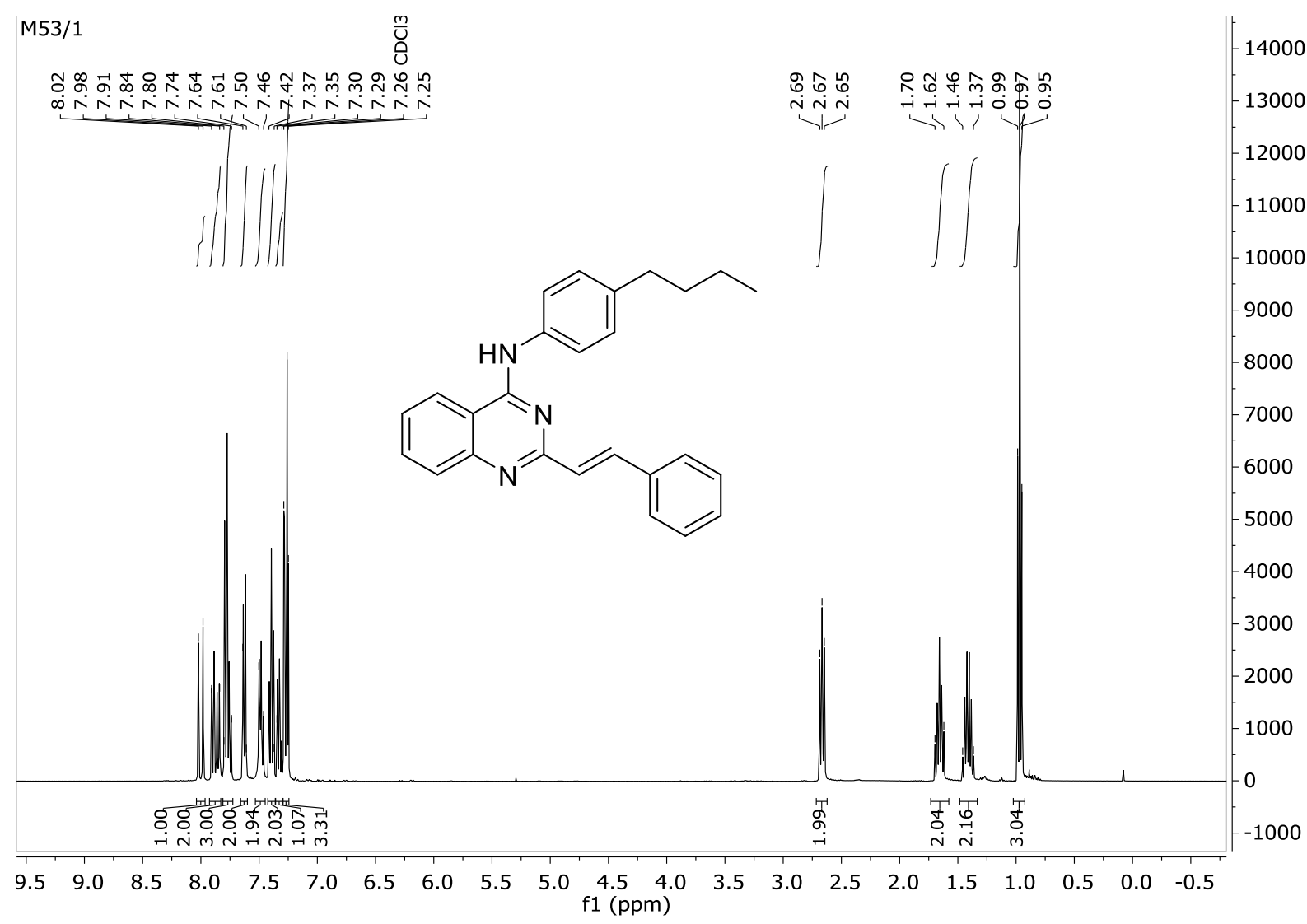

${ }^{1} \mathrm{H}$-NMR spectrum of compound $\mathbf{3 n}$

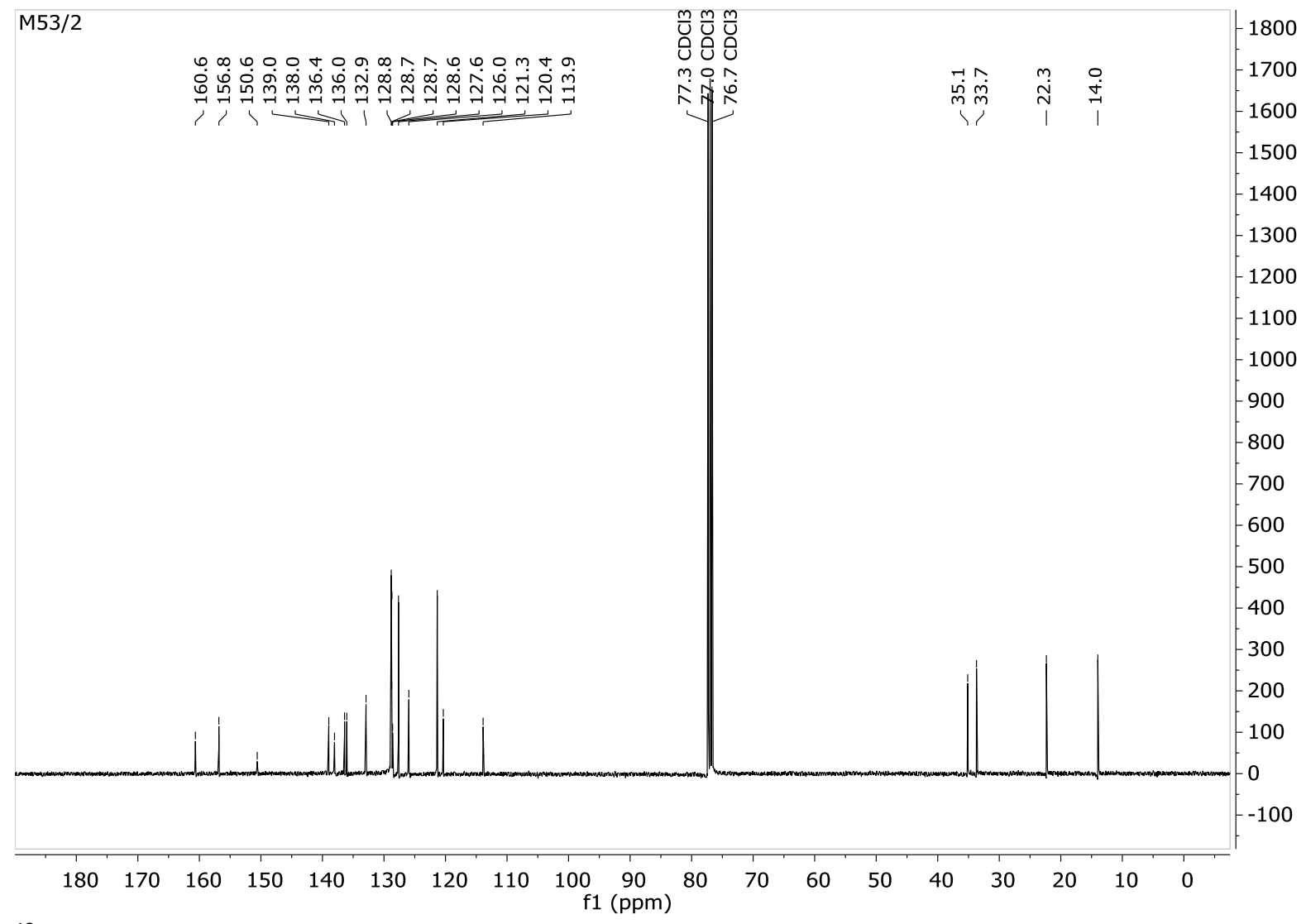

${ }^{13} \mathrm{C}-\mathrm{NMR}$ spectrum of compound $\mathbf{3 n}$ 


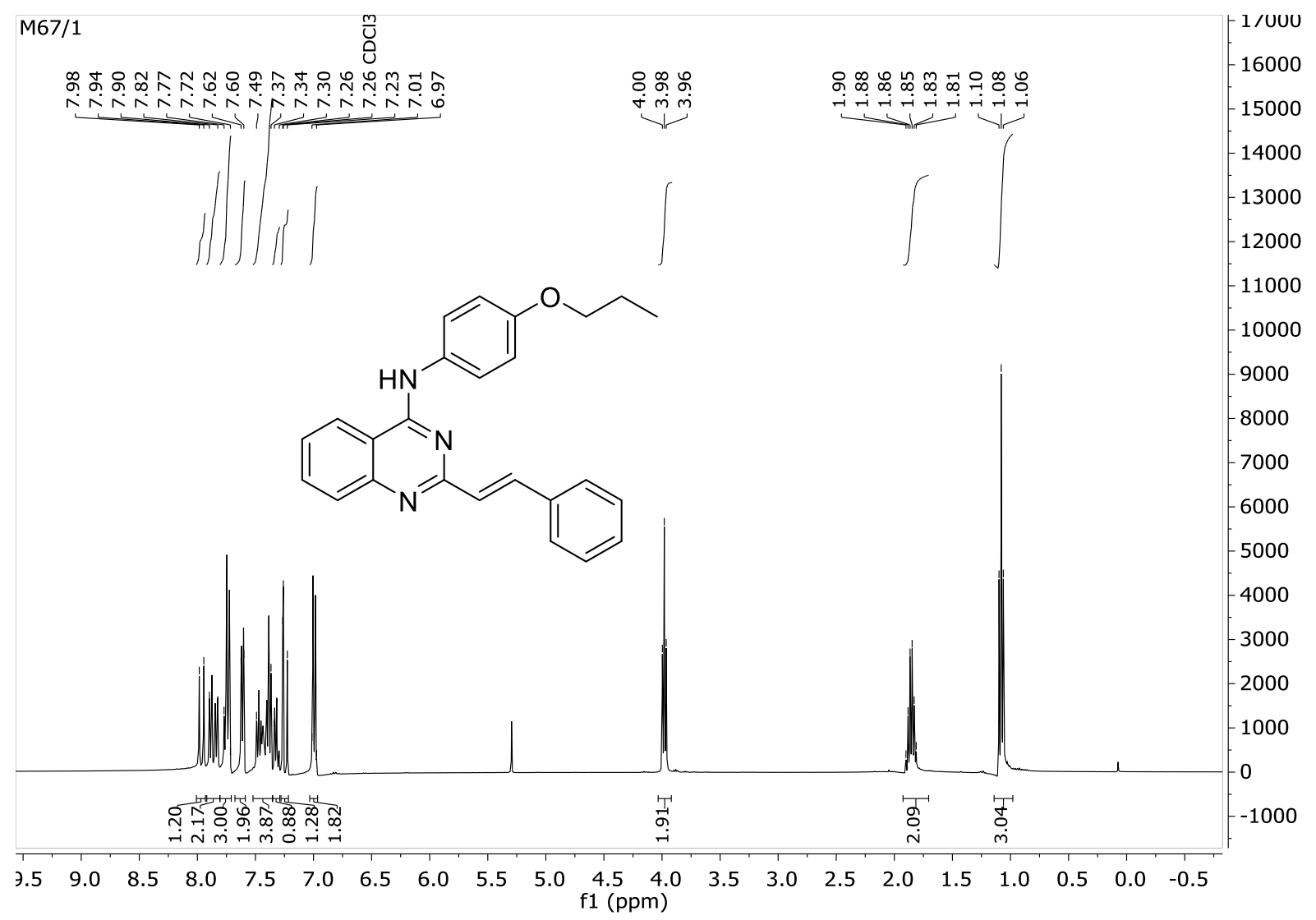

${ }^{1} \mathrm{H}-\mathrm{NMR}$ spectrum of compound $\mathbf{3 0}$

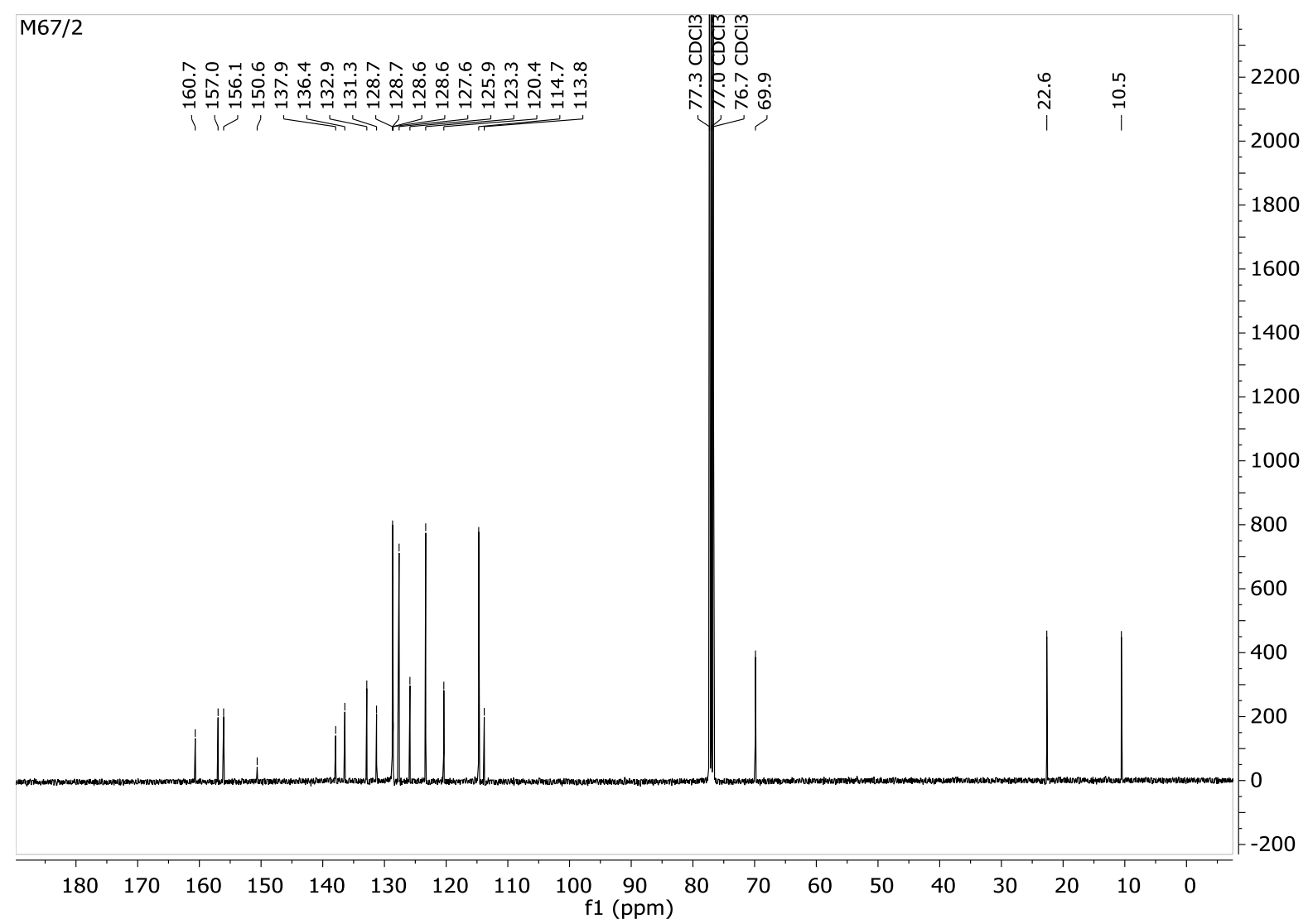

${ }^{13} \mathrm{C}-\mathrm{NMR}$ spectrum of compound 30 


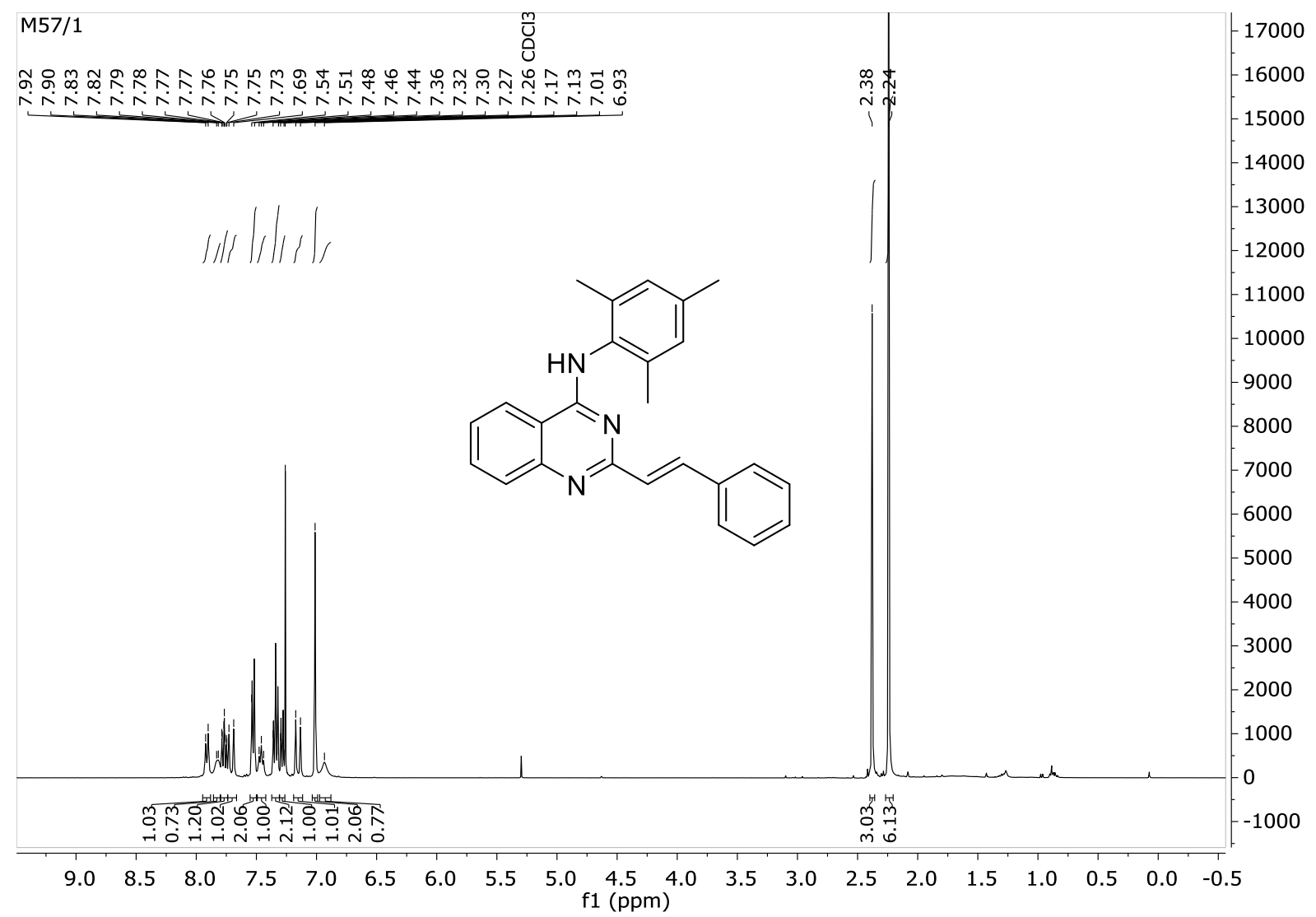

${ }^{1} \mathrm{H}-\mathrm{NMR}$ spectrum of compound $\mathbf{3 p}$

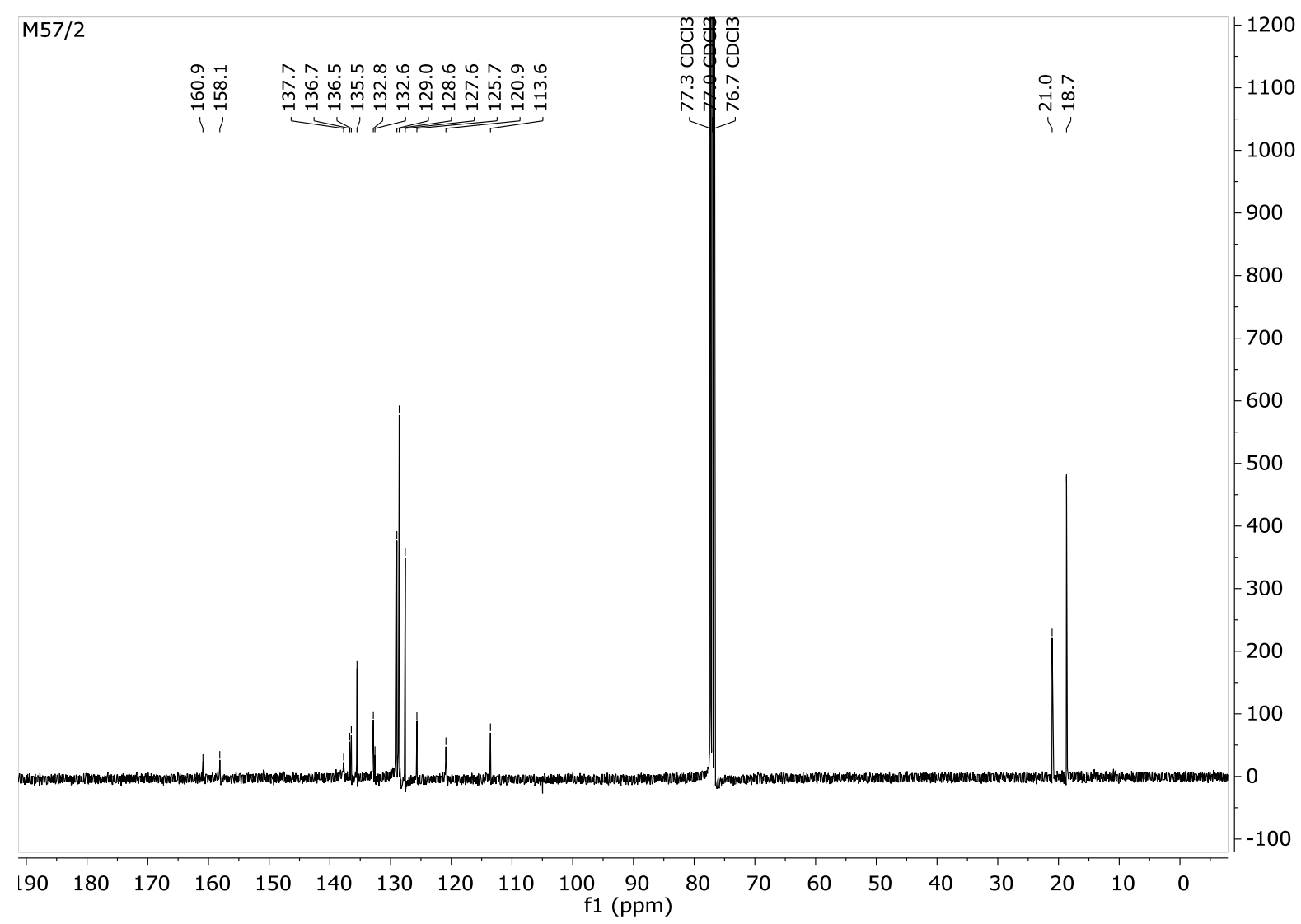

${ }^{13} \mathrm{C}-\mathrm{NMR}$ spectrum of compound $\mathbf{3 p}$ 


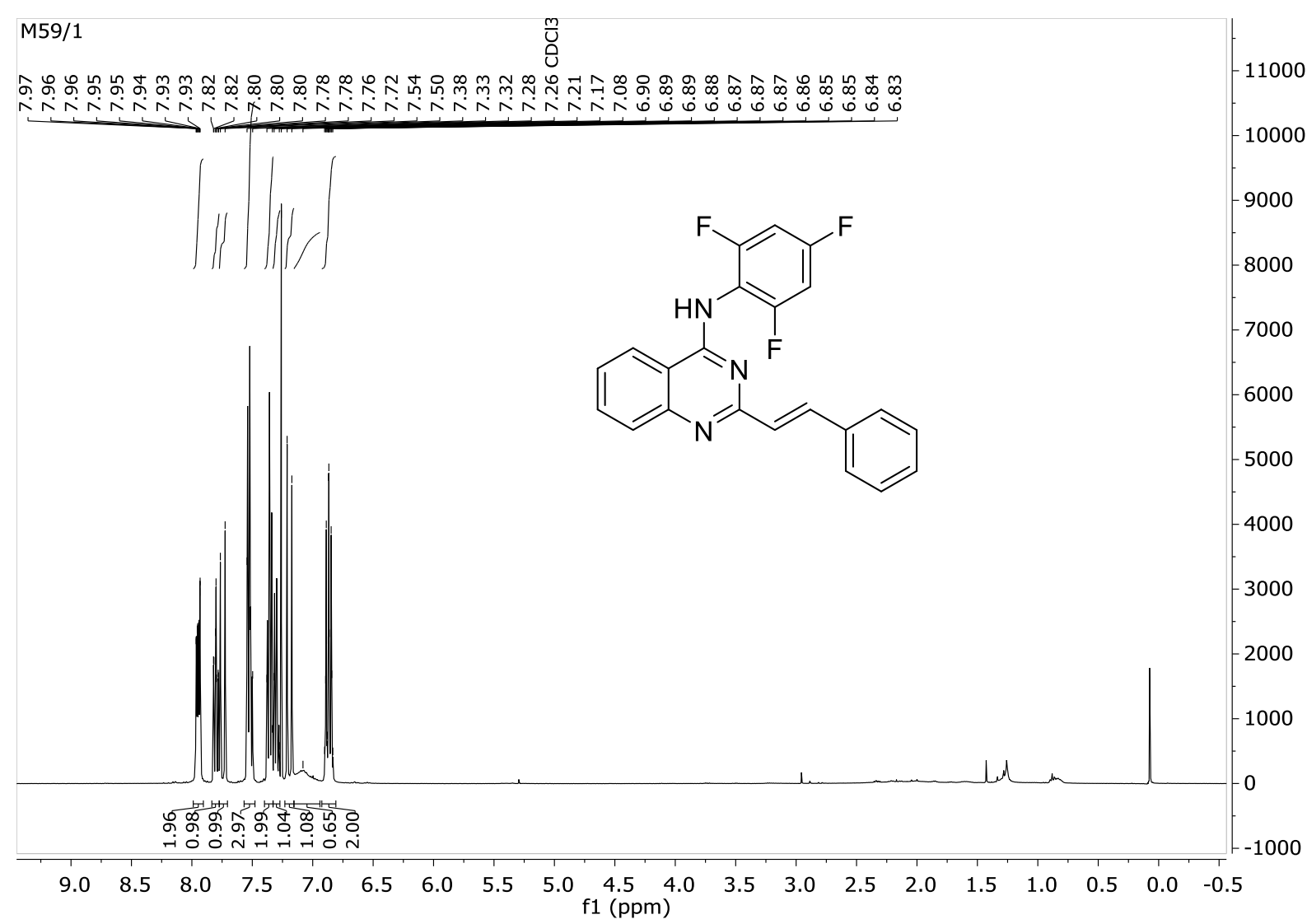

${ }^{1} \mathrm{H}-\mathrm{NMR}$ spectrum of compound $\mathbf{3 q}$

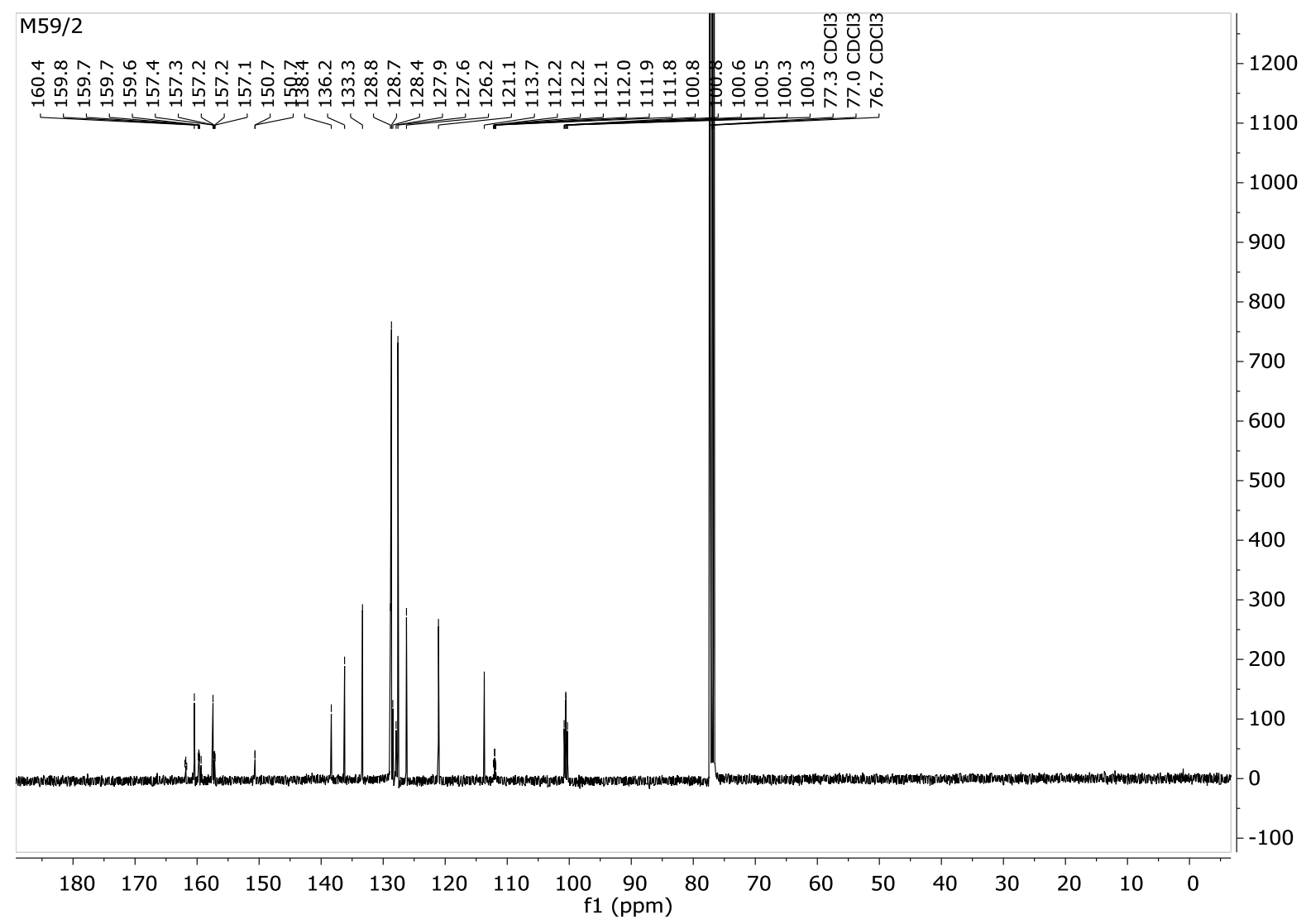

${ }^{13} \mathrm{C}-\mathrm{NMR}$ spectrum of compound $\mathbf{3 q}$ 


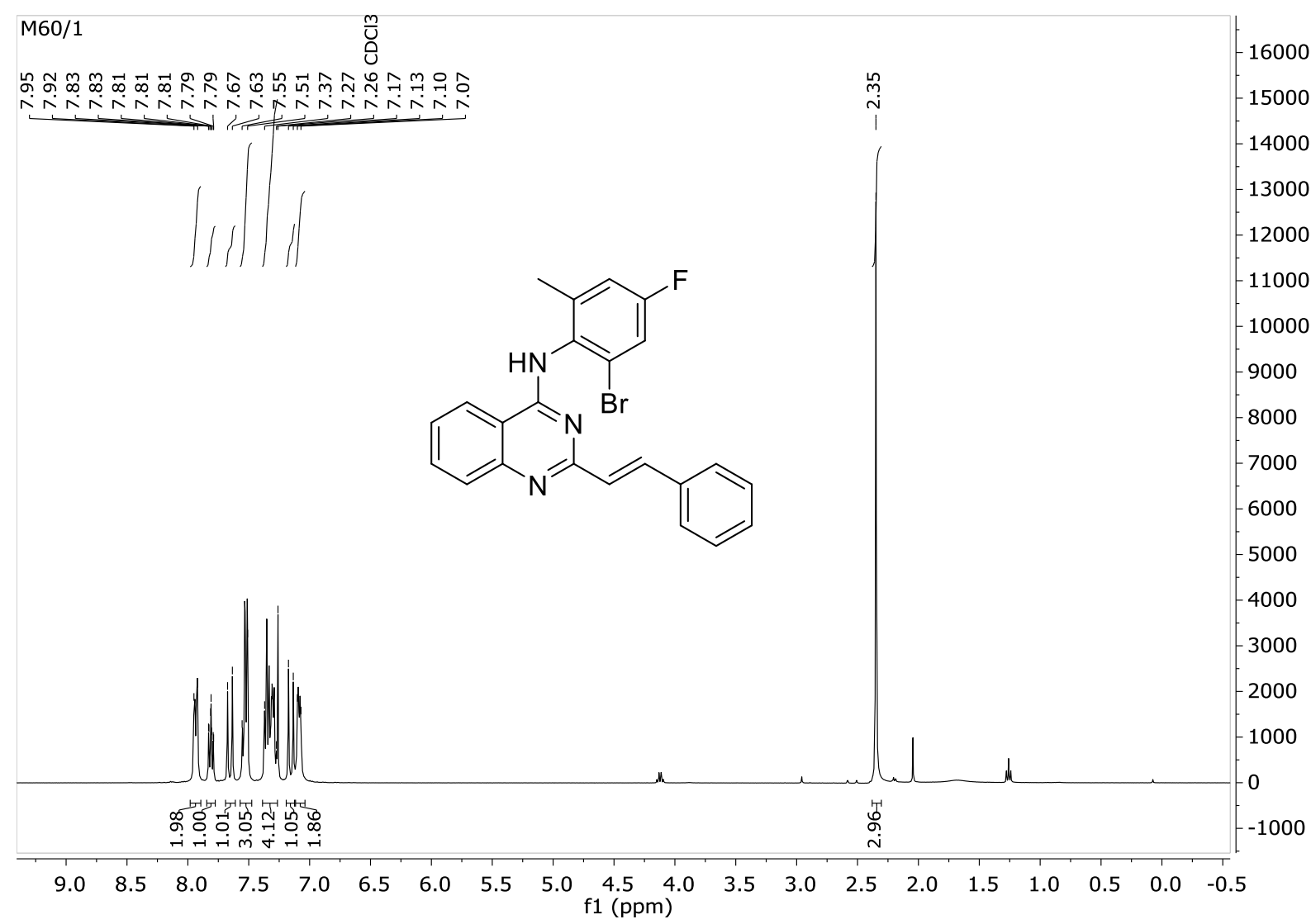

${ }^{1} \mathrm{H}-\mathrm{NMR}$ spectrum of compound $\mathbf{3 r}$

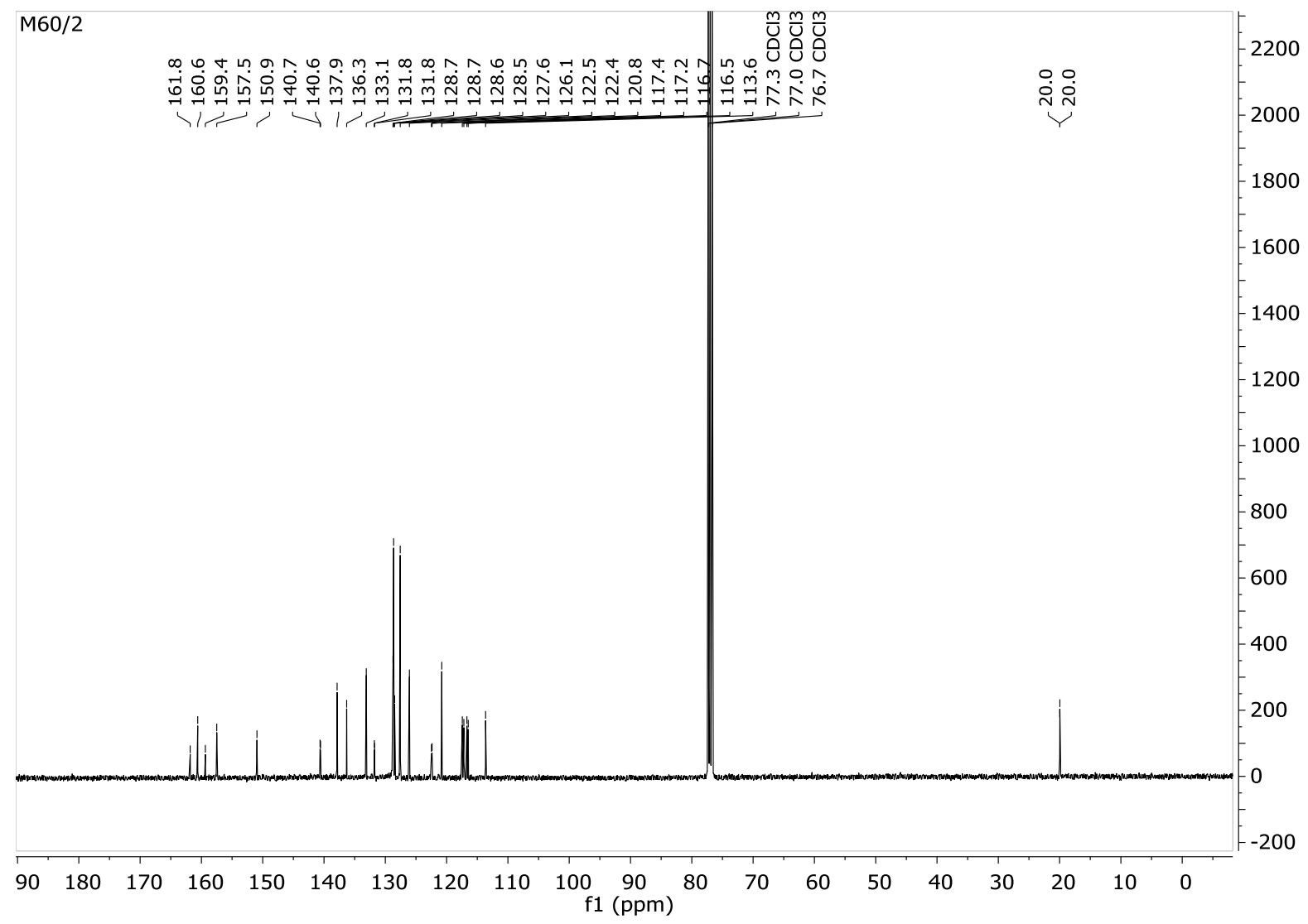

${ }^{13} \mathrm{C}-\mathrm{NMR}$ spectrum of compound $\mathbf{3 r}$ 


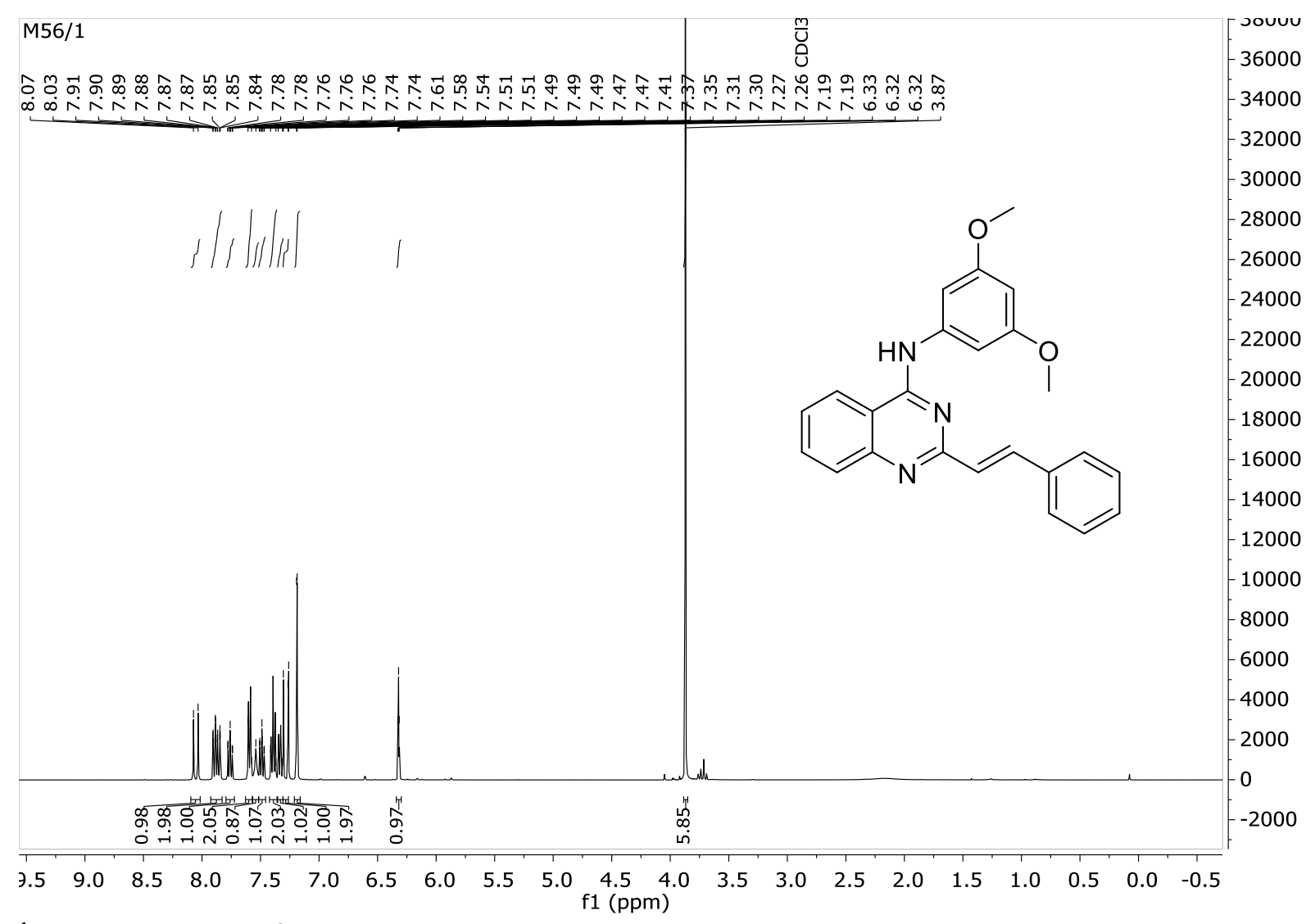

${ }^{1} \mathrm{H}$-NMR spectrum of compound $\mathbf{3 s}$

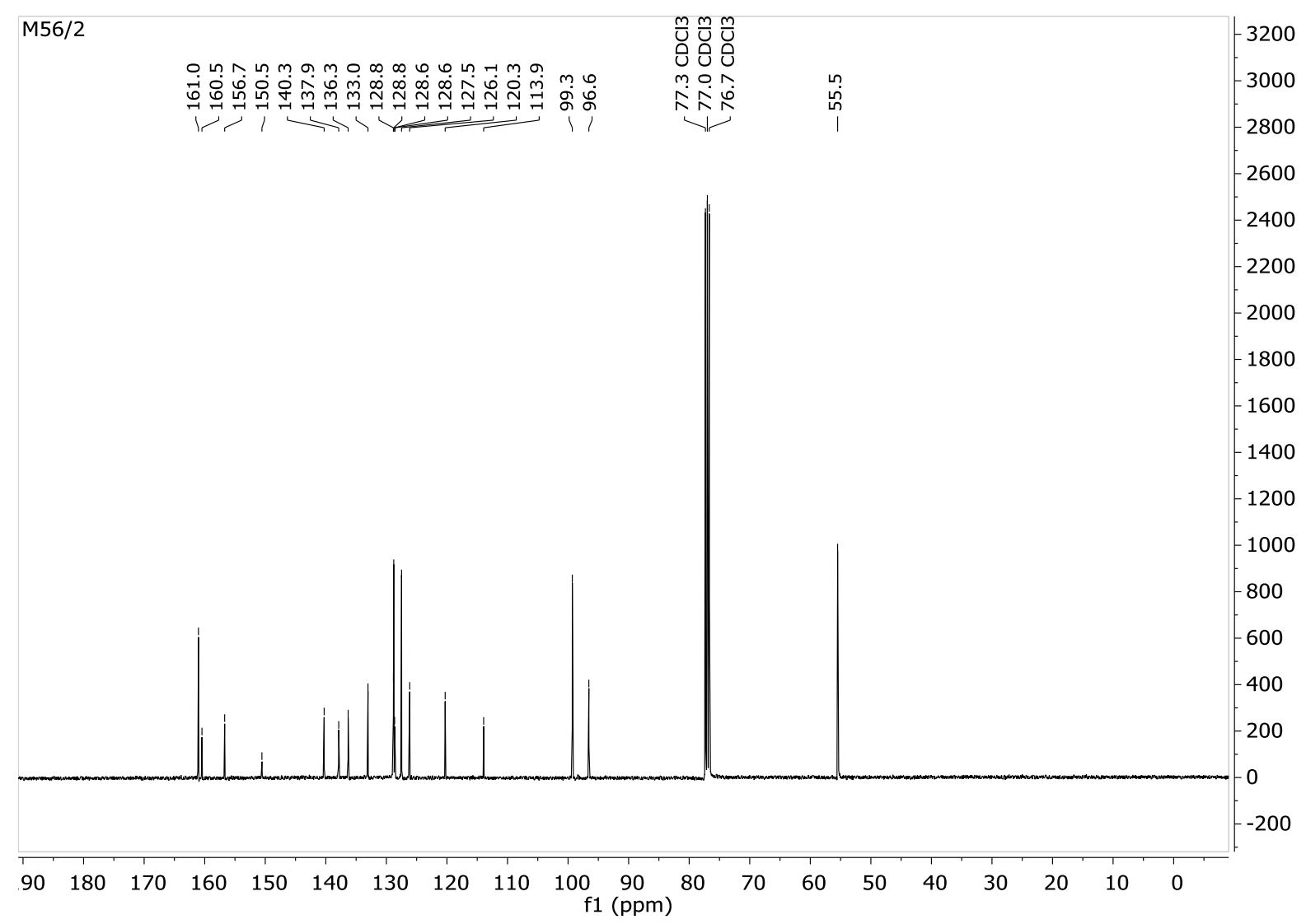

${ }^{13} \mathrm{C}-\mathrm{NMR}$ spectrum of compound $3 \mathrm{~s}$ 


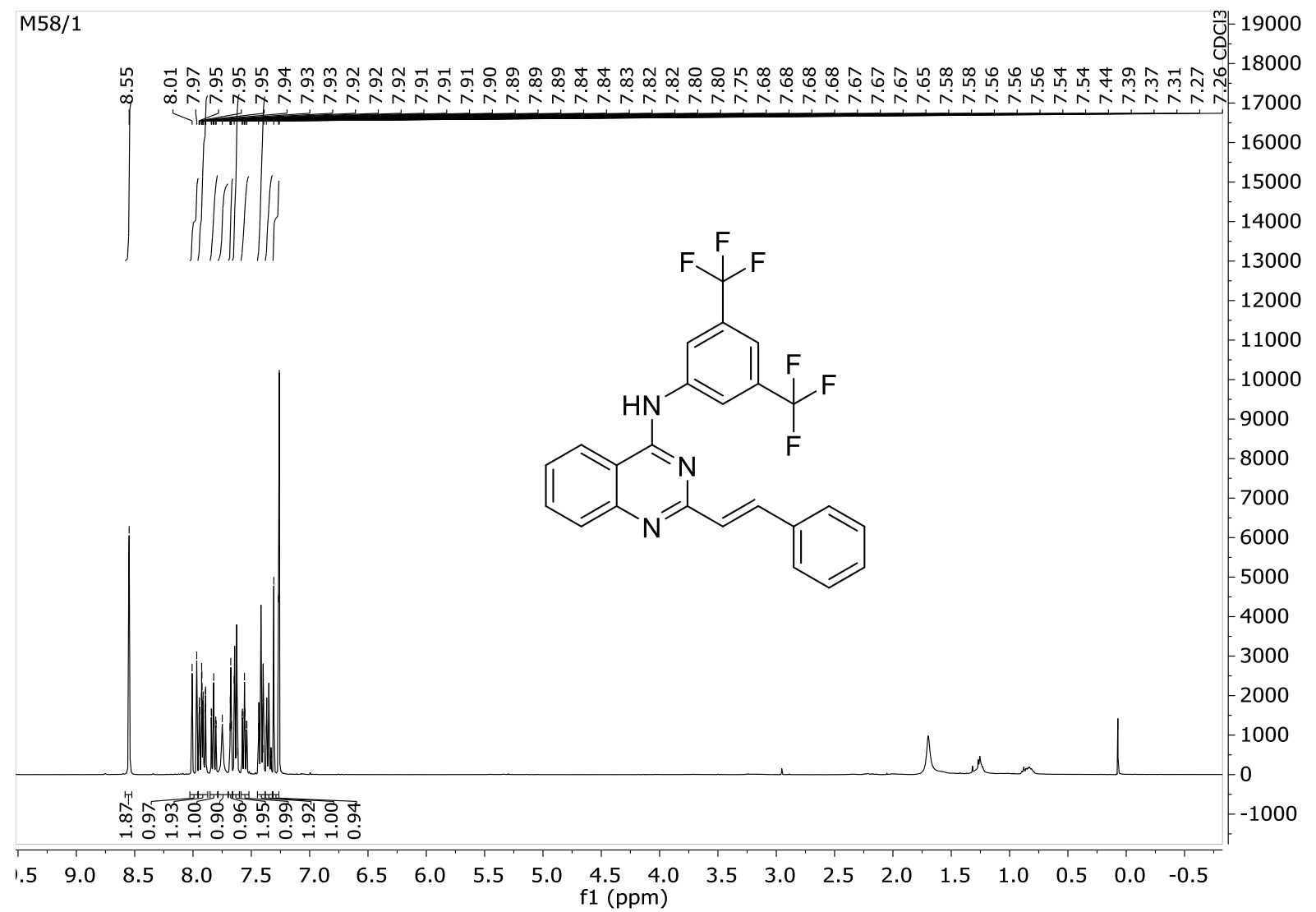

${ }^{1} \mathrm{H}-\mathrm{NMR}$ spectrum of compound $\mathbf{3 t}$

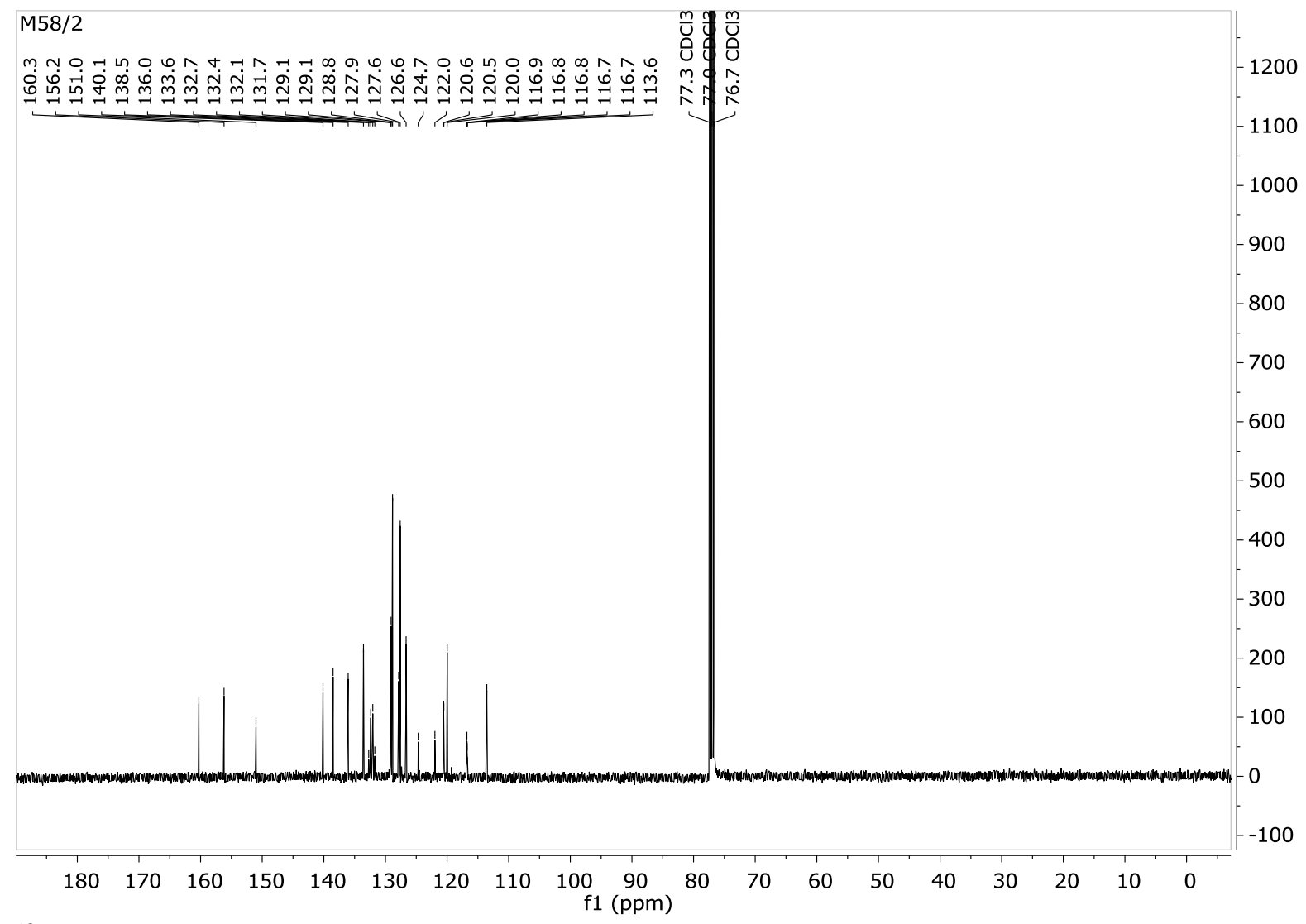

${ }^{13} \mathrm{C}-\mathrm{NMR}$ spectrum of compound $\mathbf{3 t}$ 


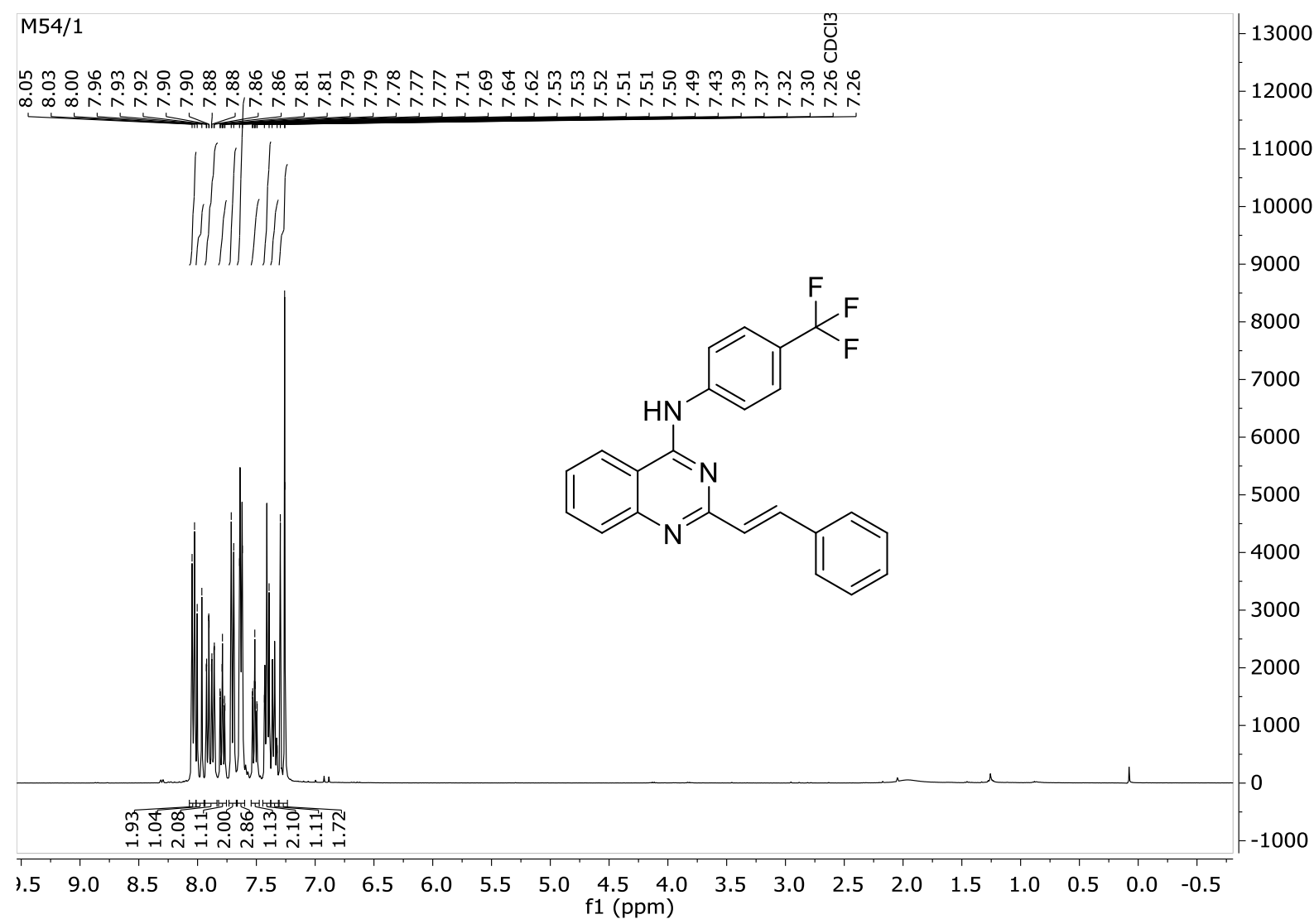

${ }^{1} \mathrm{H}-\mathrm{NMR}$ spectrum of compound $\mathbf{3 u}$

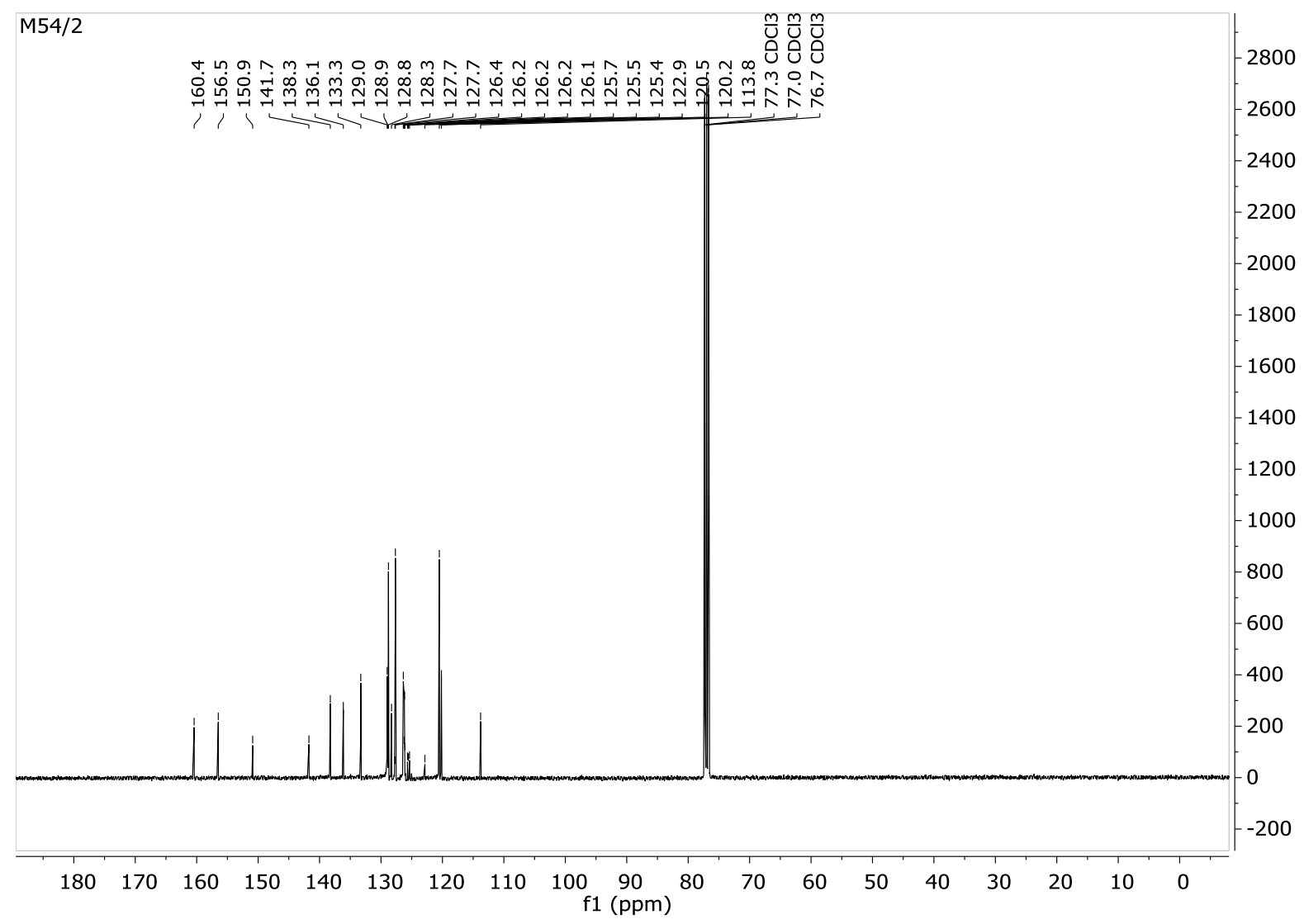

${ }^{13} \mathrm{C}-\mathrm{NMR}$ spectrum of compound $\mathbf{3 u}$ 


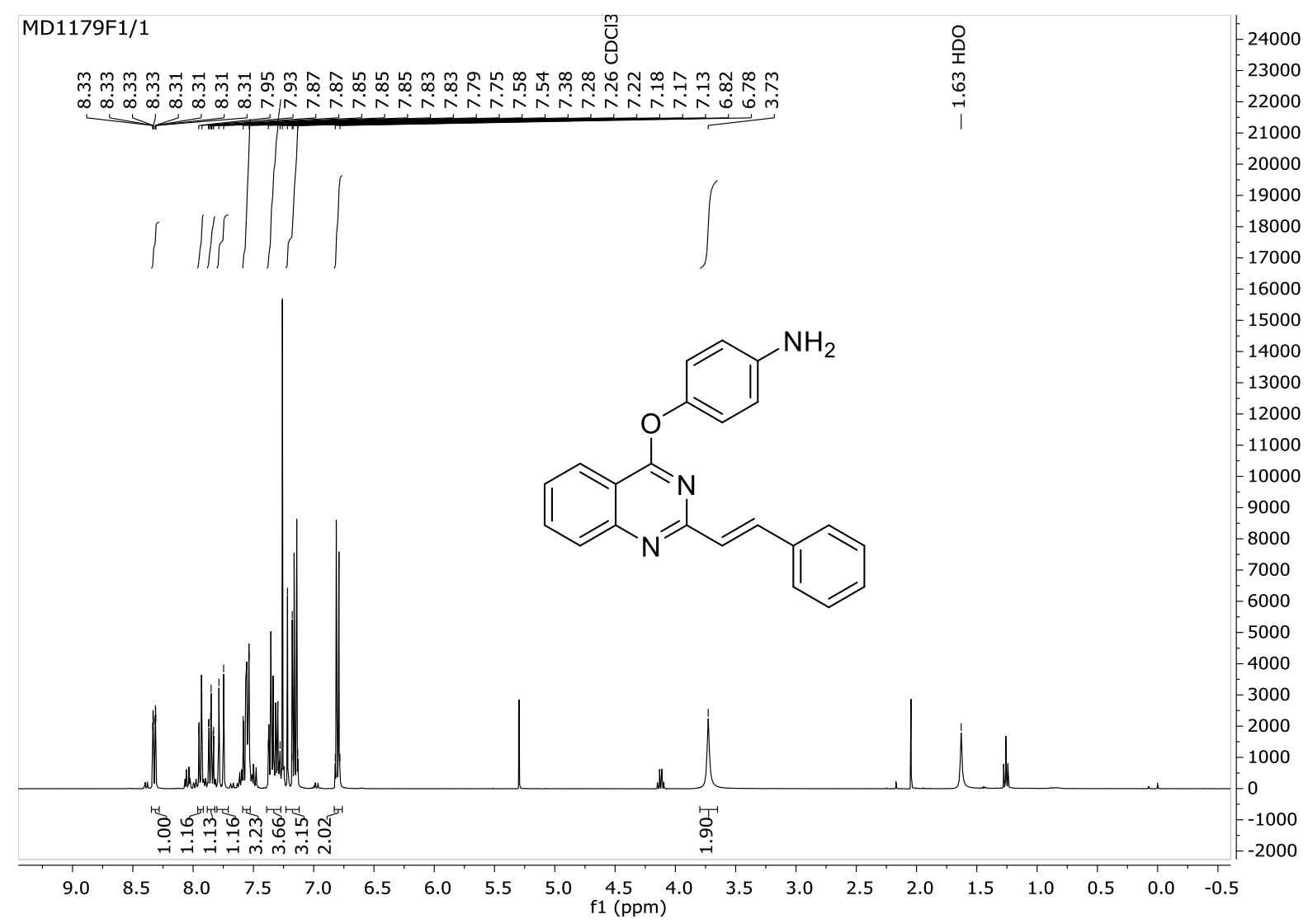

${ }^{1} \mathrm{H}-\mathrm{NMR}$ spectrum of compound $3 \mathrm{v}$

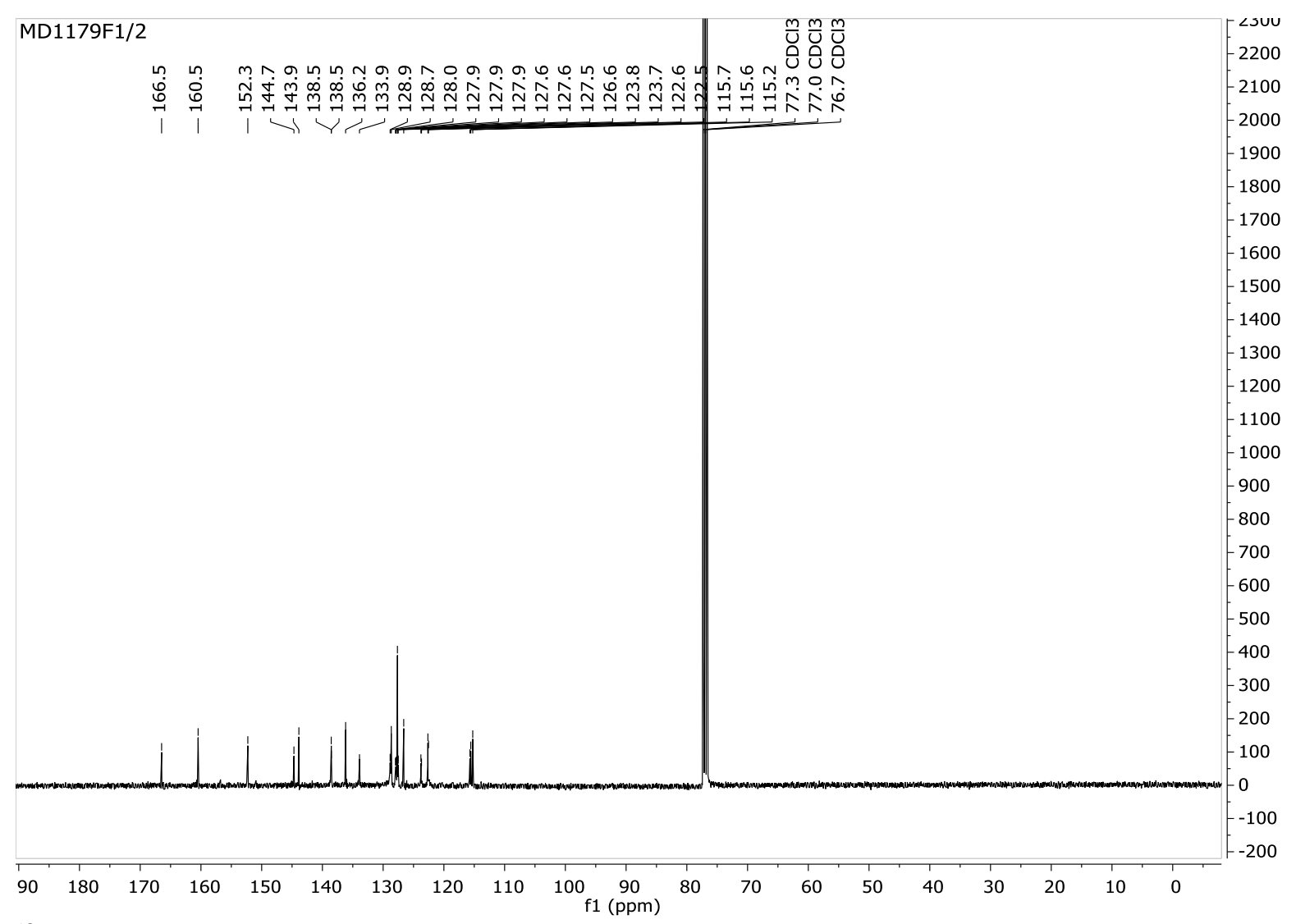

${ }^{13} \mathrm{C}-\mathrm{NMR}$ spectrum of compound $\mathbf{3} \mathbf{v}$ 


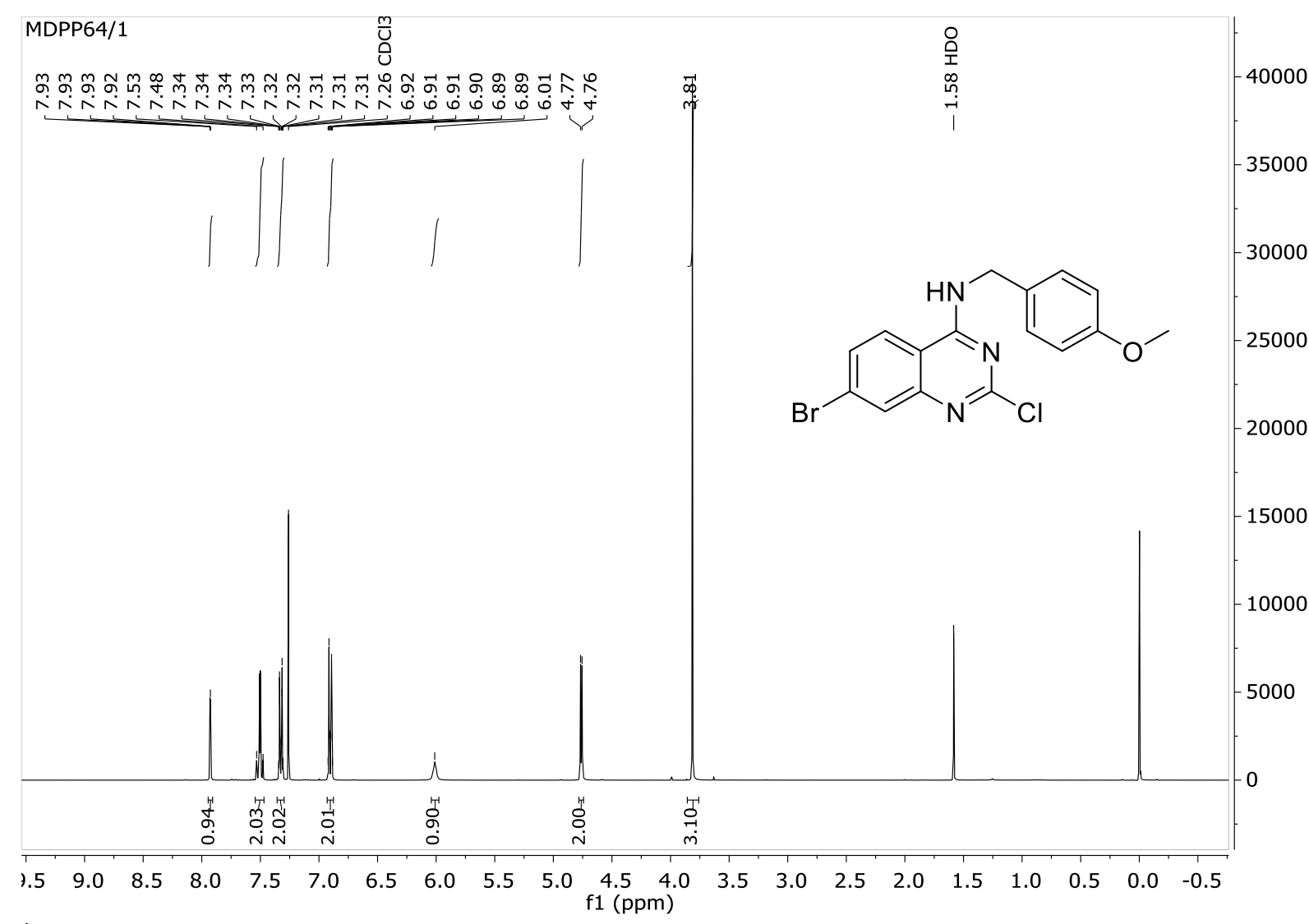

${ }^{1} \mathrm{H}-\mathrm{NMR}$ spectrum of compound $\mathbf{5 a}$

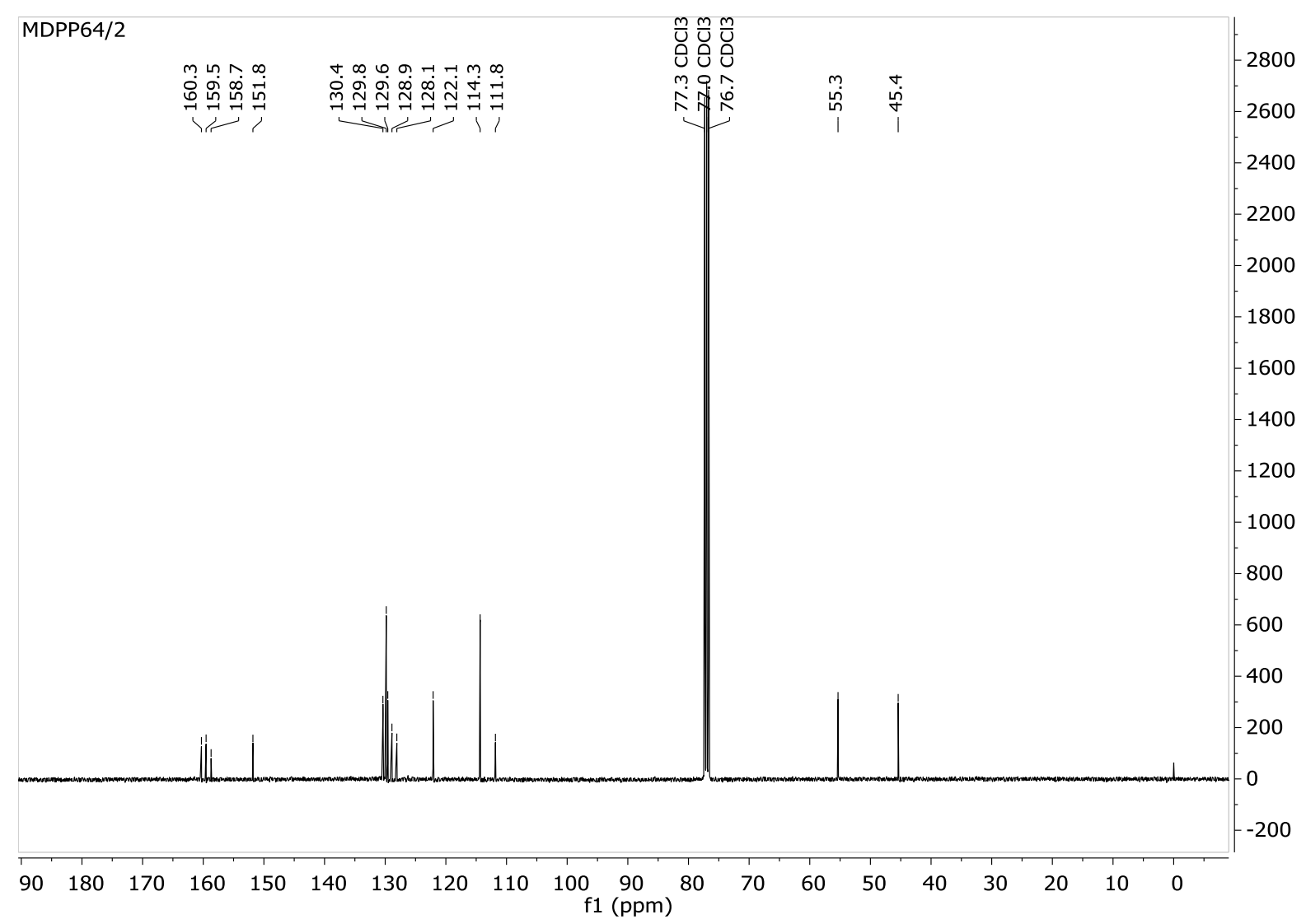

${ }^{13} \mathrm{C}-\mathrm{NMR}$ spectrum of compound $\mathbf{5 a}$ 


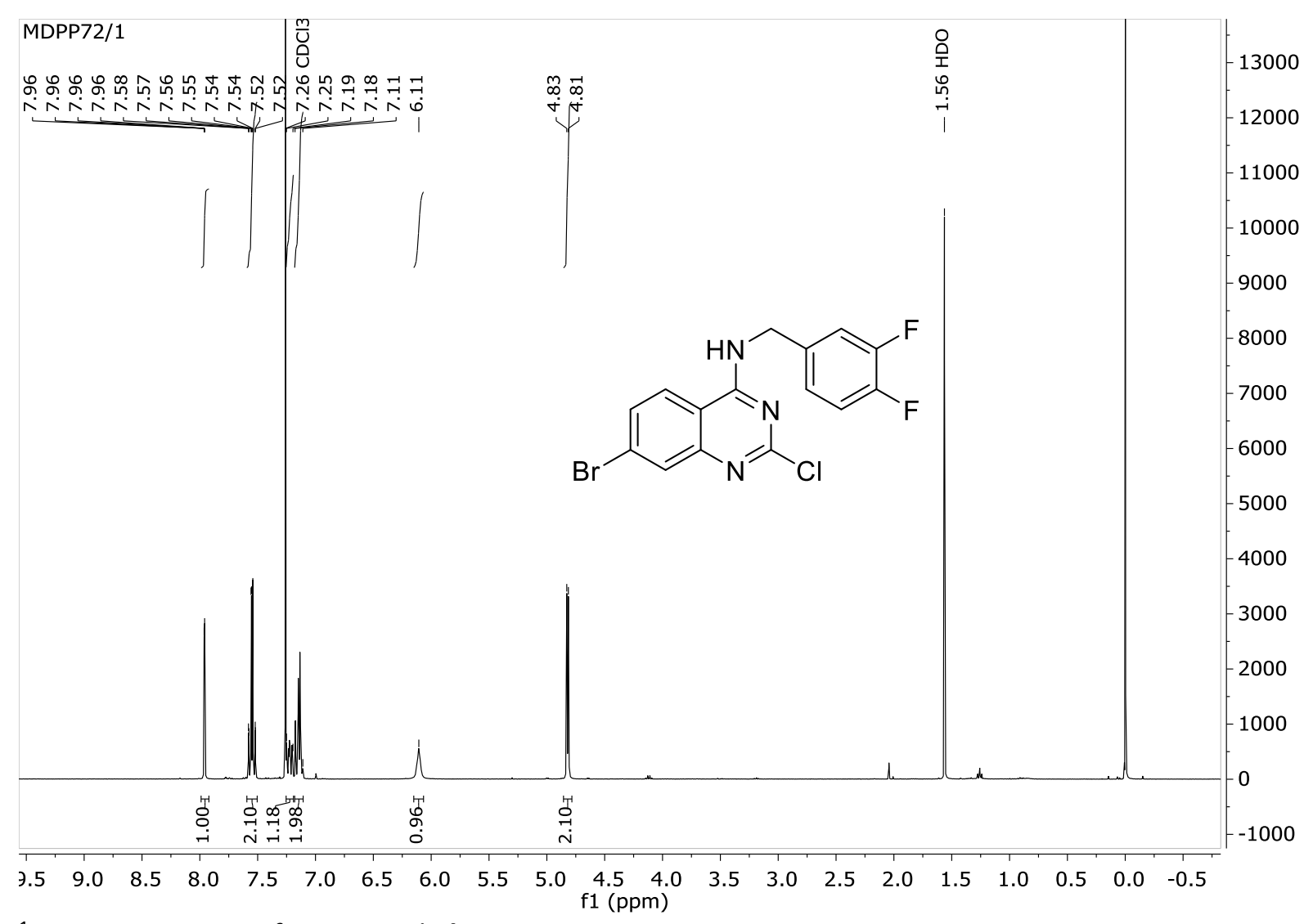

${ }^{1} \mathrm{H}-\mathrm{NMR}$ spectrum of compound $\mathbf{5 b}$

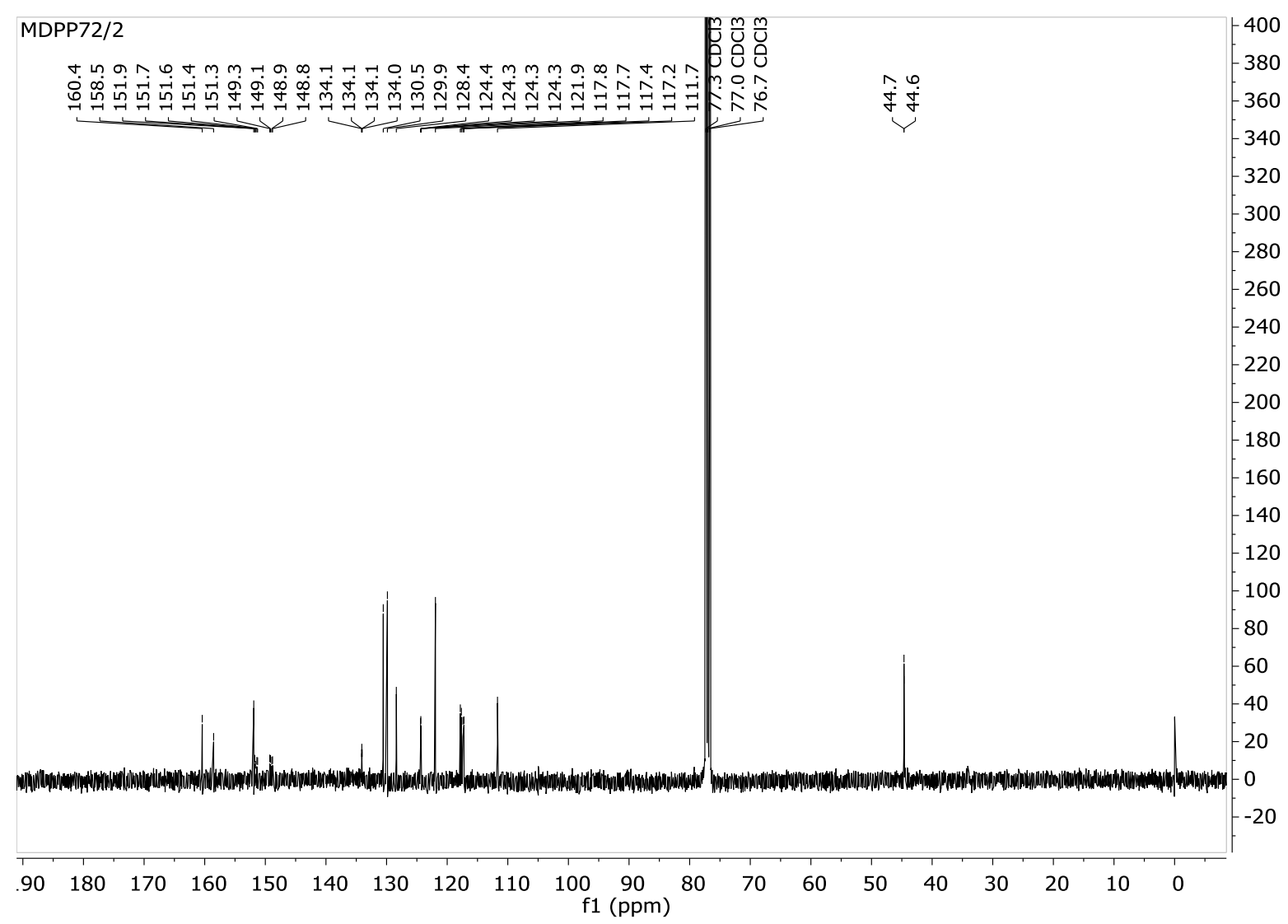

${ }^{13} \mathrm{C}-\mathrm{NMR}$ spectrum of compound $\mathbf{5 b}$ 


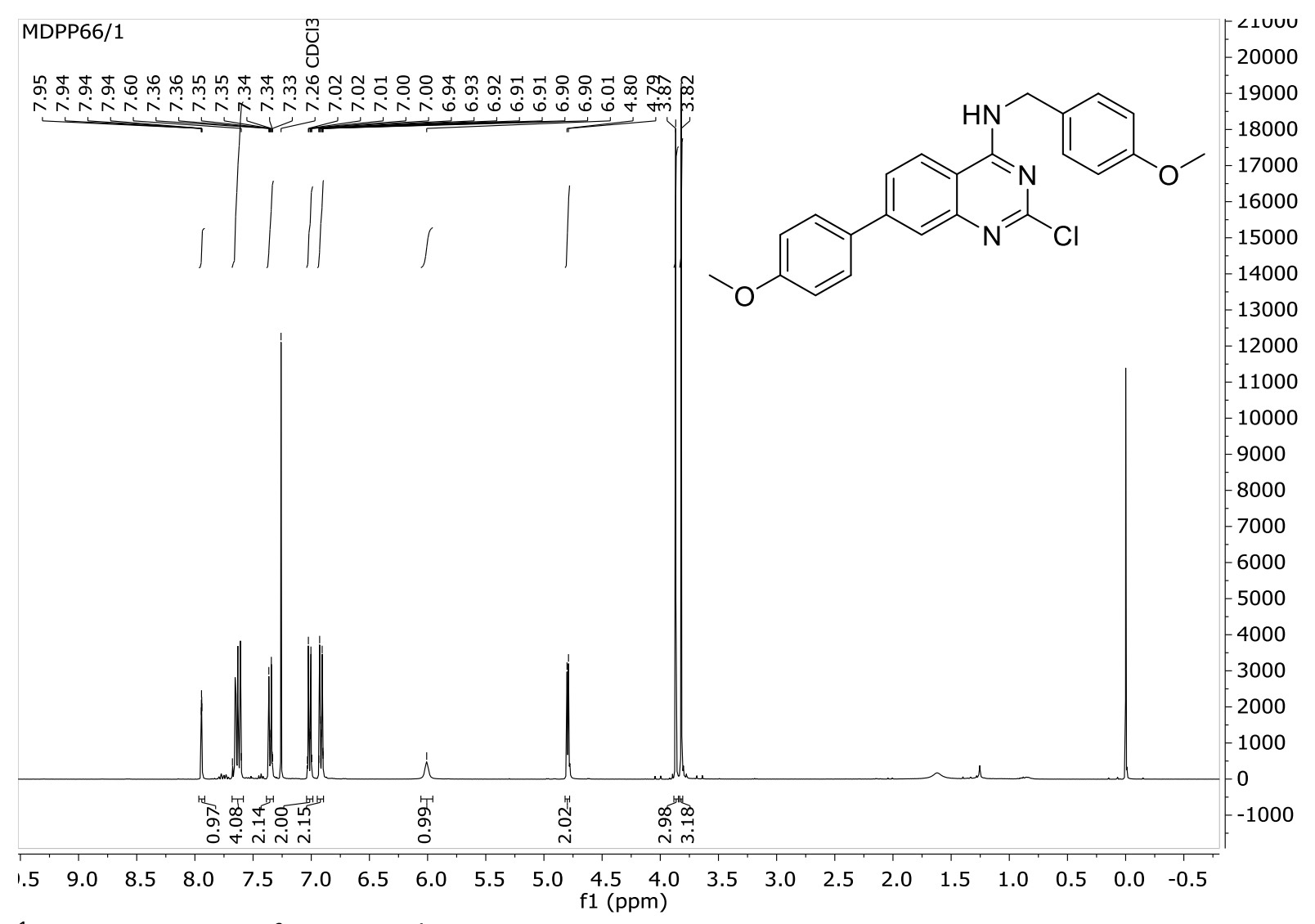

${ }^{1} \mathrm{H}-\mathrm{NMR}$ spectrum of compound $6 \mathrm{a}$

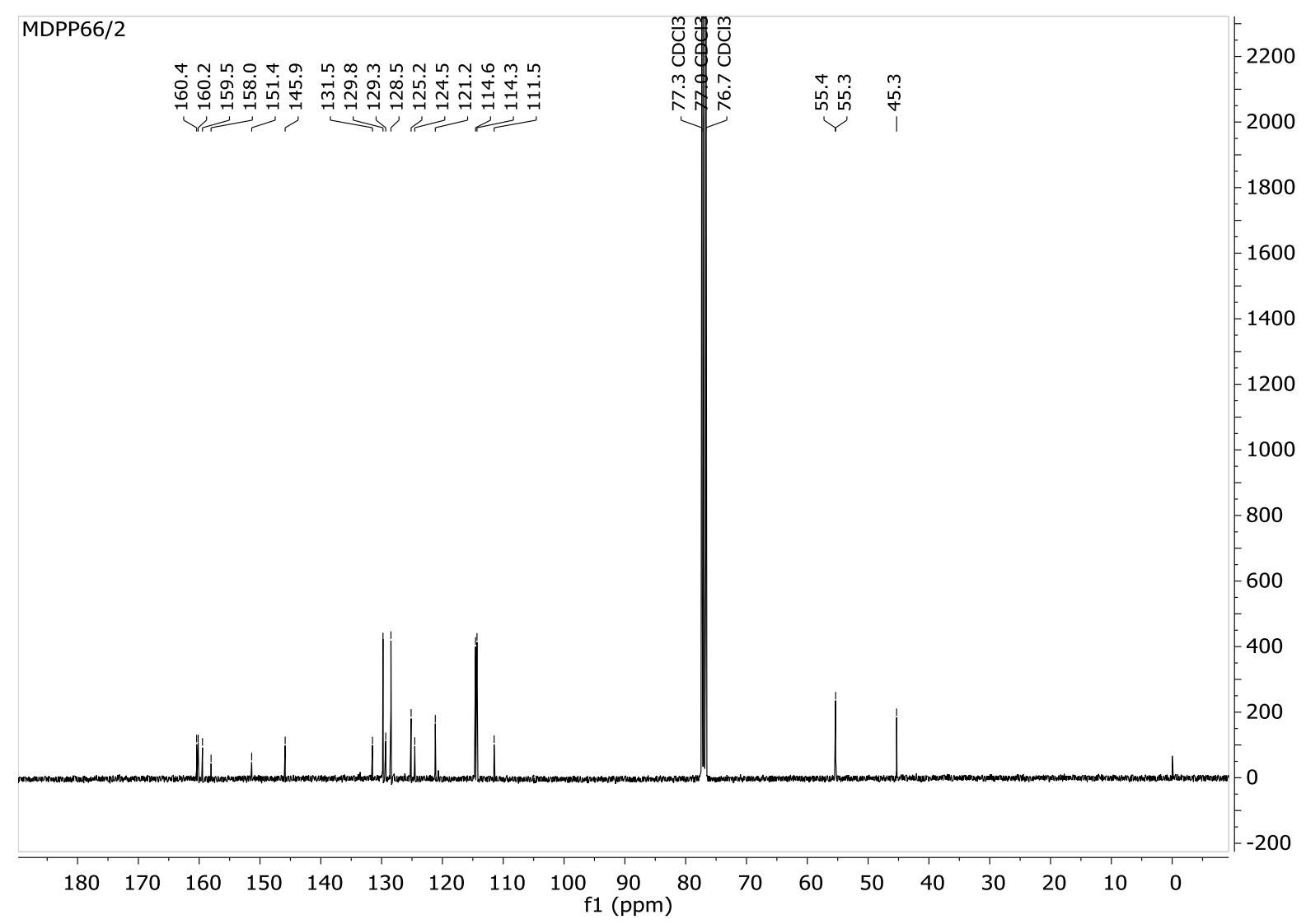

${ }^{13} \mathrm{C}$-NMR spectrum of compound $\mathbf{6 a}$ 


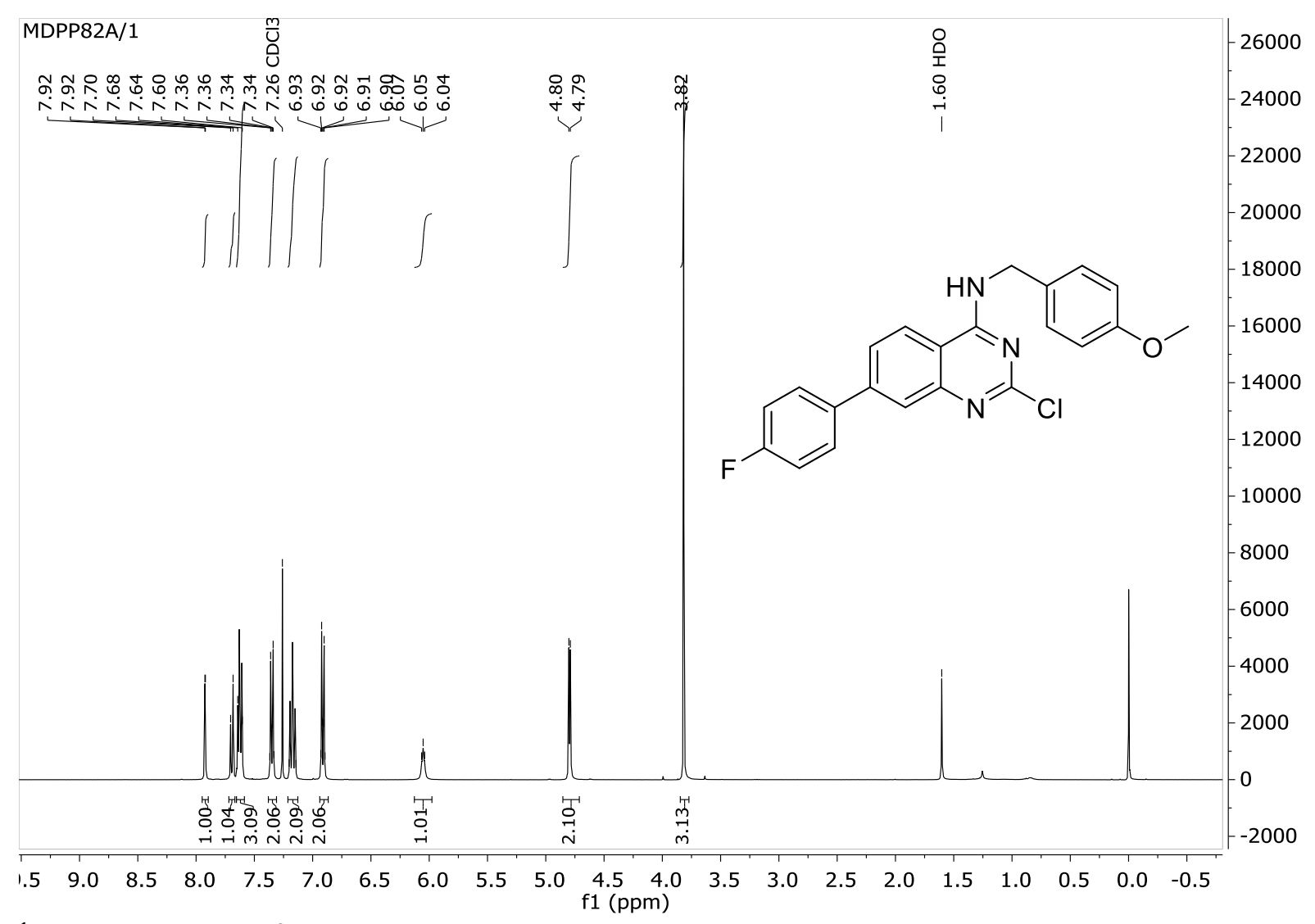

${ }^{1} \mathrm{H}-\mathrm{NMR}$ spectrum of compound $\mathbf{6 b}$

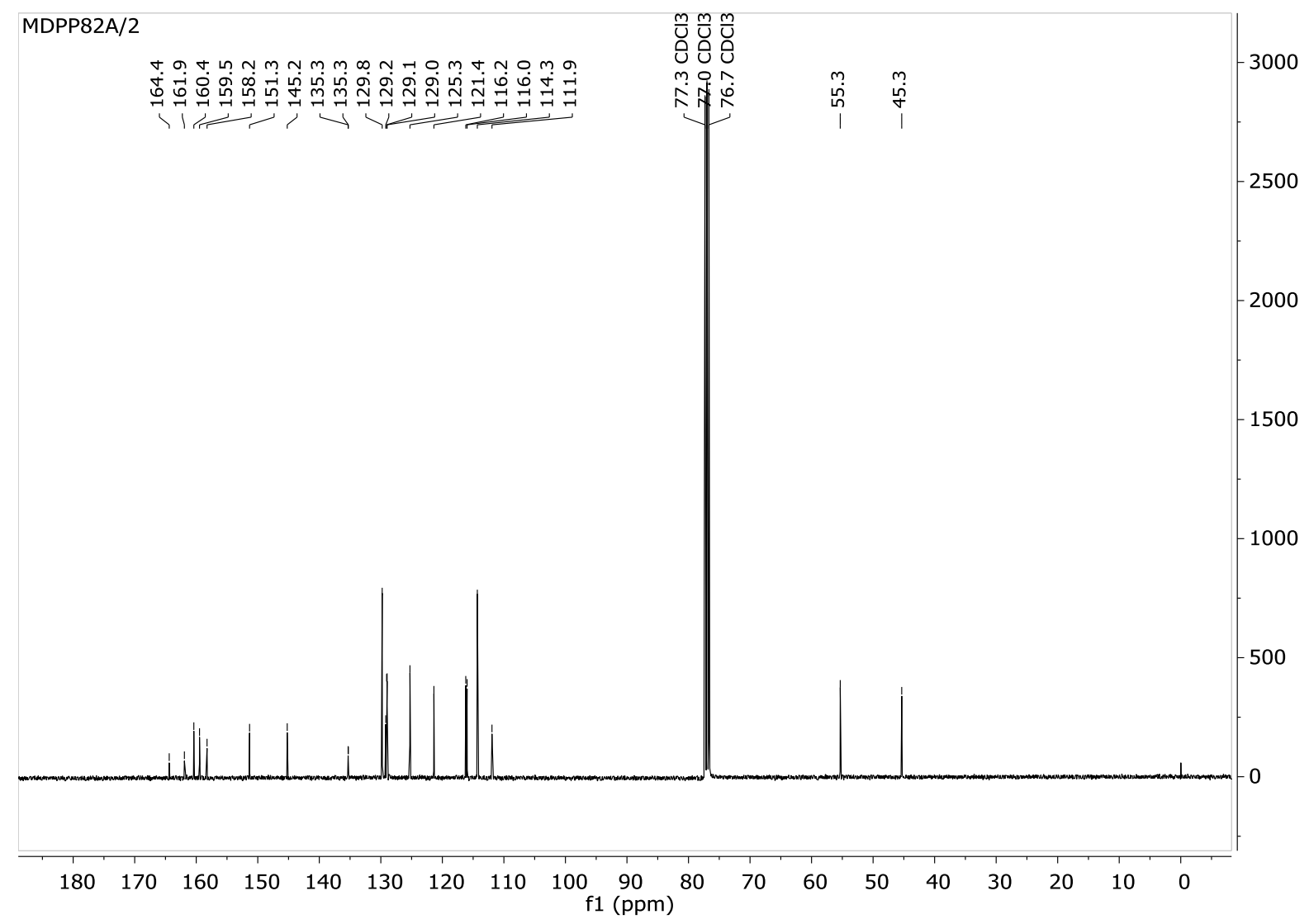

${ }^{13} \mathrm{C}$-NMR spectrum of compound $\mathbf{6 b}$ 


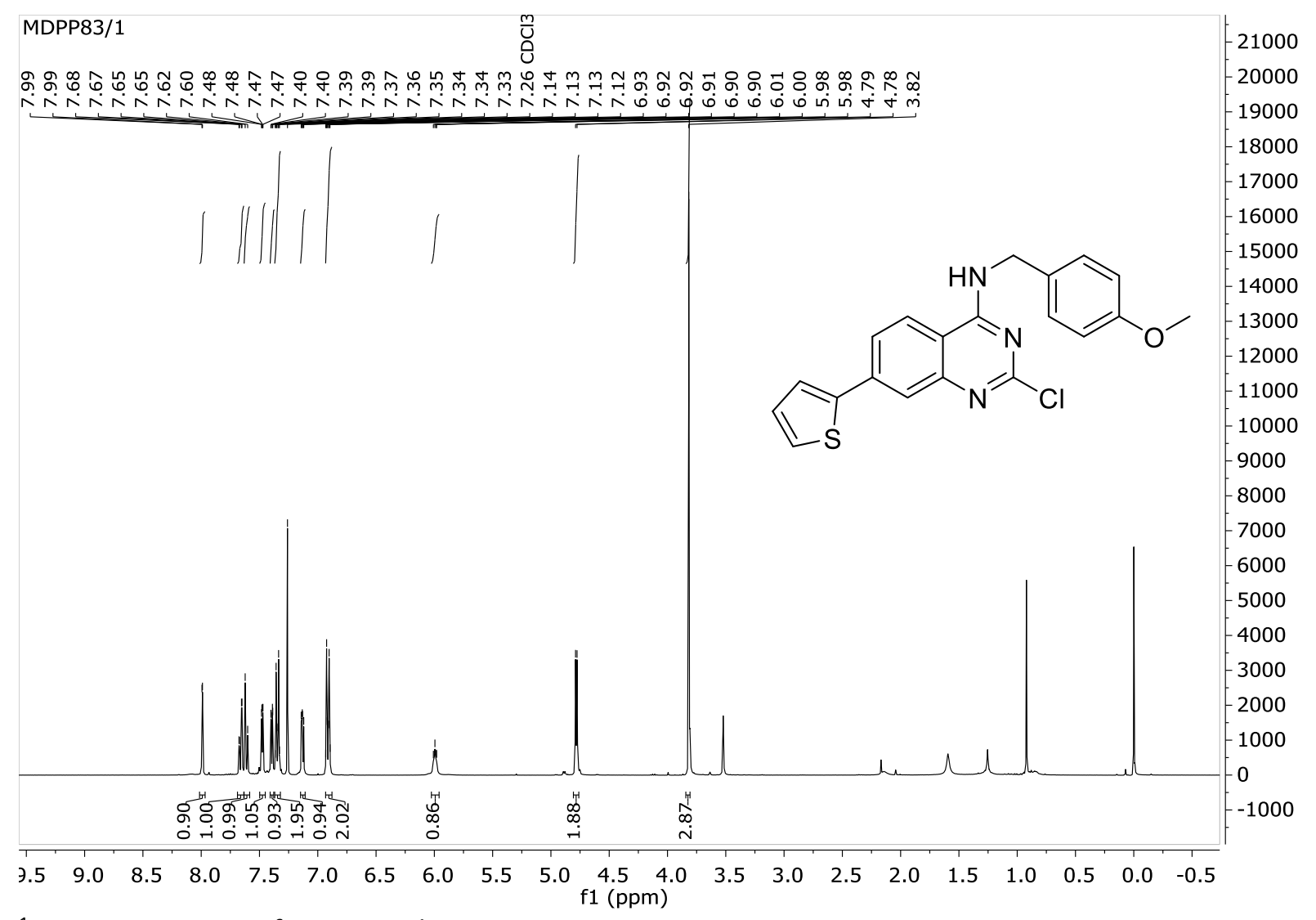

${ }^{1} \mathrm{H}-\mathrm{NMR}$ spectrum of compound $\mathbf{6 c}$

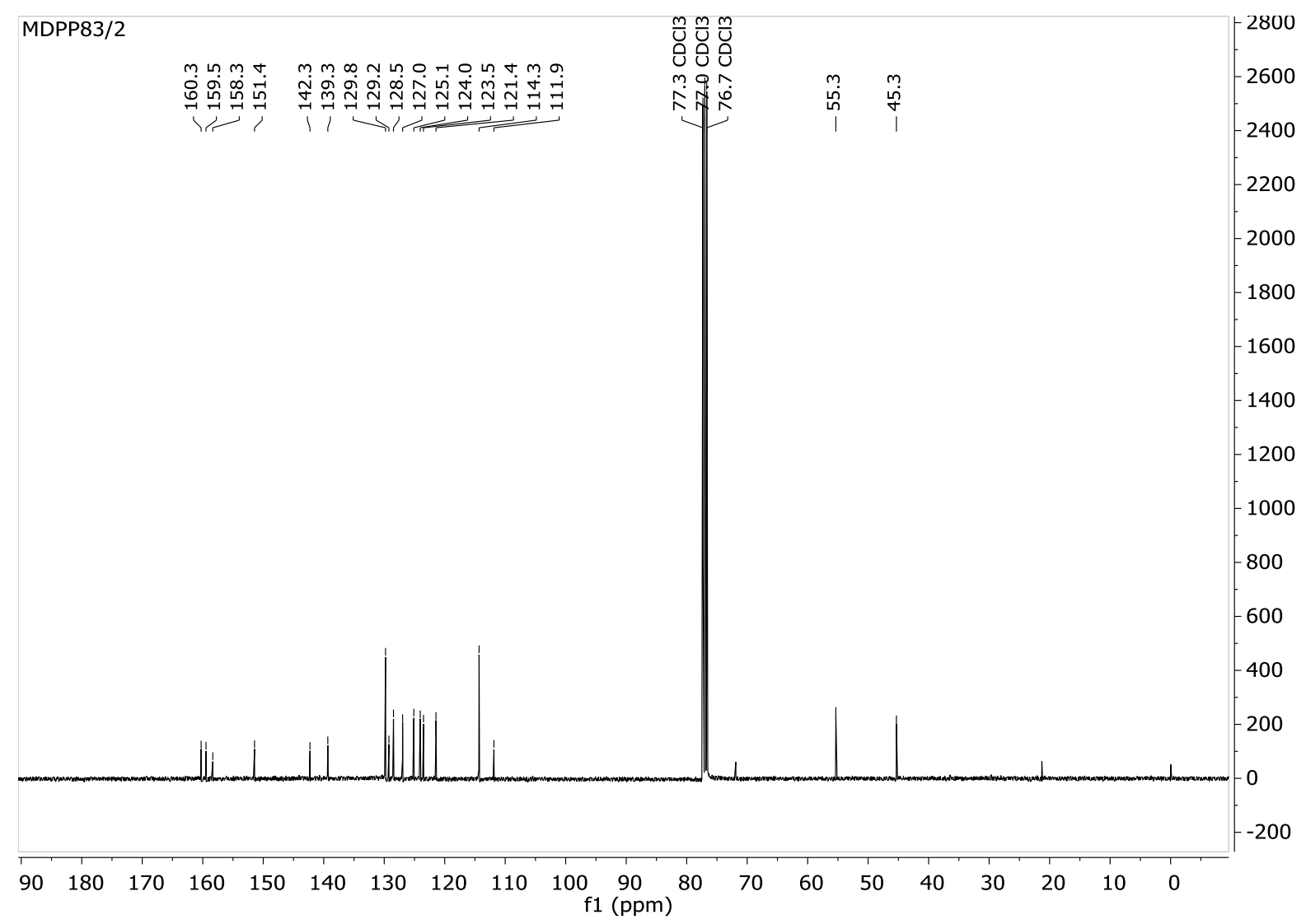

${ }^{13} \mathrm{C}$-NMR spectrum of compound $\mathbf{6 c}$ 


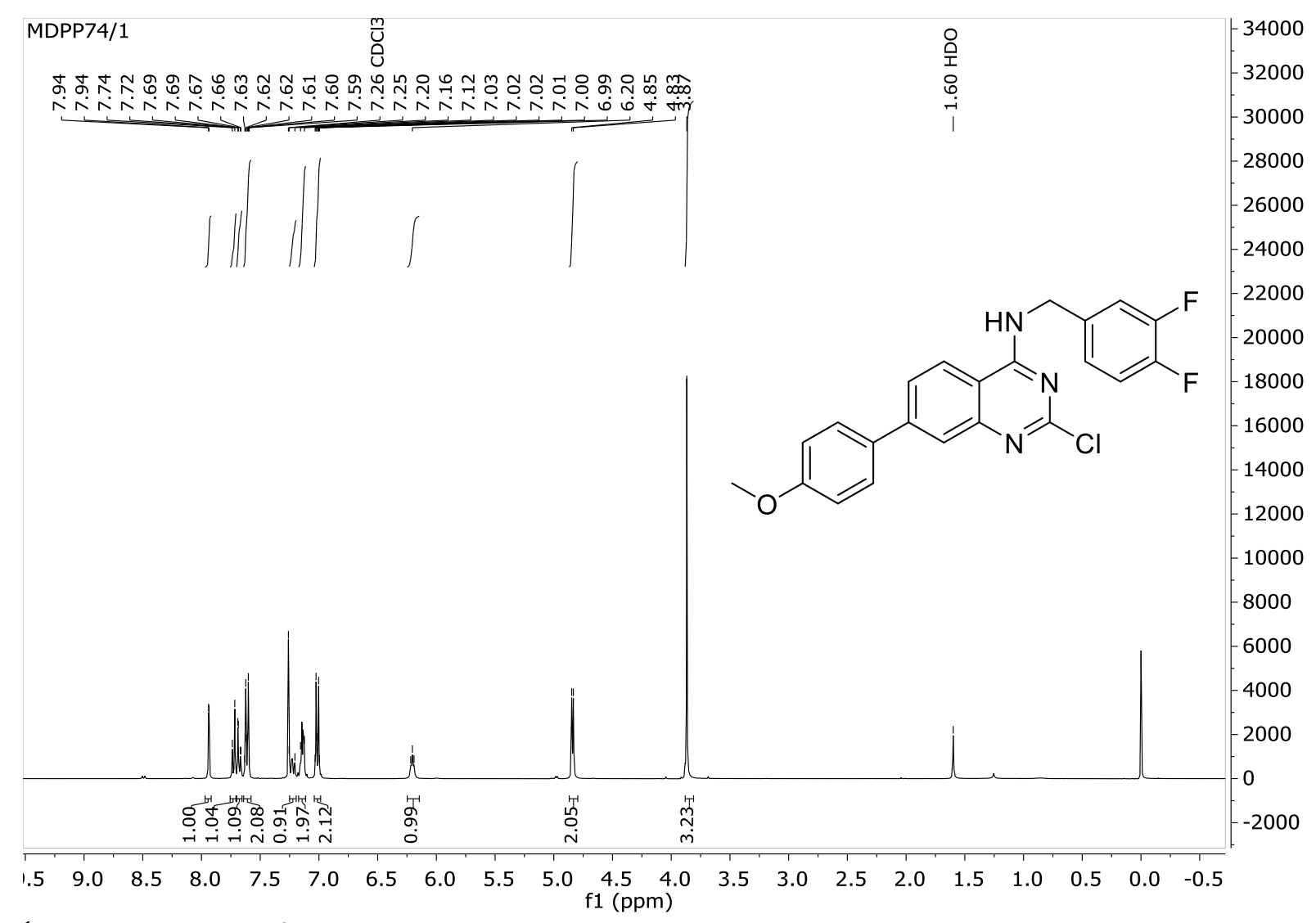

${ }^{1} \mathrm{H}-\mathrm{NMR}$ spectrum of compound $\mathbf{6 d}$

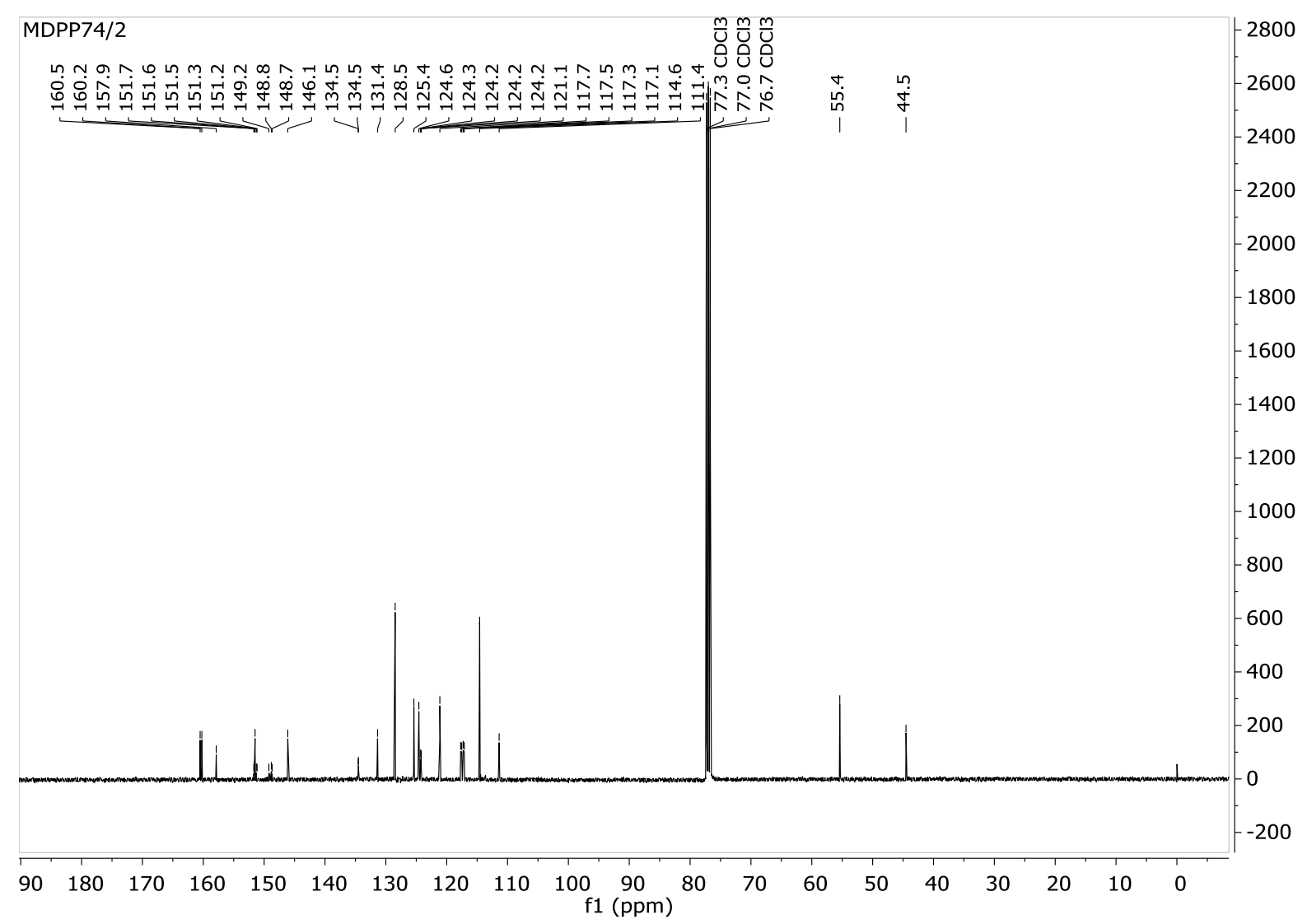

${ }^{13} \mathrm{C}-\mathrm{NMR}$ spectrum of compound $\mathbf{6 d}$ 


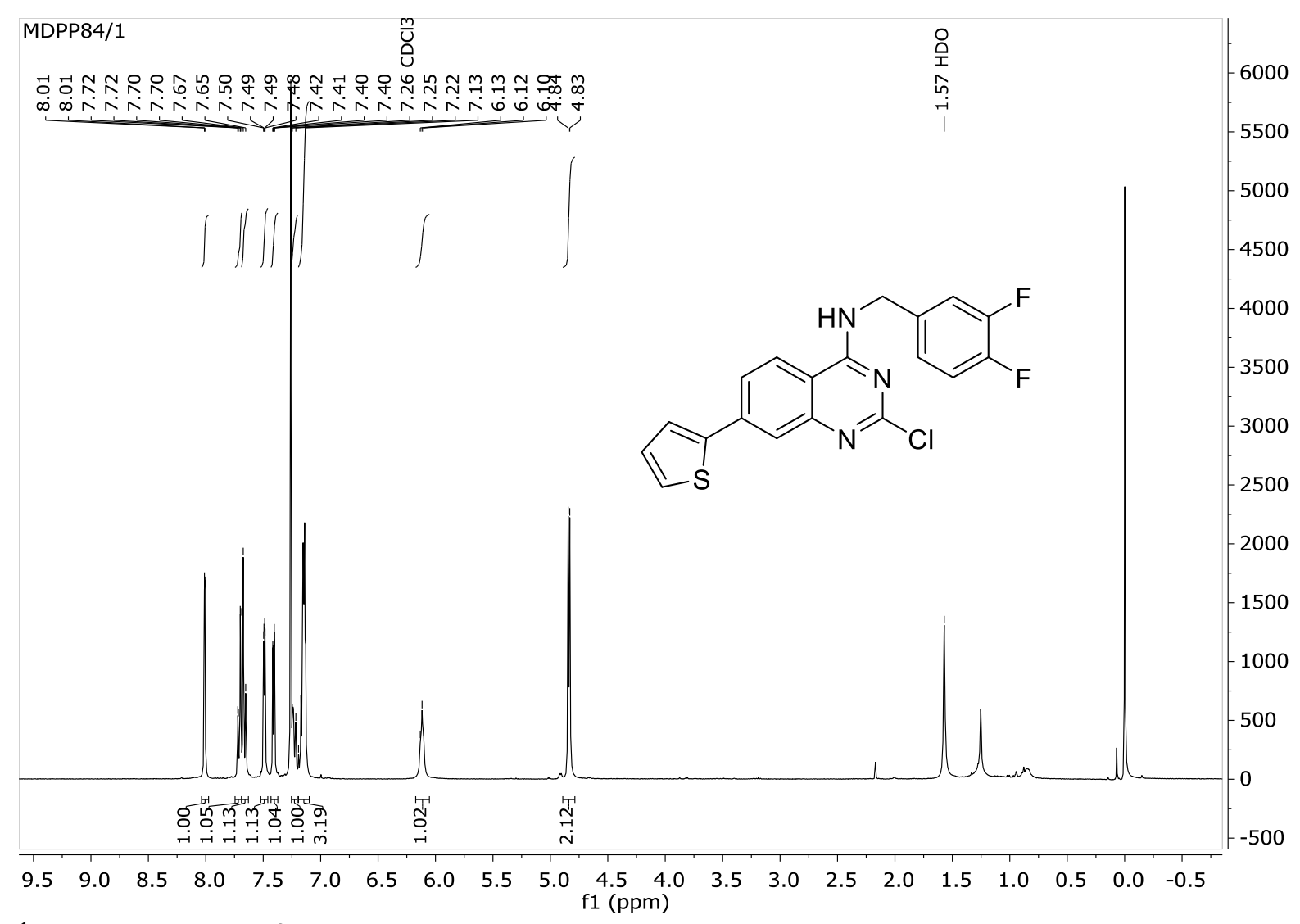

${ }^{1} \mathrm{H}-\mathrm{NMR}$ spectrum of compound $6 \mathrm{e}$

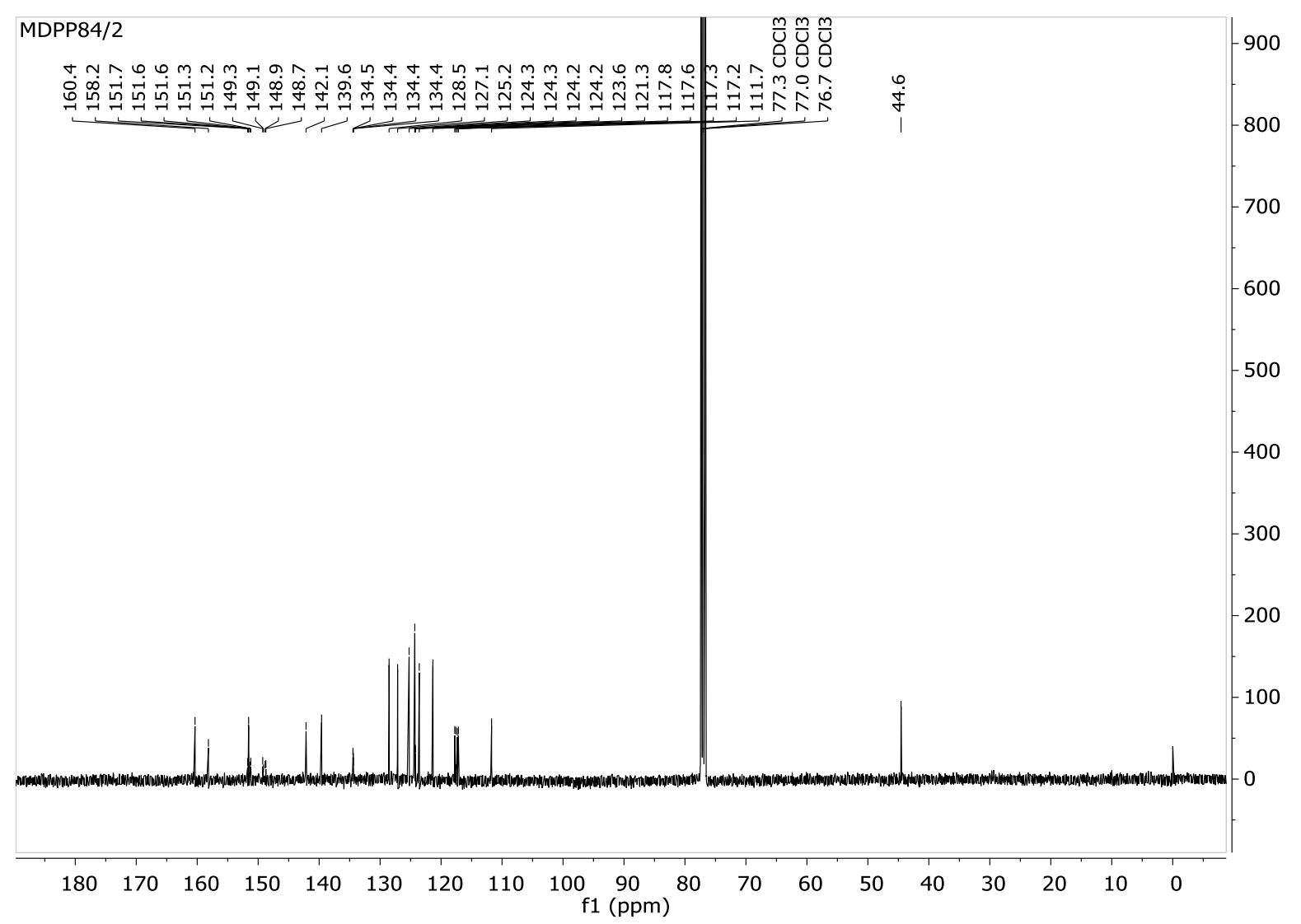

${ }^{13} \mathrm{C}-\mathrm{NMR}$ spectrum of compound $6 \mathrm{e}$ 


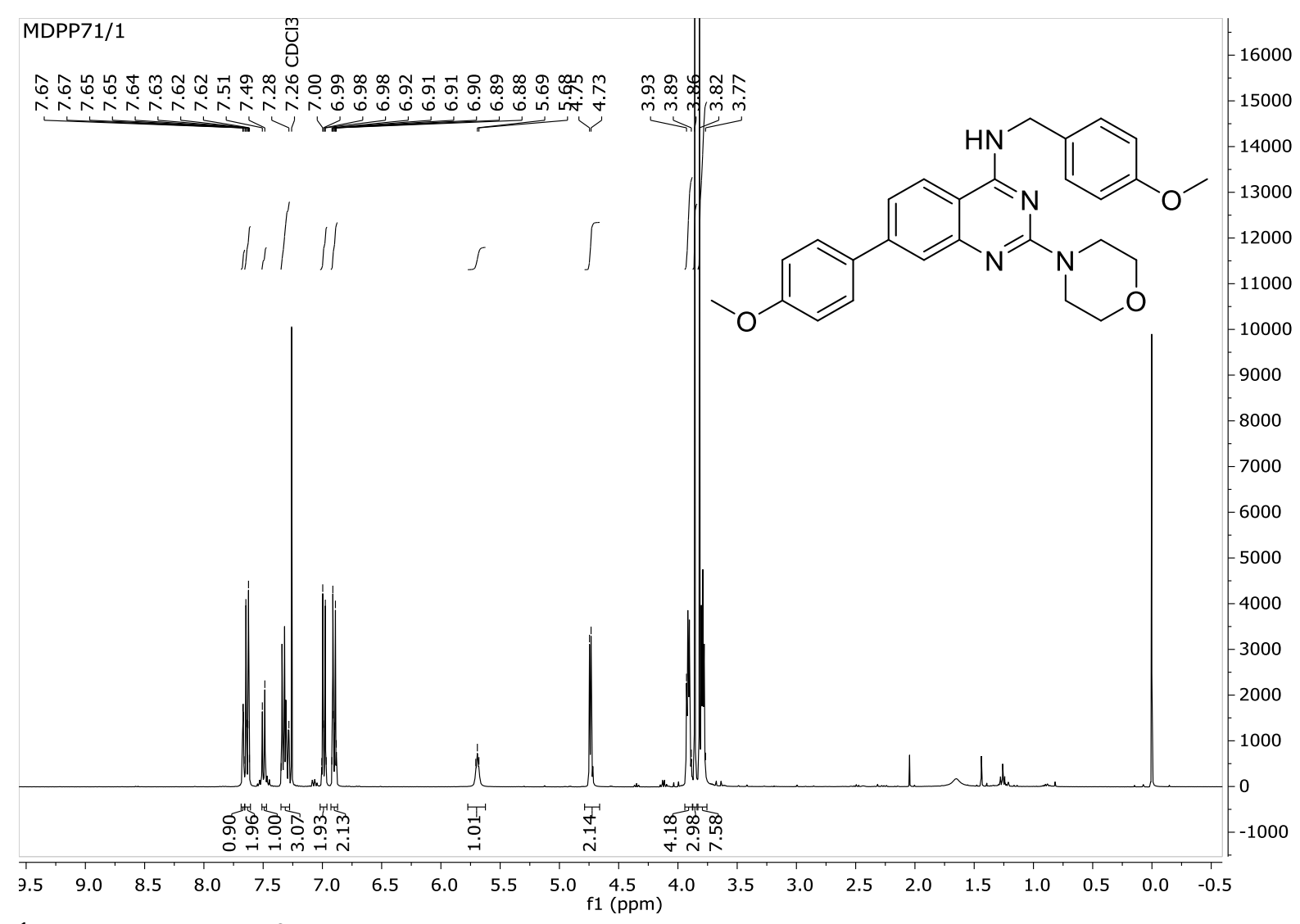

${ }^{1} \mathrm{H}-\mathrm{NMR}$ spectrum of compound $7 \mathrm{a}$

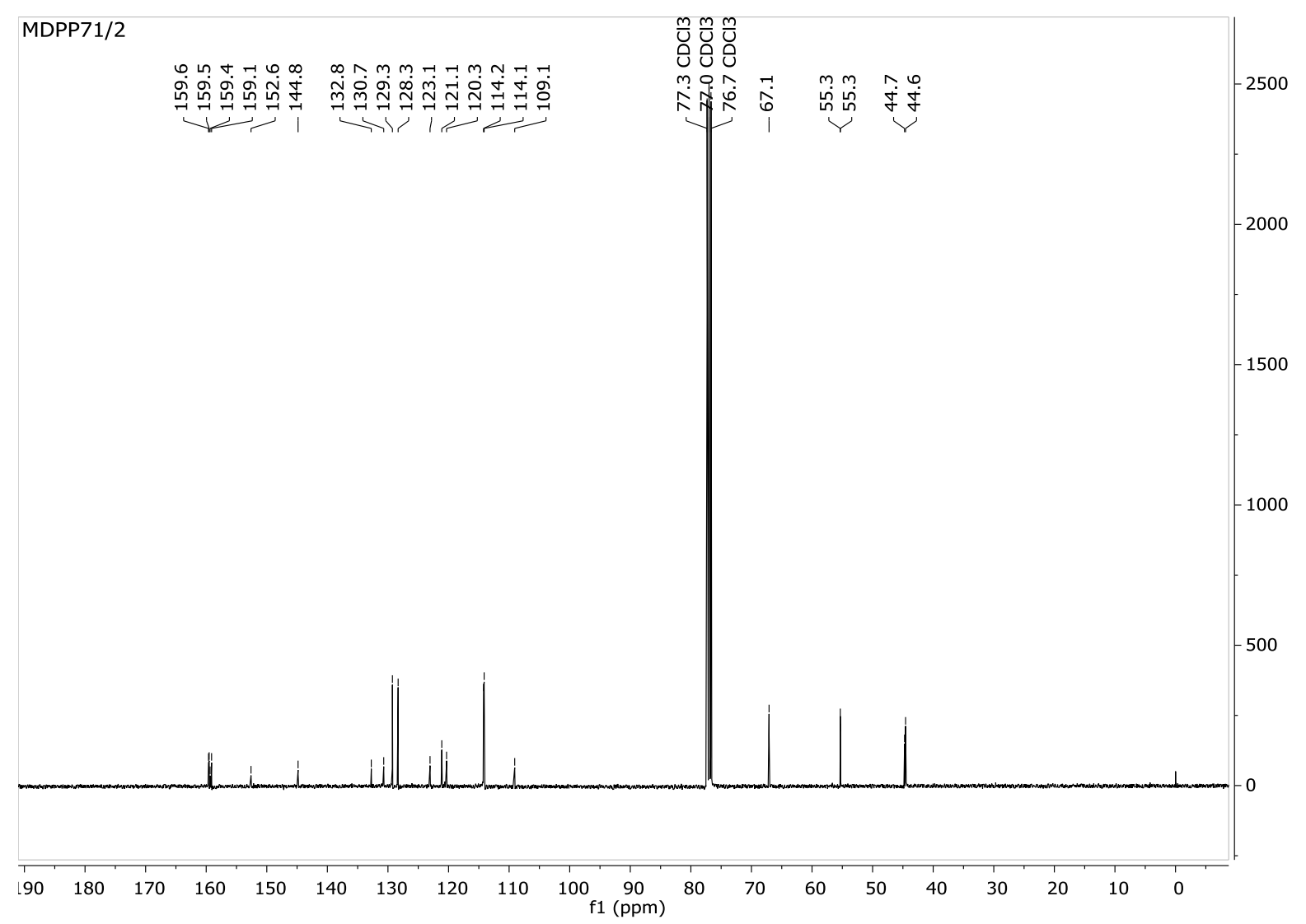

${ }^{13} \mathrm{C}-\mathrm{NMR}$ spectrum of compound $7 \mathrm{a}$ 


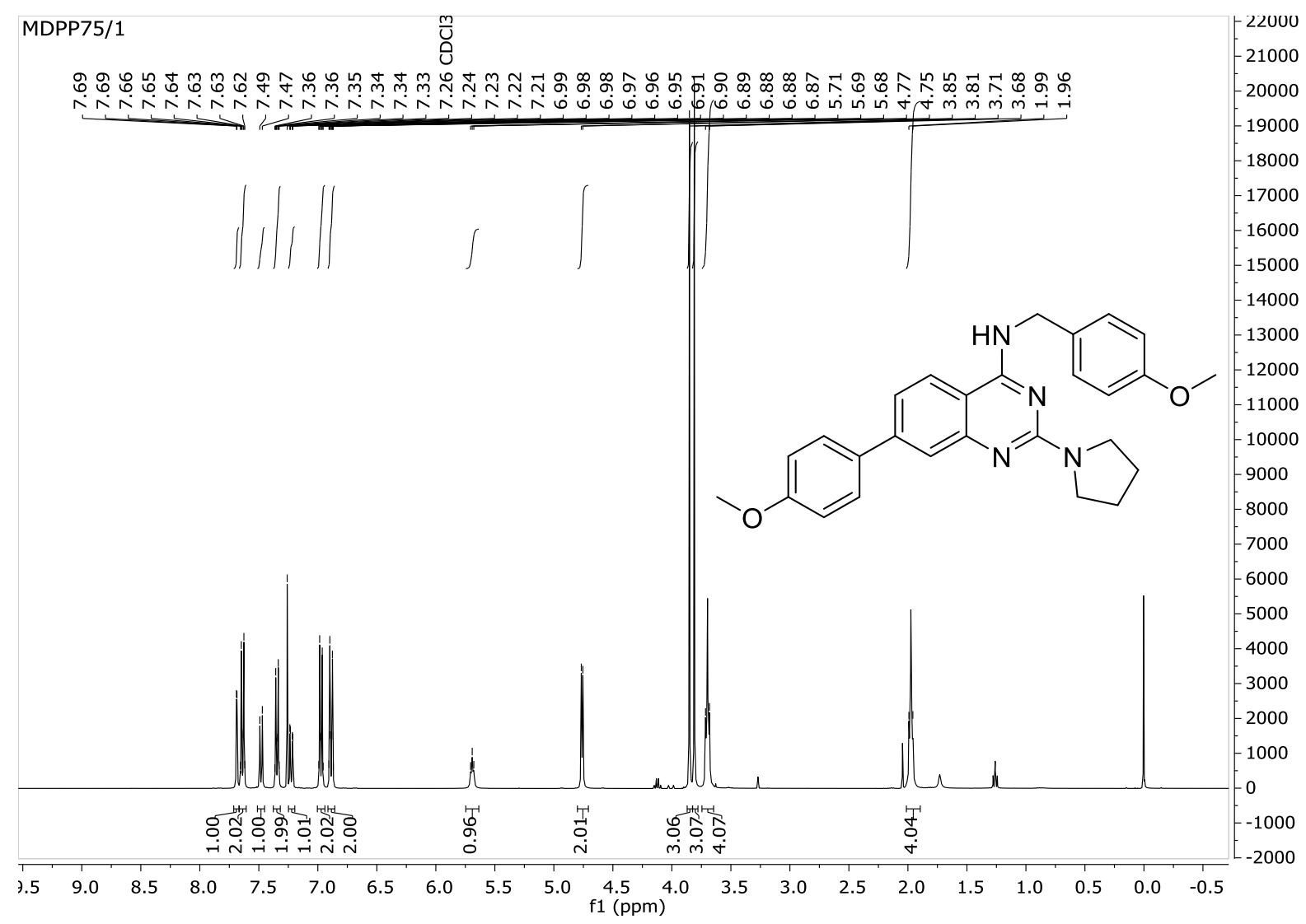

${ }^{1} \mathrm{H}-\mathrm{NMR}$ spectrum of compound $7 \mathrm{~b}$

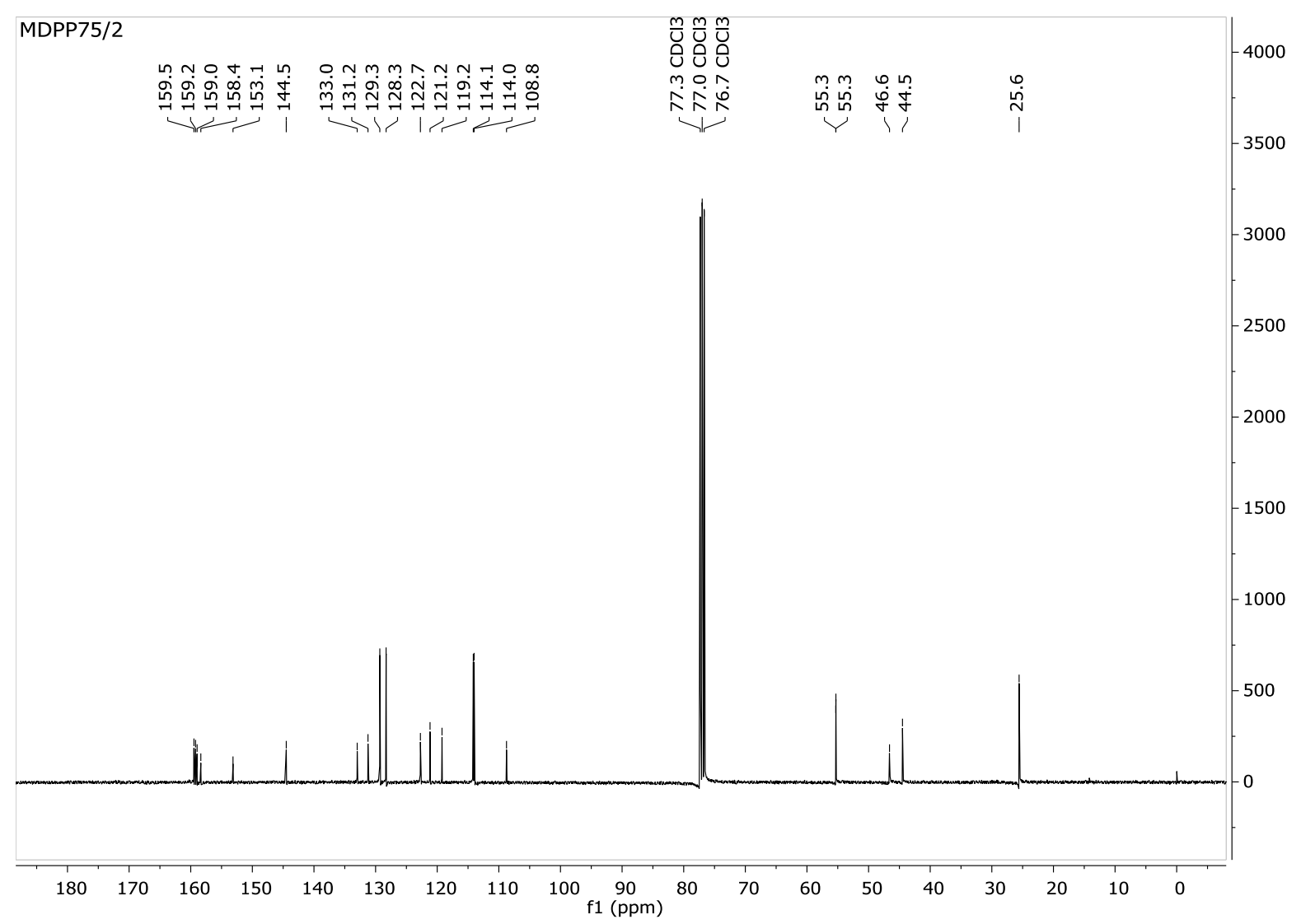

${ }^{13} \mathrm{C}-\mathrm{NMR}$ spectrum of compound $7 \mathrm{~b}$ 


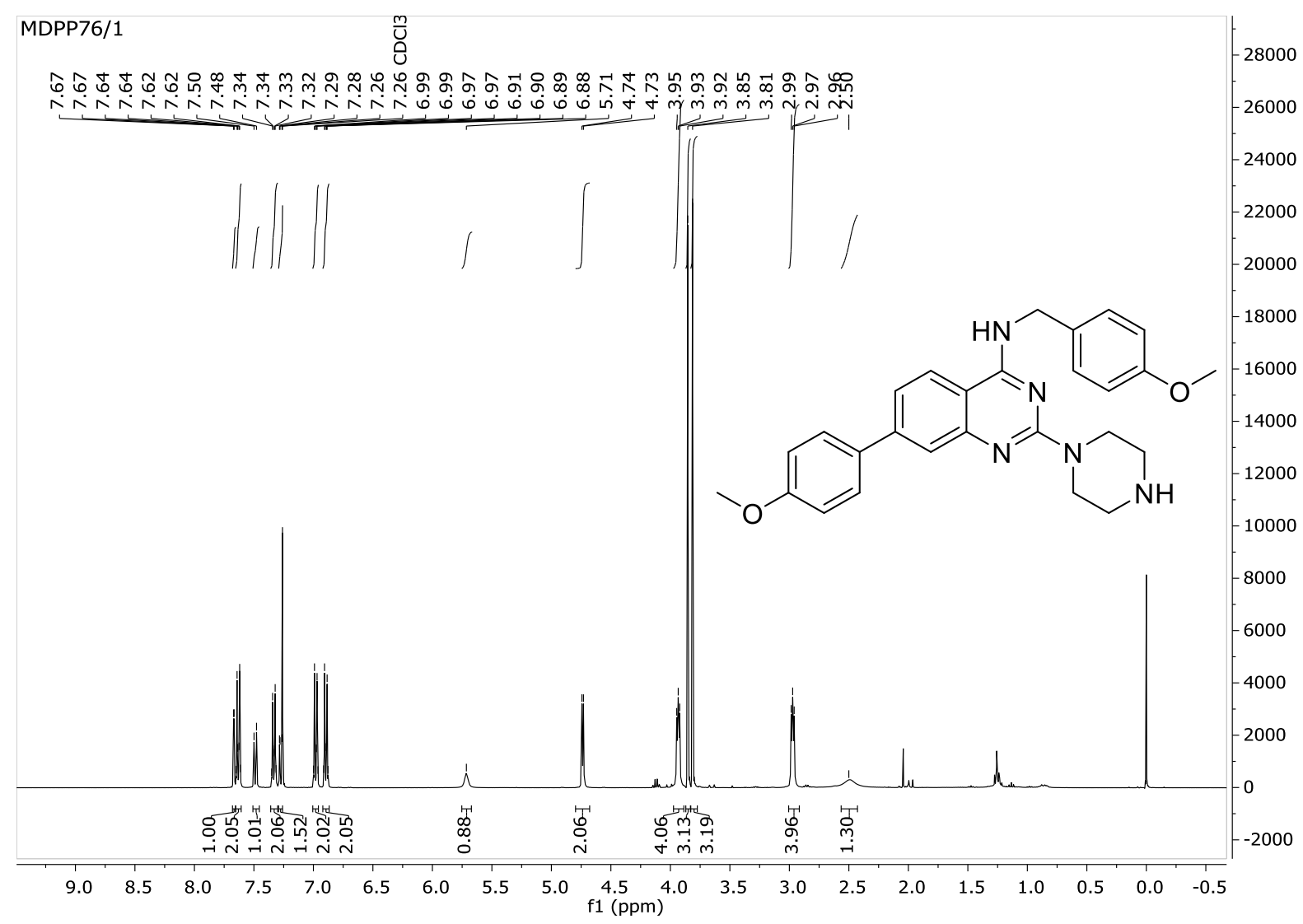

${ }^{1} \mathrm{H}-\mathrm{NMR}$ spectrum of compound $7 \mathrm{c}$

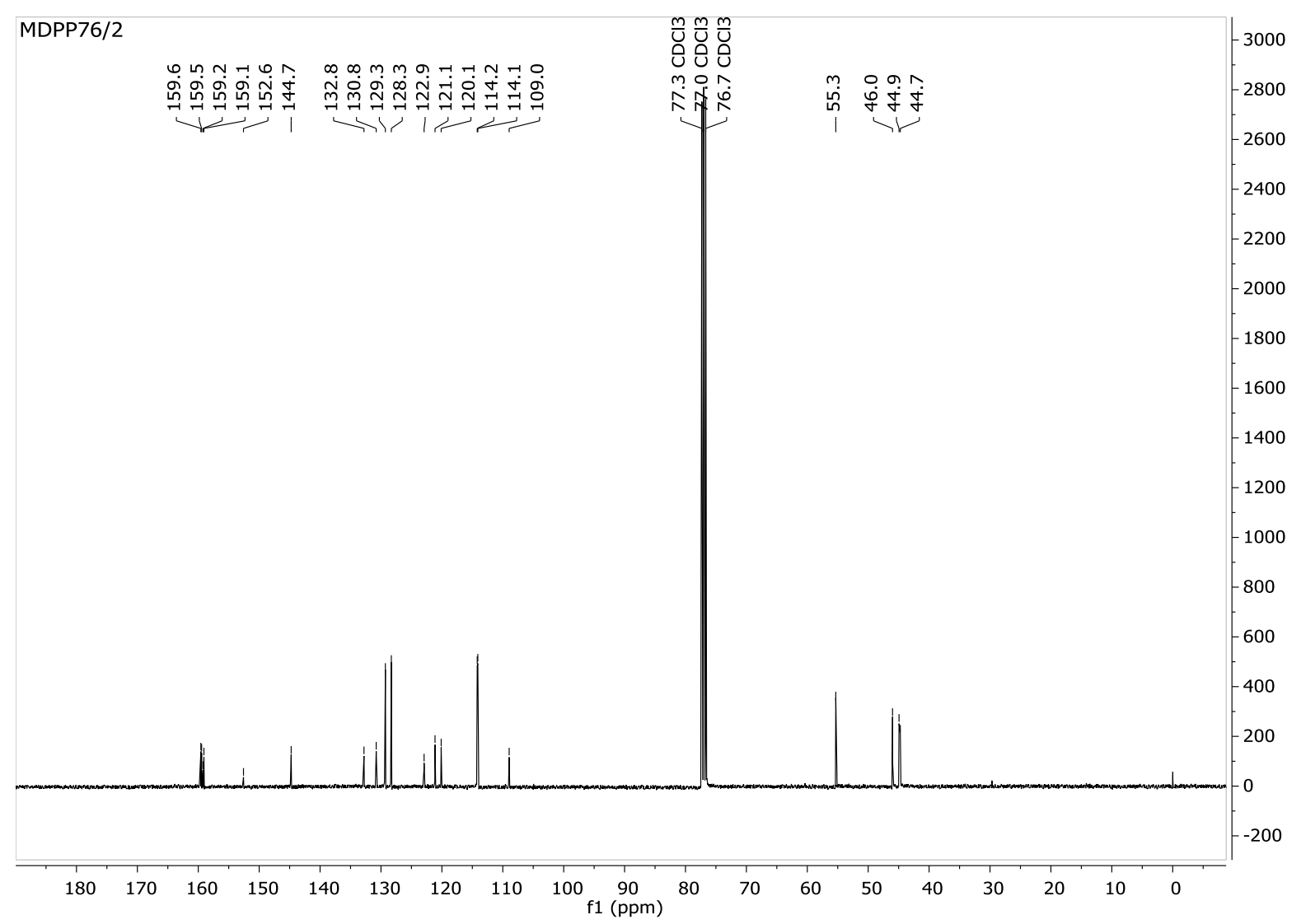

${ }^{13} \mathrm{C}-\mathrm{NMR}$ spectrum of compound 7c 


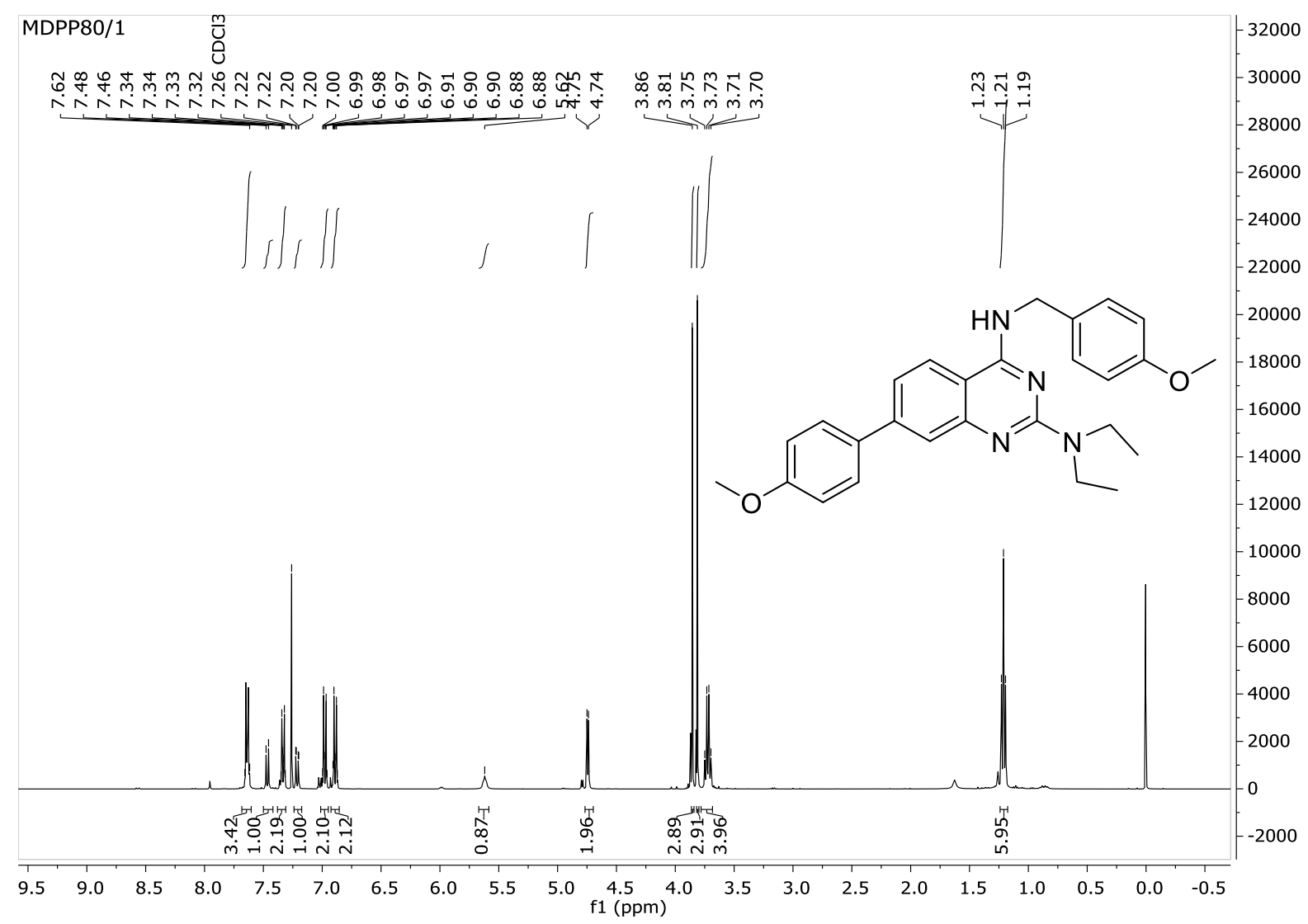

${ }^{1} \mathrm{H}$-NMR spectrum of compound $\mathbf{7 d}$

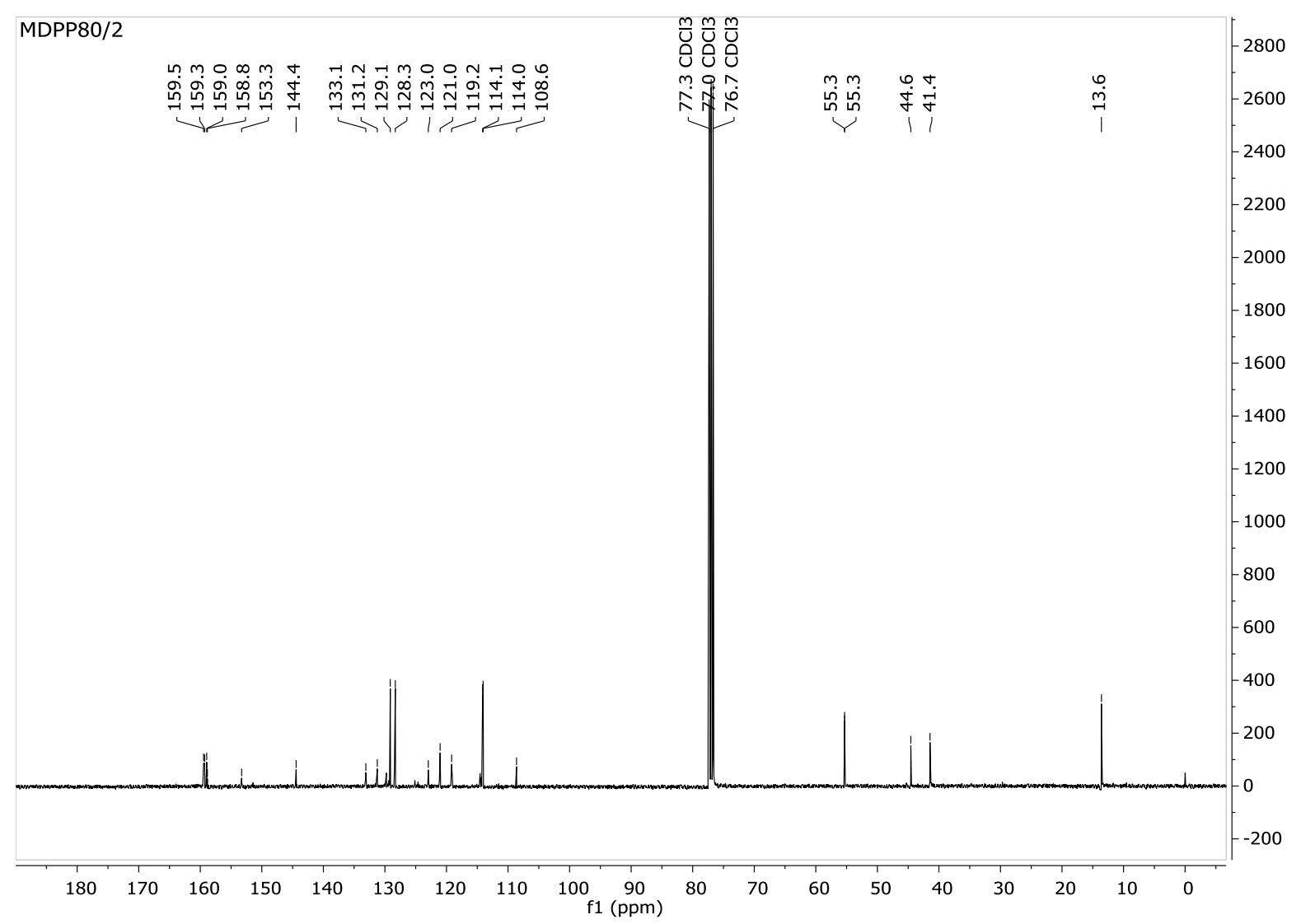

${ }^{13} \mathrm{C}$-NMR spectrum of compound $\mathbf{7 d}$ 


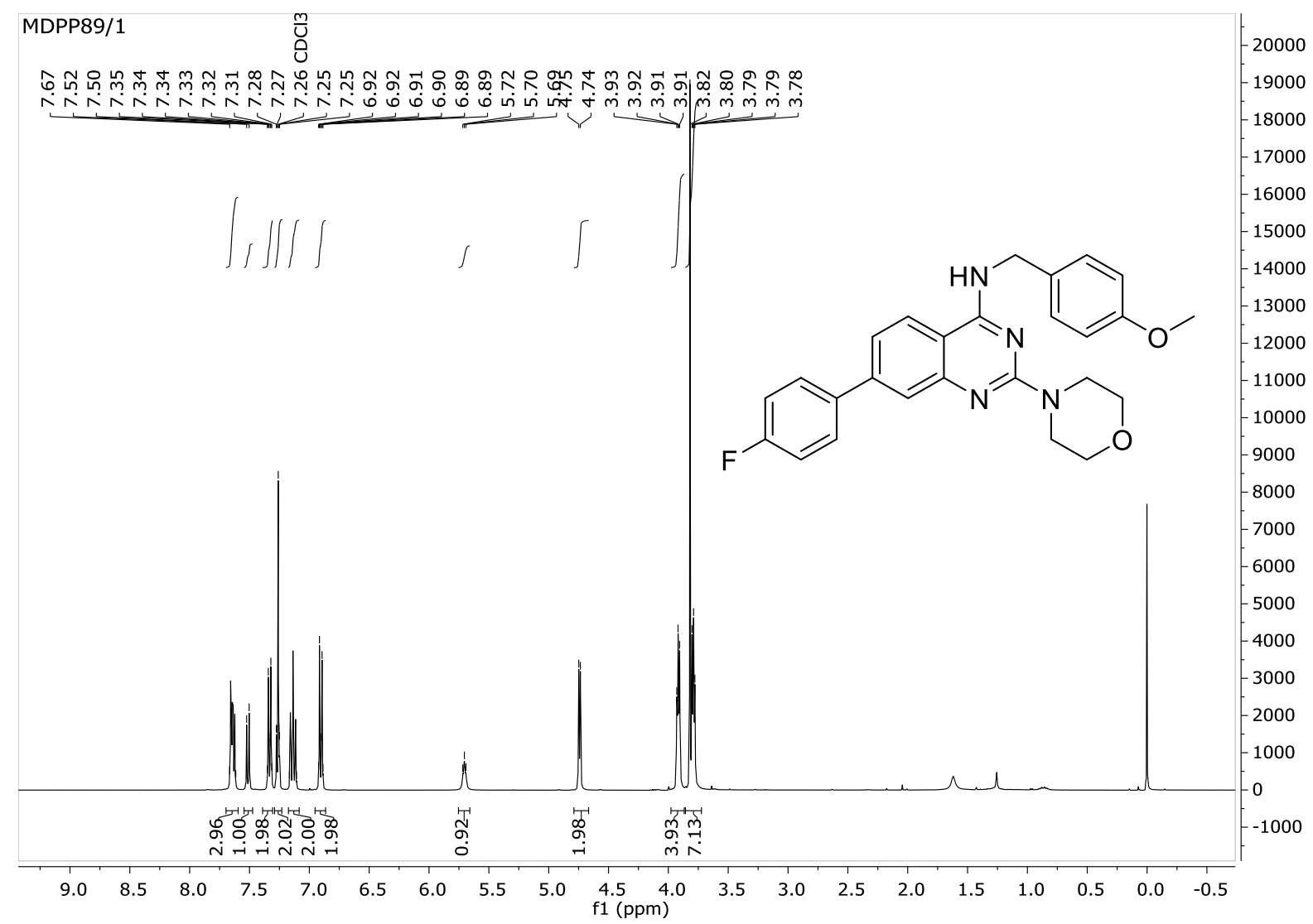

${ }^{1} \mathrm{H}-\mathrm{NMR}$ spectrum of compound $7 \mathrm{e}$

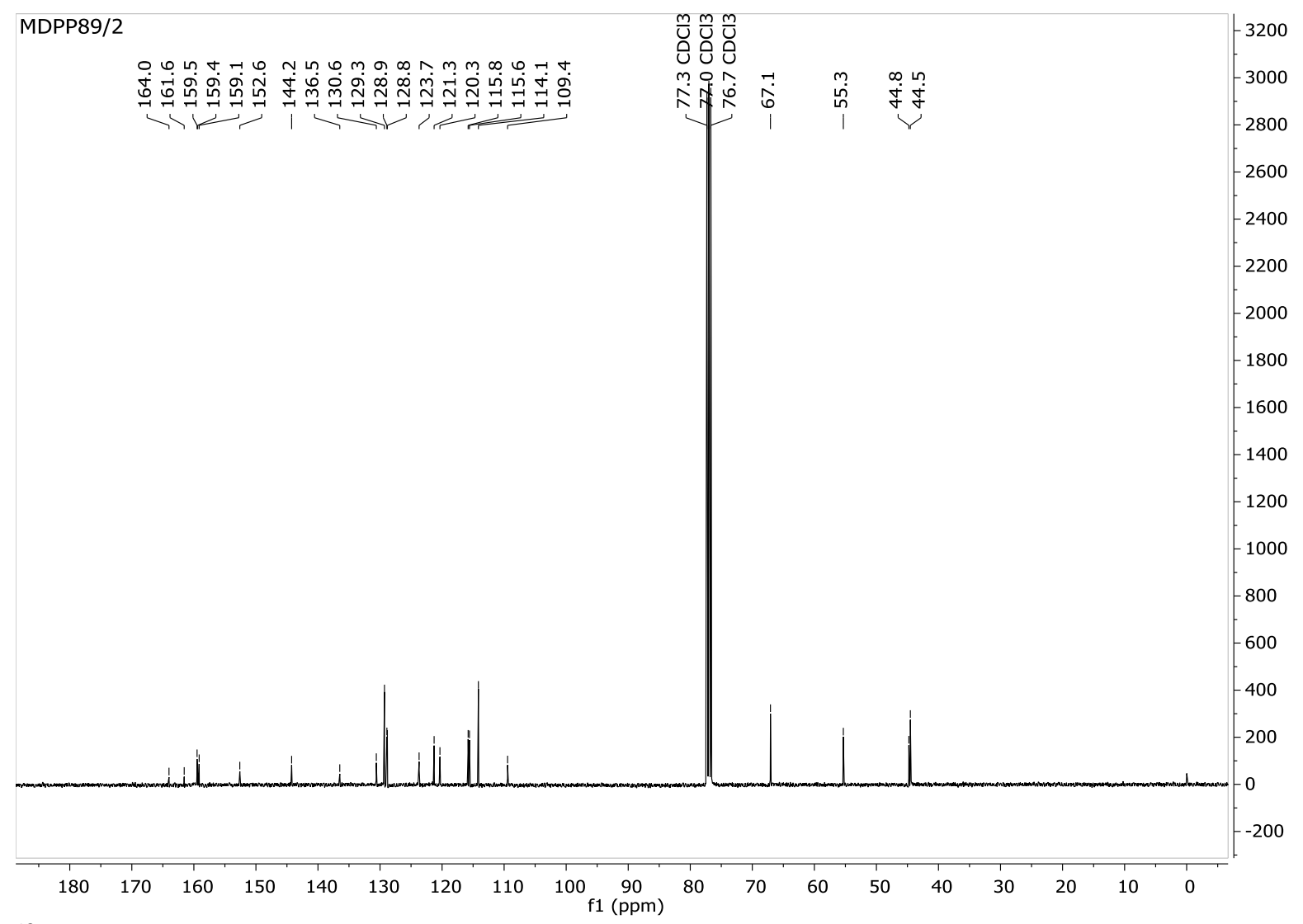

${ }^{13} \mathrm{C}-\mathrm{NMR}$ spectrum of compound $7 \mathrm{e}$ 


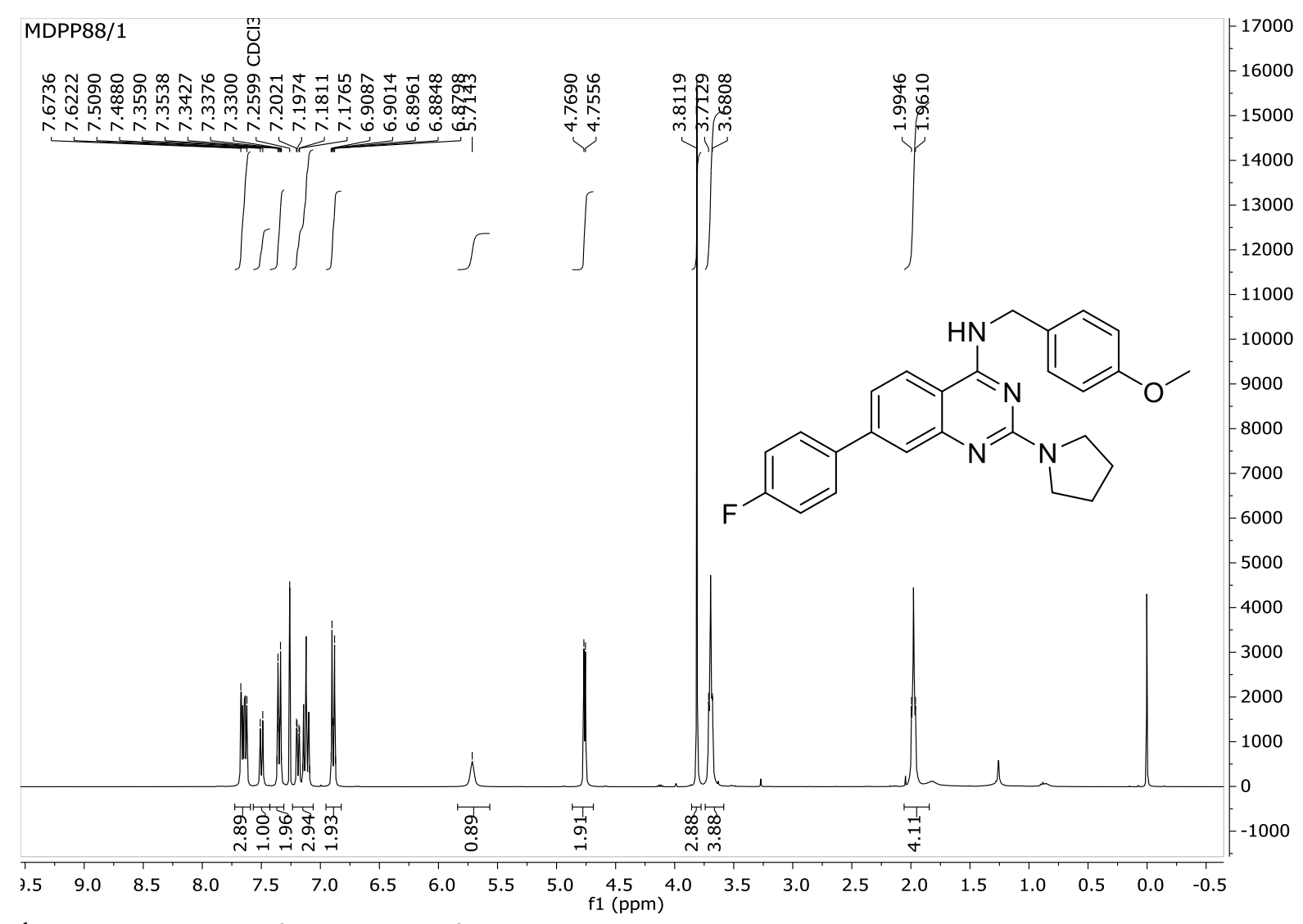

${ }^{1} \mathrm{H}-\mathrm{NMR}$ spectrum of compound $7 \mathrm{ff}$

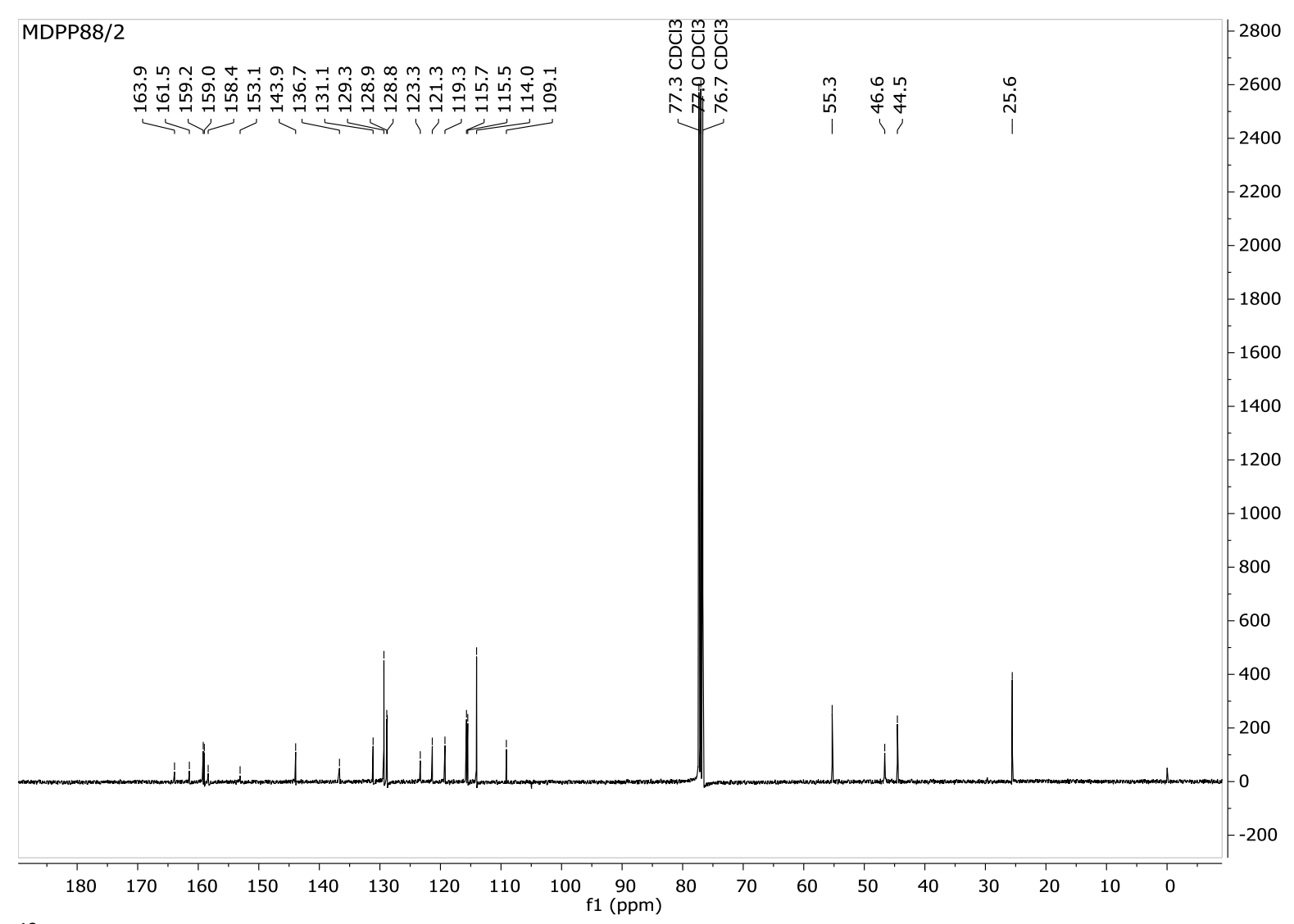

${ }^{13} \mathrm{C}-\mathrm{NMR}$ spectrum of compound $\mathbf{7 f}$ 


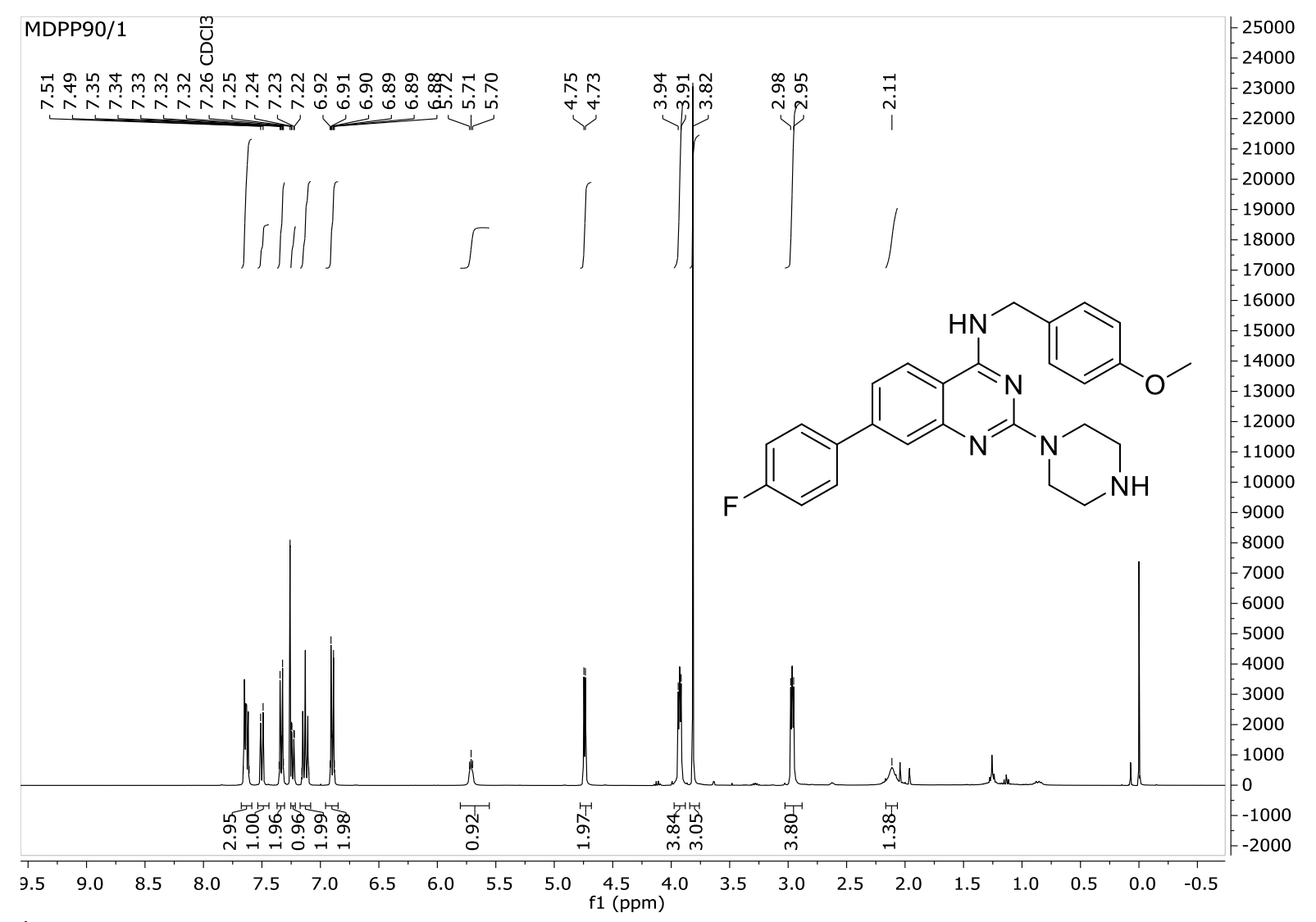

${ }^{1} \mathrm{H}-\mathrm{NMR}$ spectrum of compound $7 \mathrm{~g}$

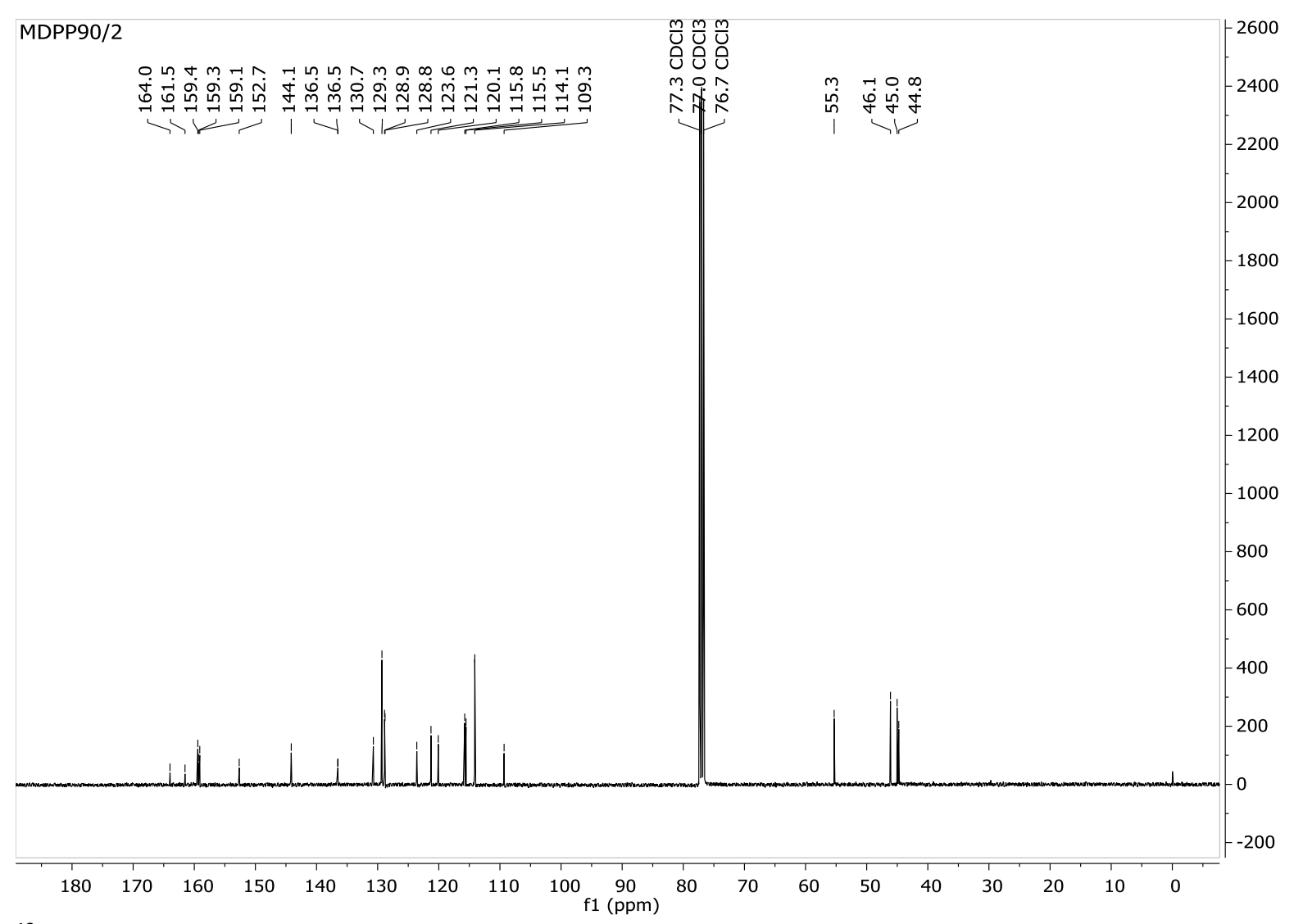

${ }^{13} \mathrm{C}-\mathrm{NMR}$ spectrum of compound $\mathbf{7 g}$ 


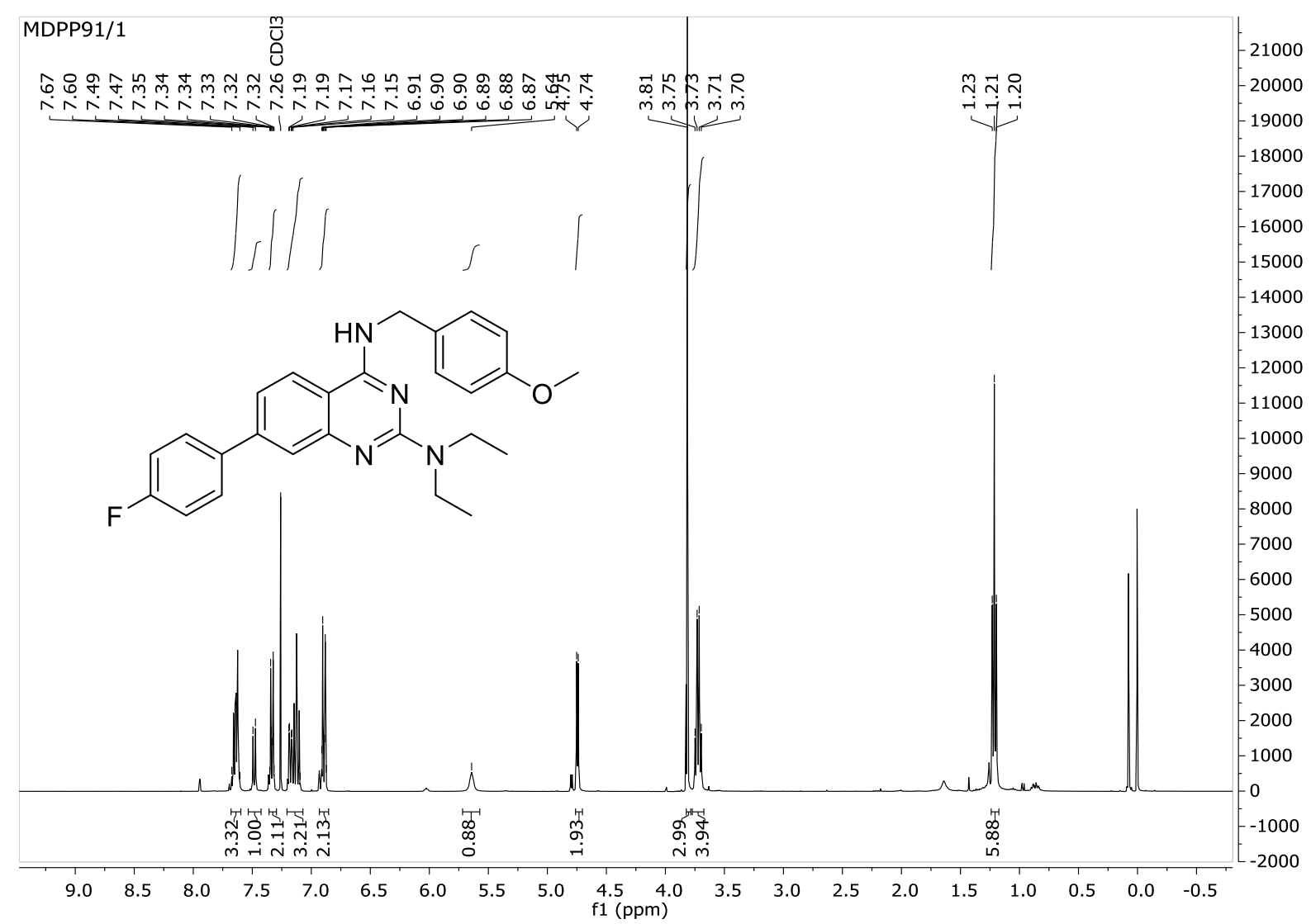

${ }^{1} \mathrm{H}$-NMR spectrum of compound $\mathbf{7 h}$

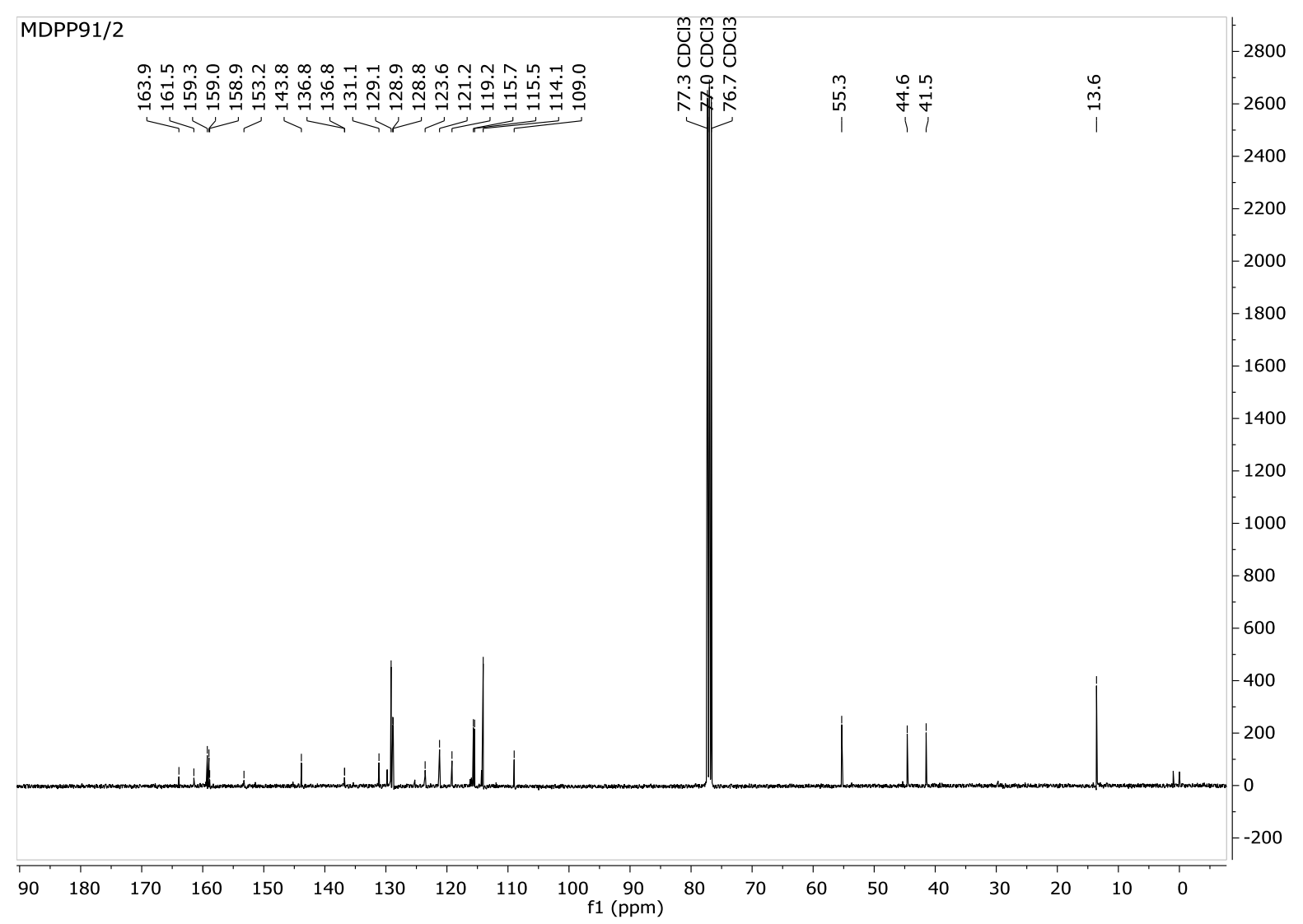

${ }^{13} \mathrm{C}$-NMR spectrum of compound $7 \mathrm{~h}$ 


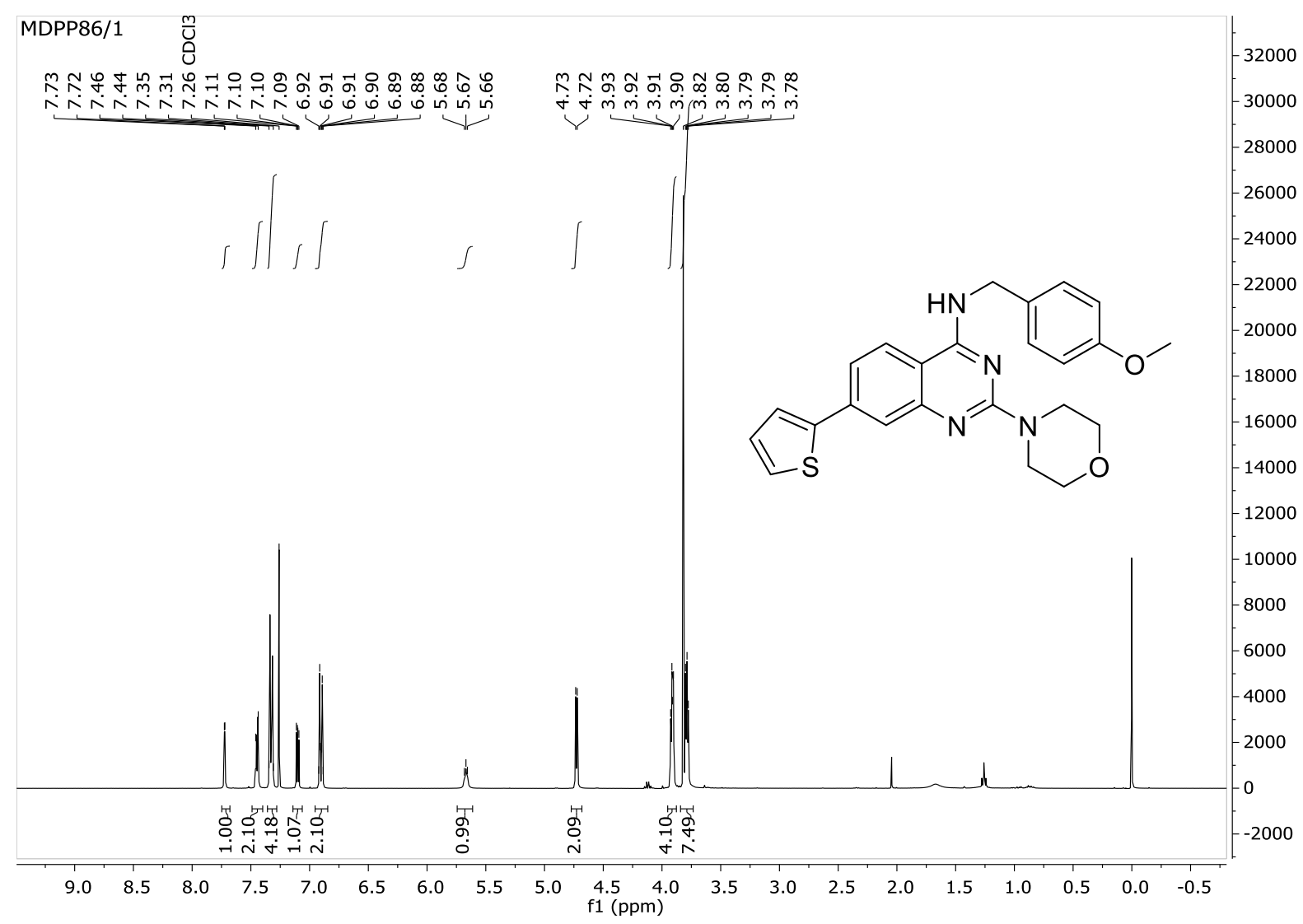

${ }^{1} \mathrm{H}$-NMR spectrum of compound $7 \mathbf{i}$

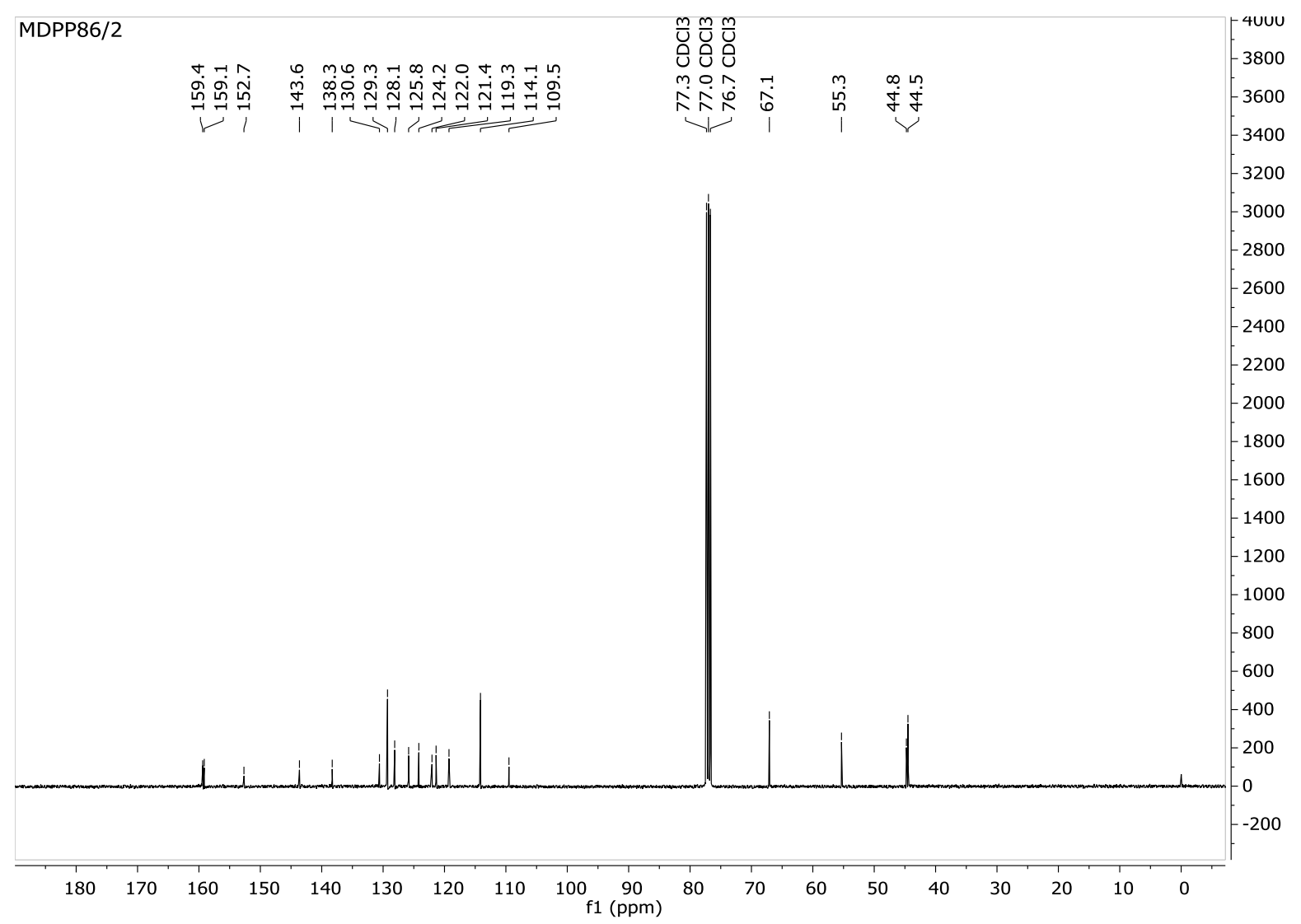

${ }^{13} \mathrm{C}-\mathrm{NMR}$ spectrum of compound $\mathbf{7 i}$ 


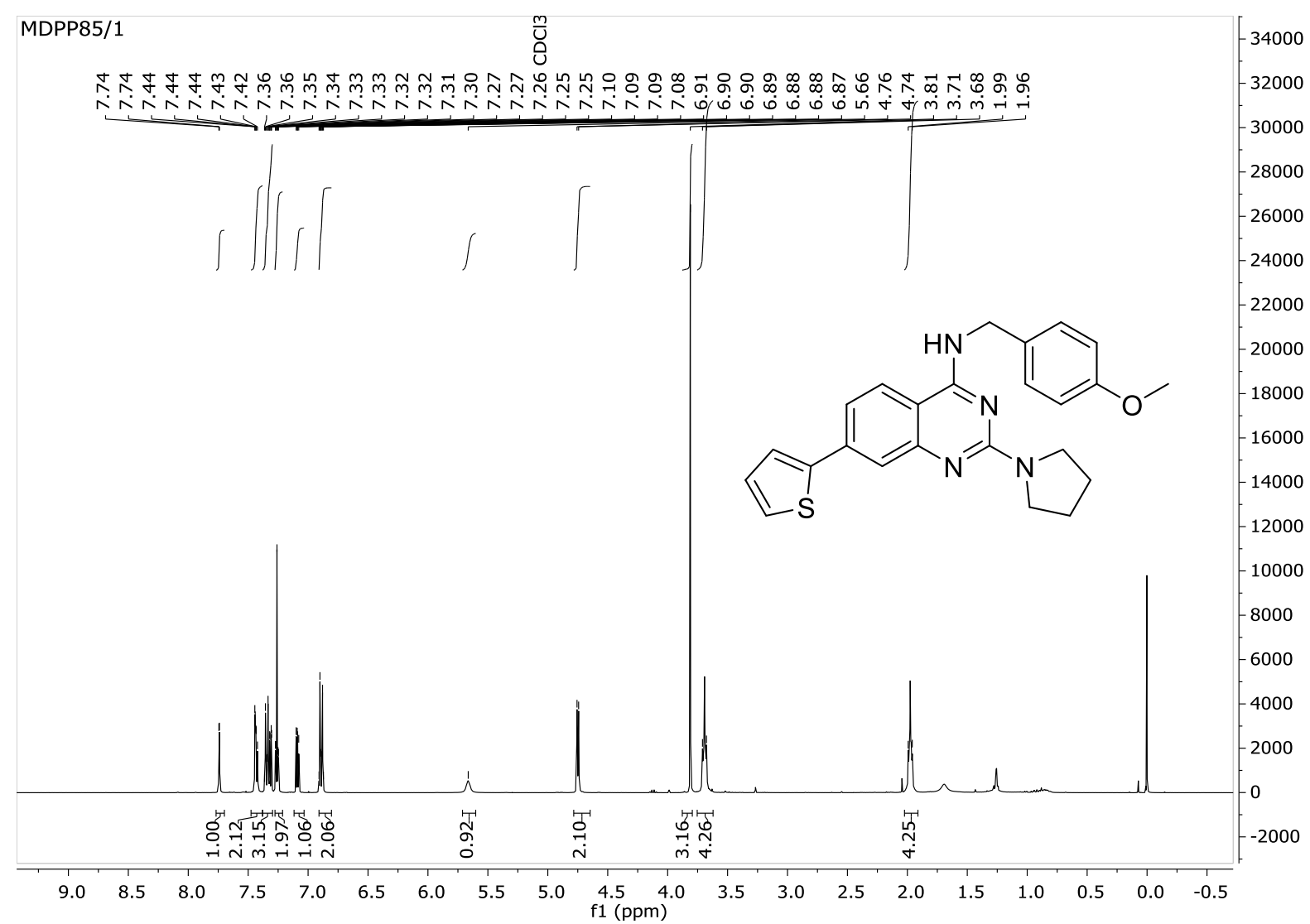

${ }^{1} \mathrm{H}-\mathrm{NMR}$ spectrum of compound $\mathbf{7 j}$

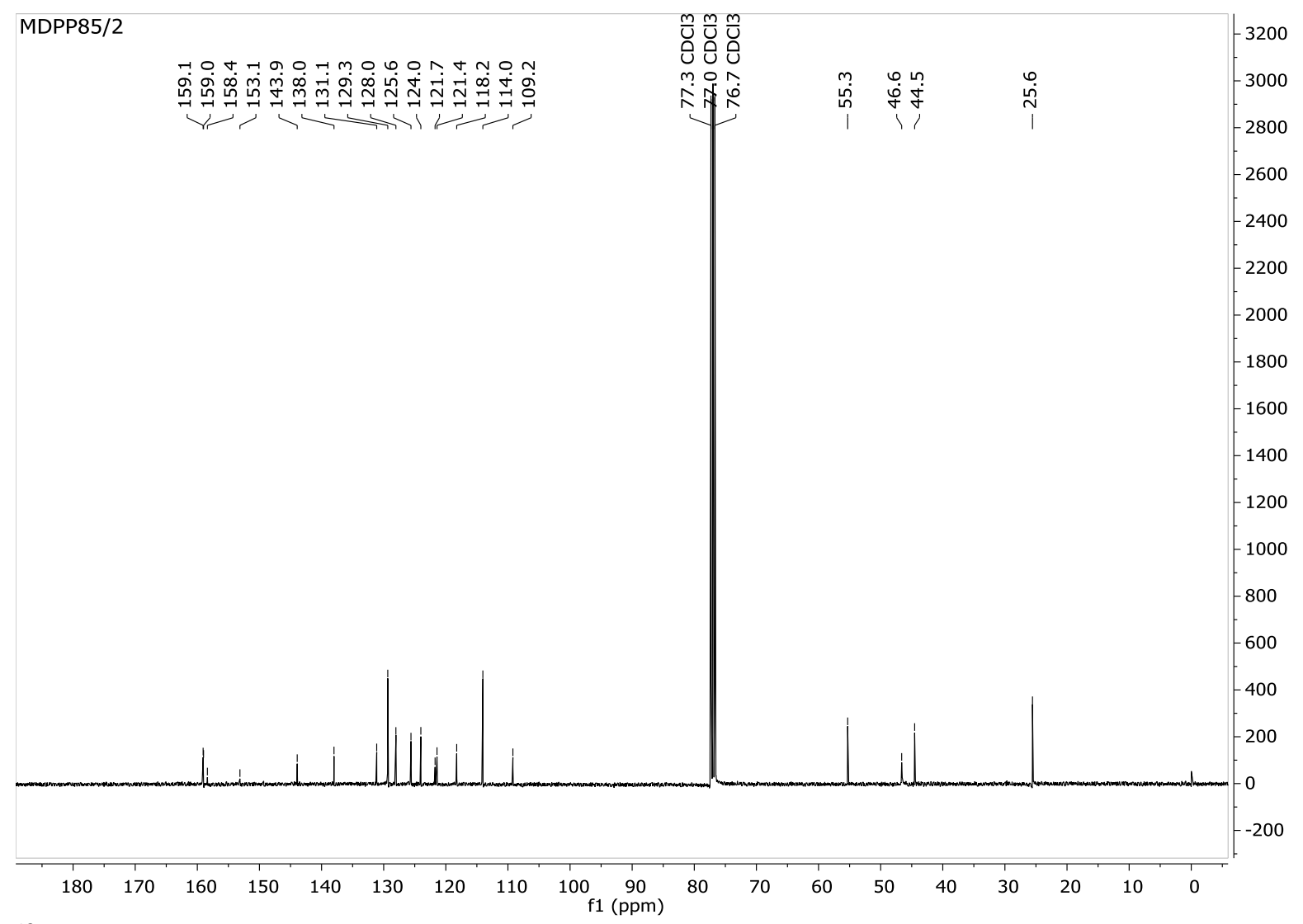

${ }^{13} \mathrm{C}-\mathrm{NMR}$ spectrum of compound $\mathbf{7 j}$ 


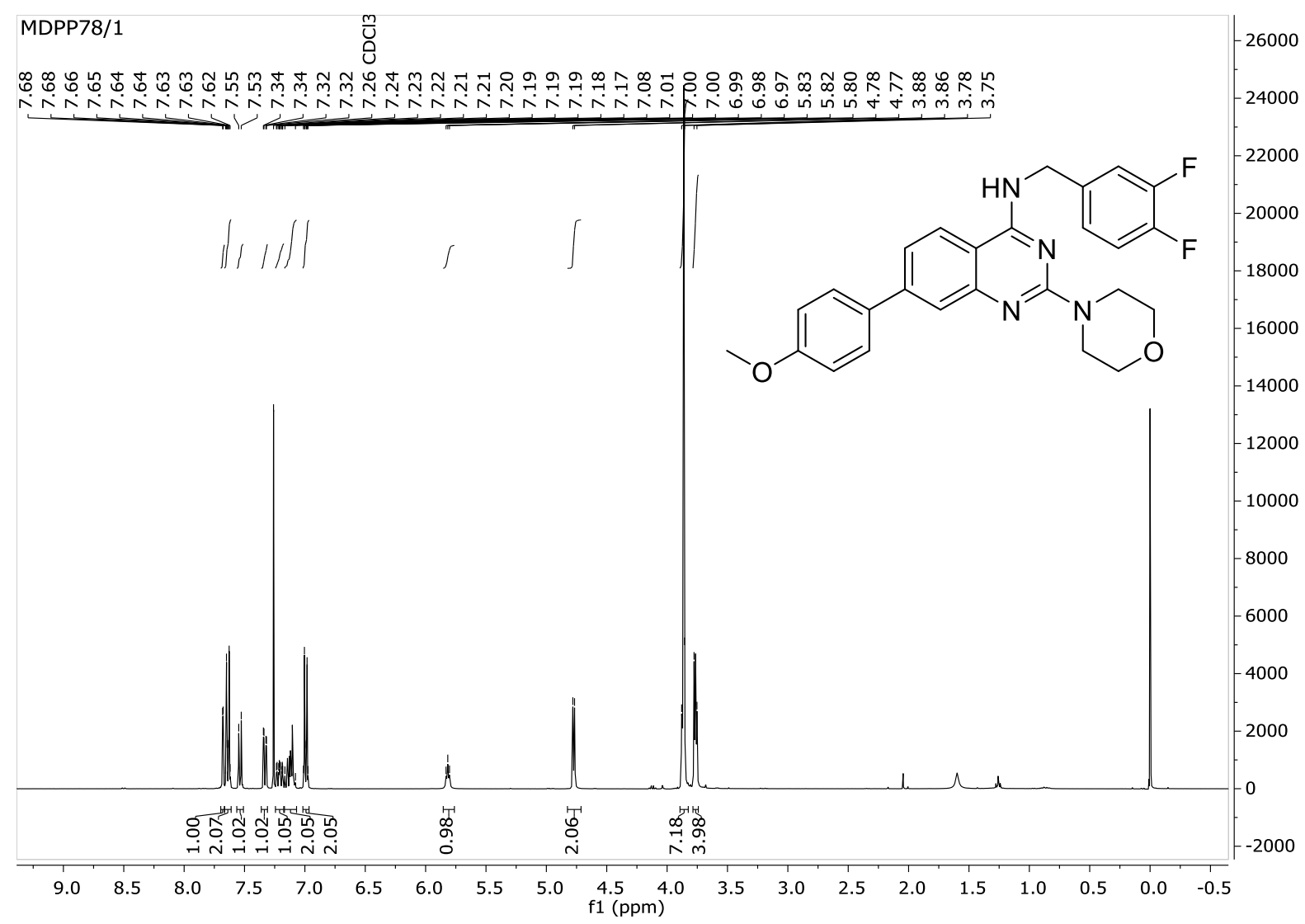

${ }^{1} \mathrm{H}-\mathrm{NMR}$ spectrum of compound $\mathbf{7 k}$

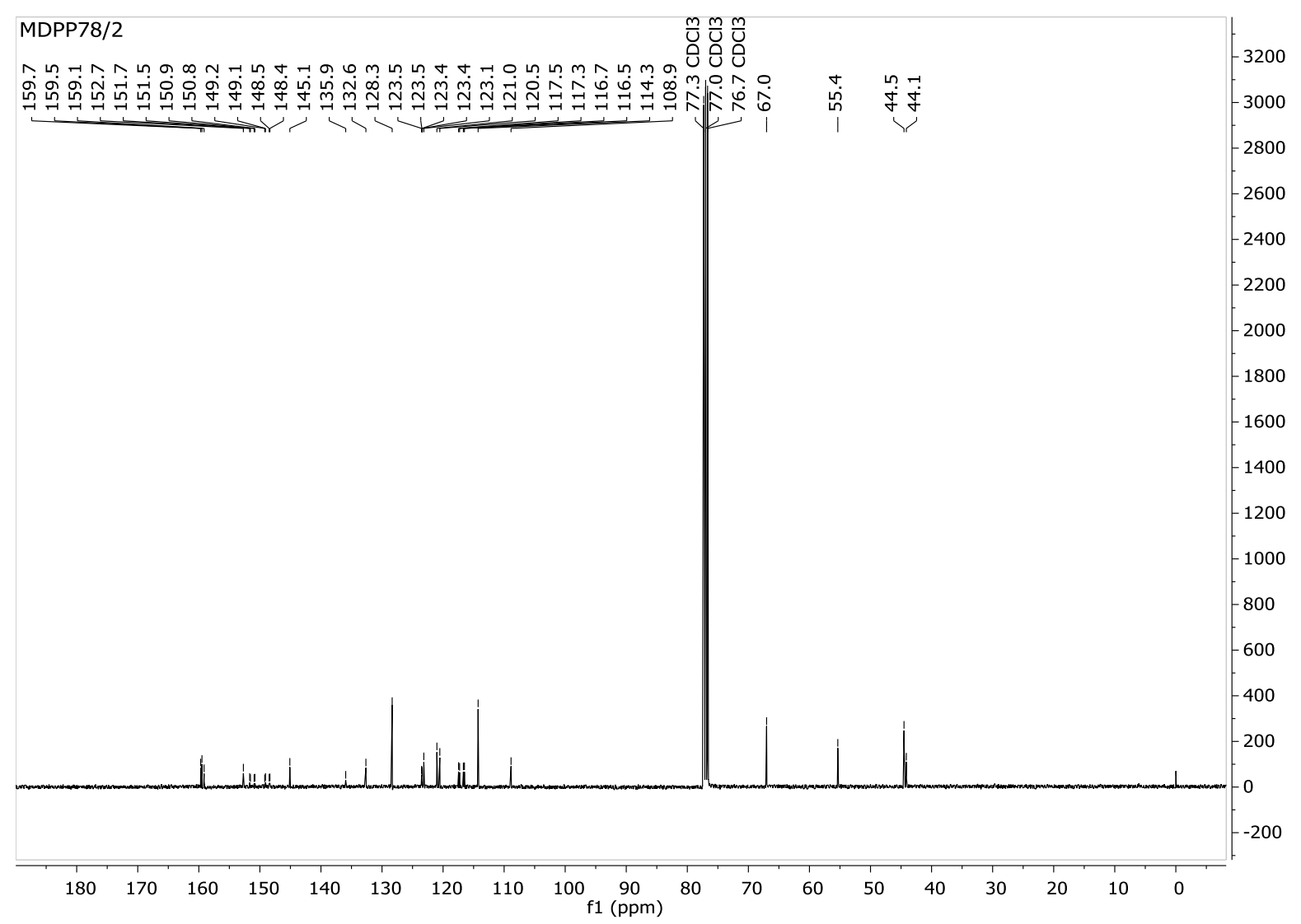

${ }^{13} \mathrm{C}-\mathrm{NMR}$ spectrum of compound $\mathbf{7 k}$ 


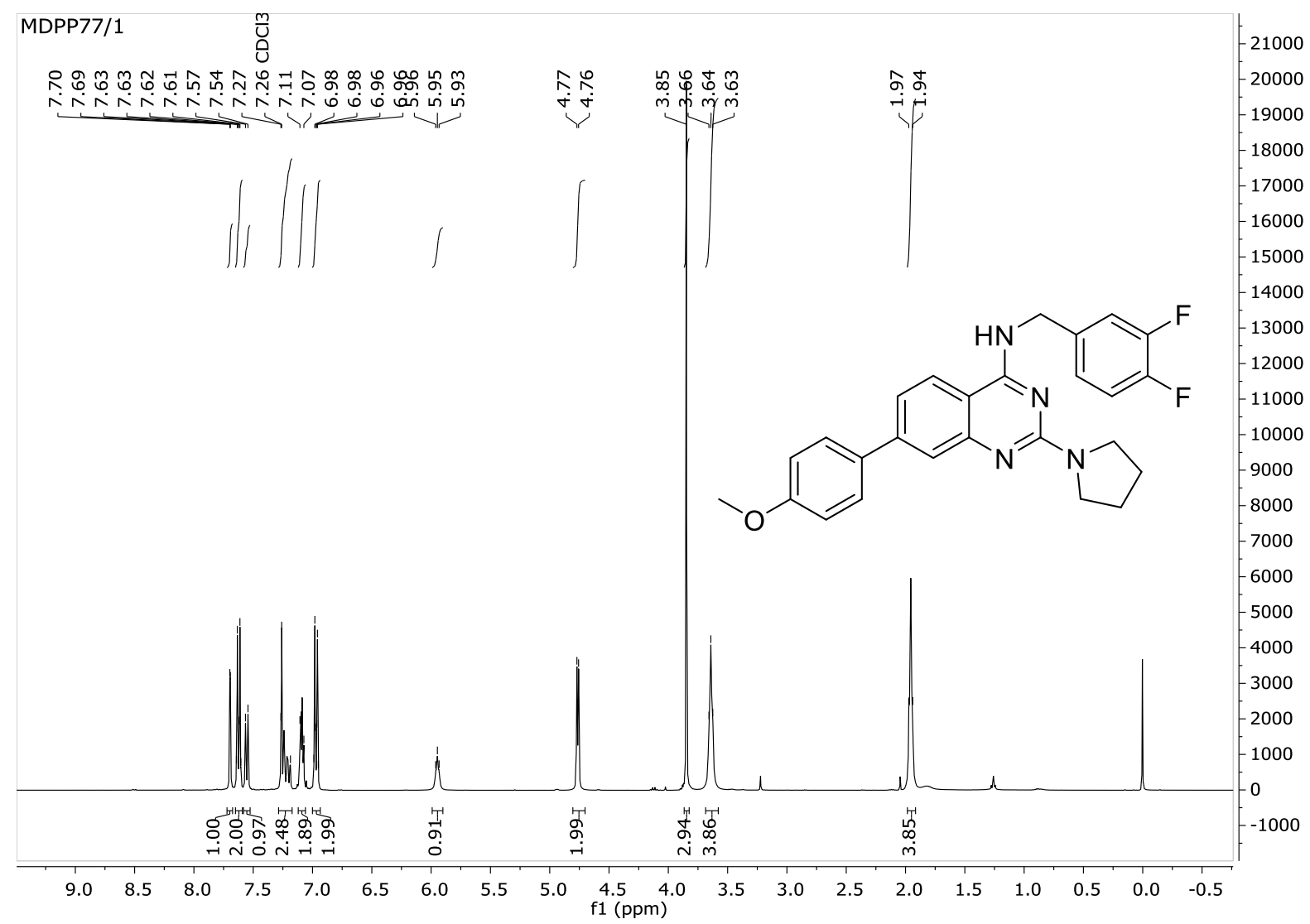

${ }^{1} \mathrm{H}-\mathrm{NMR}$ spectrum of compound $7 \mathrm{I}$

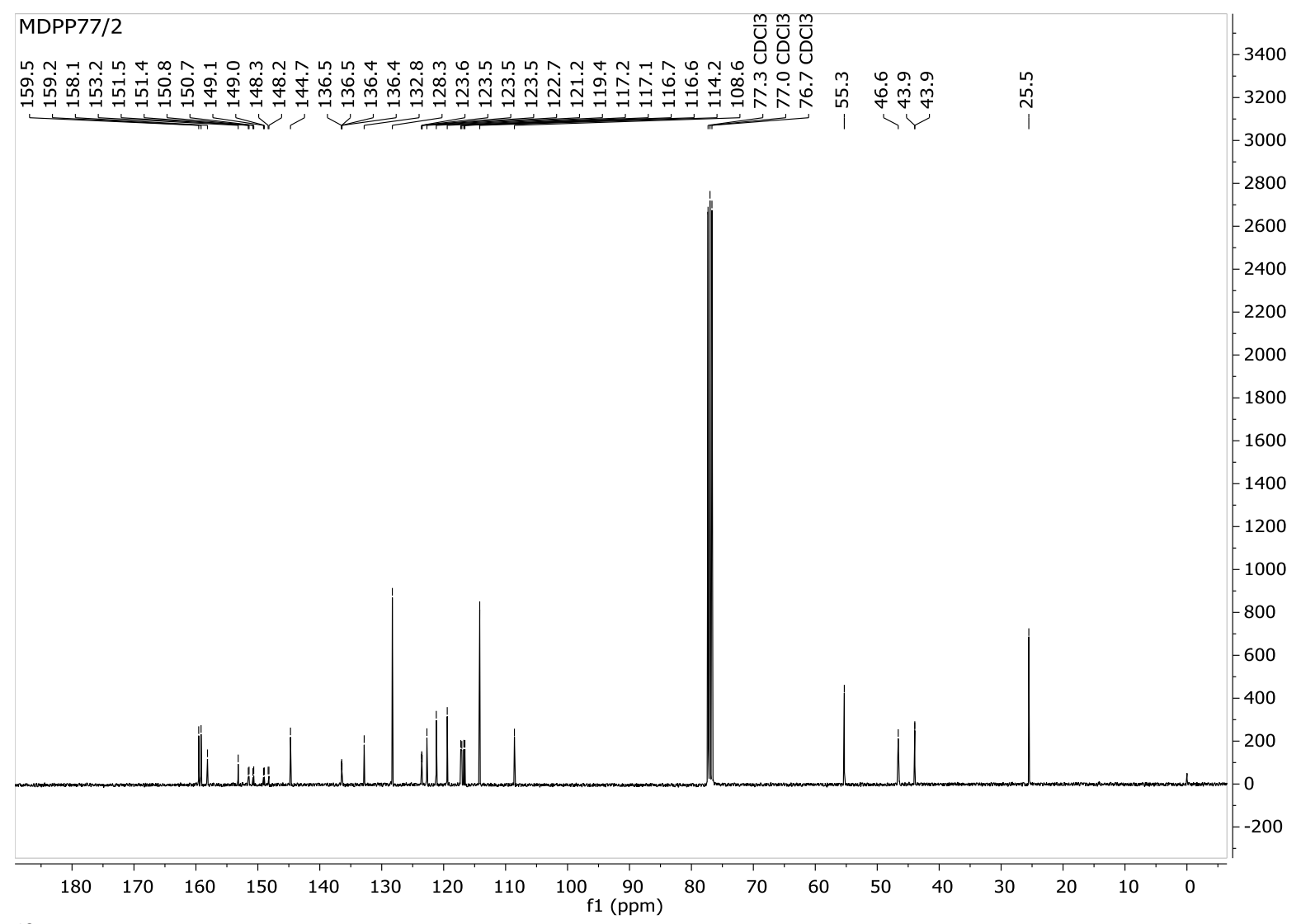

${ }^{13} \mathrm{C}$-NMR spectrum of compound $7 \mathrm{I}$ 


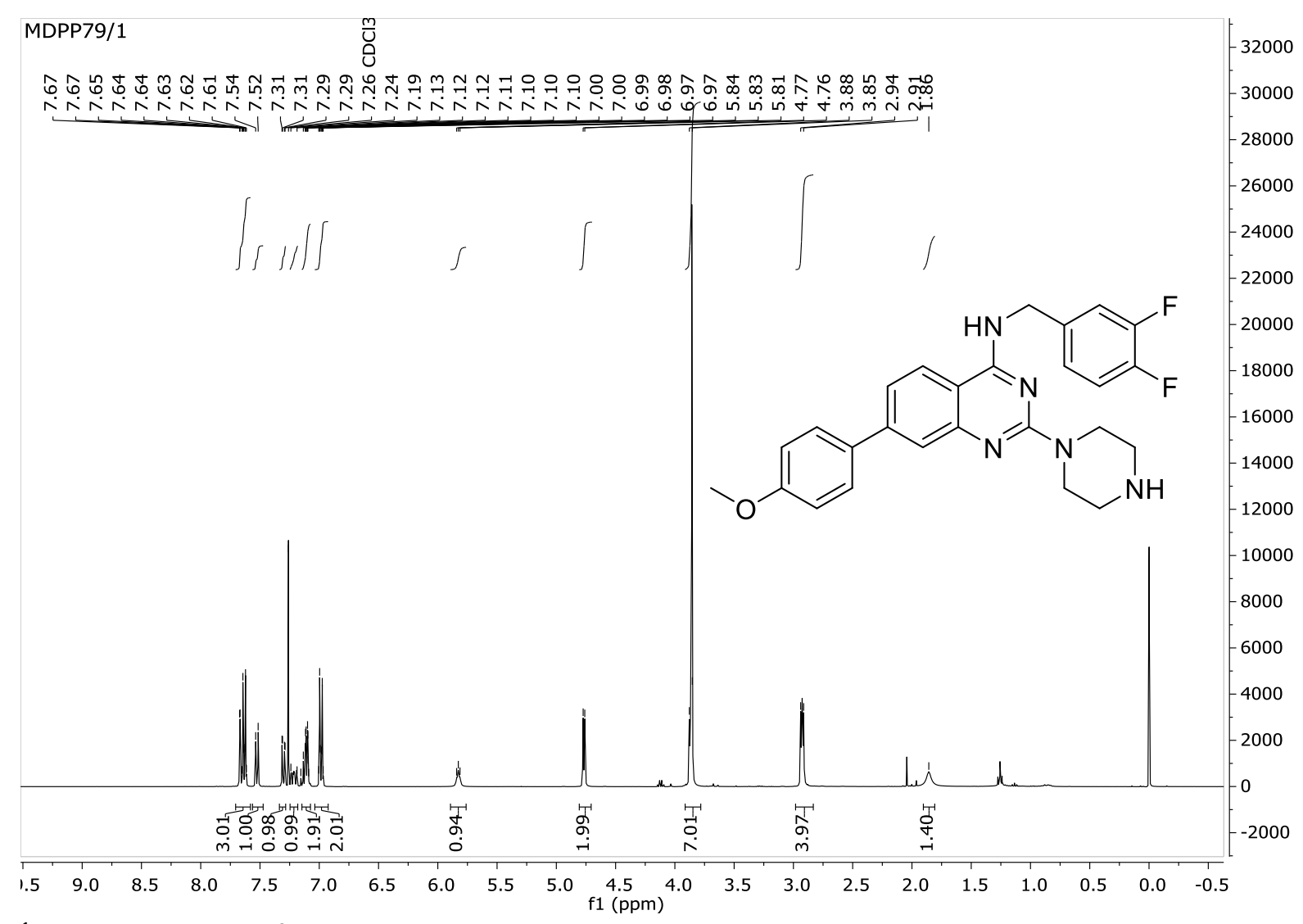

${ }^{1} \mathrm{H}-\mathrm{NMR}$ spectrum of compound $7 \mathrm{~m}$

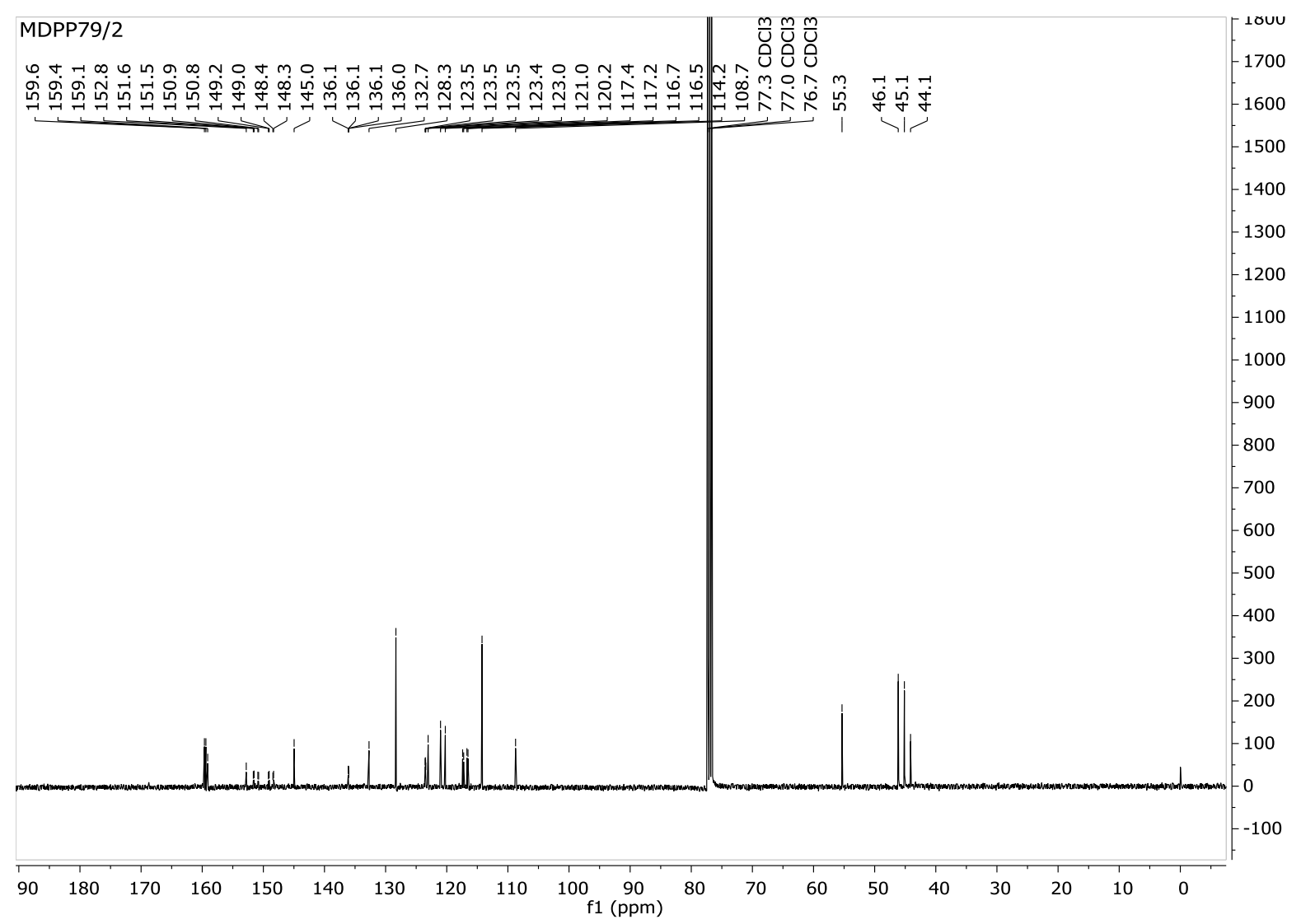

${ }^{13} \mathrm{C}$-NMR spectrum of compound $7 \mathrm{~m}$ 


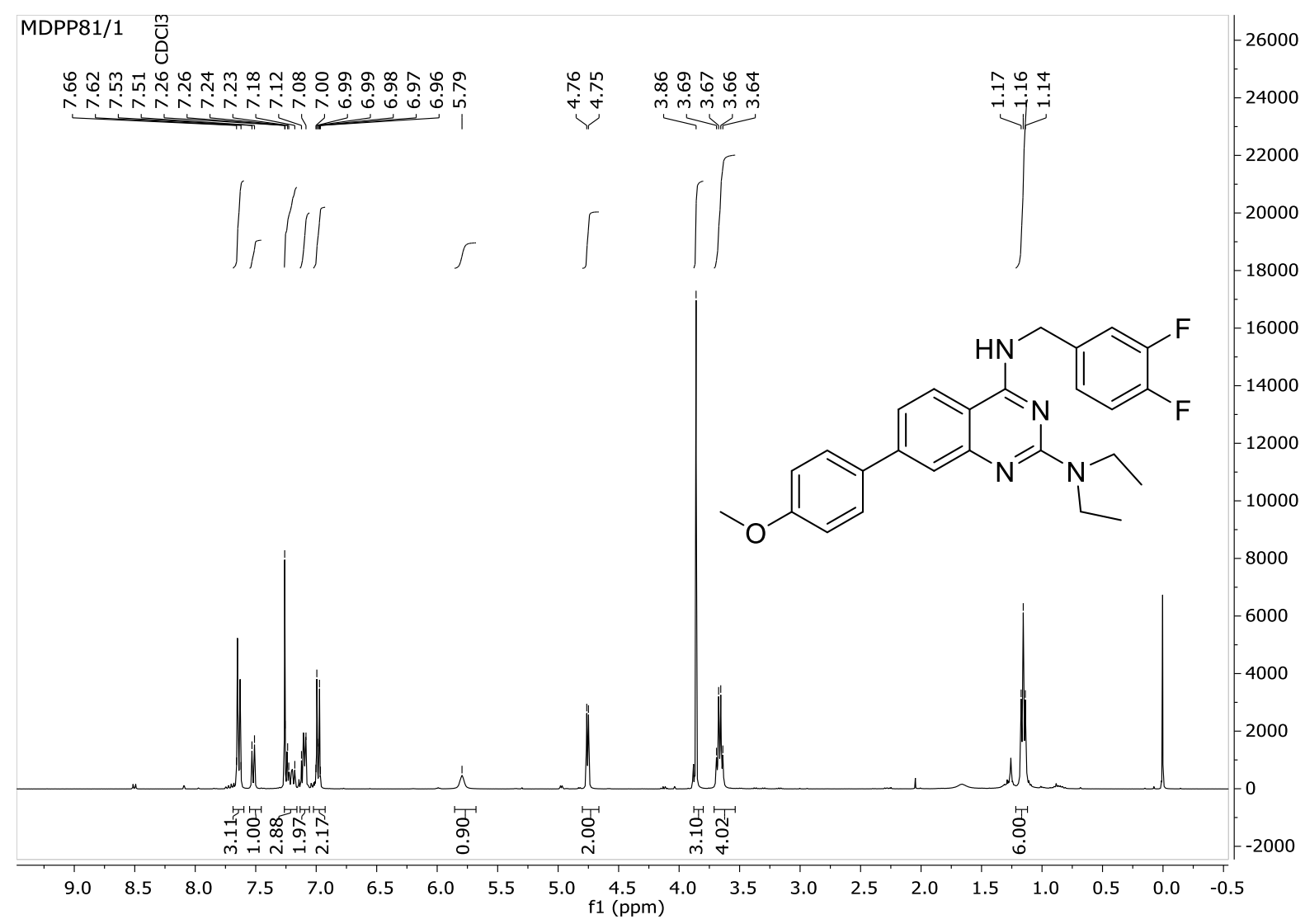

${ }^{1} \mathrm{H}-\mathrm{NMR}$ spectrum of compound $\mathbf{7 n}$

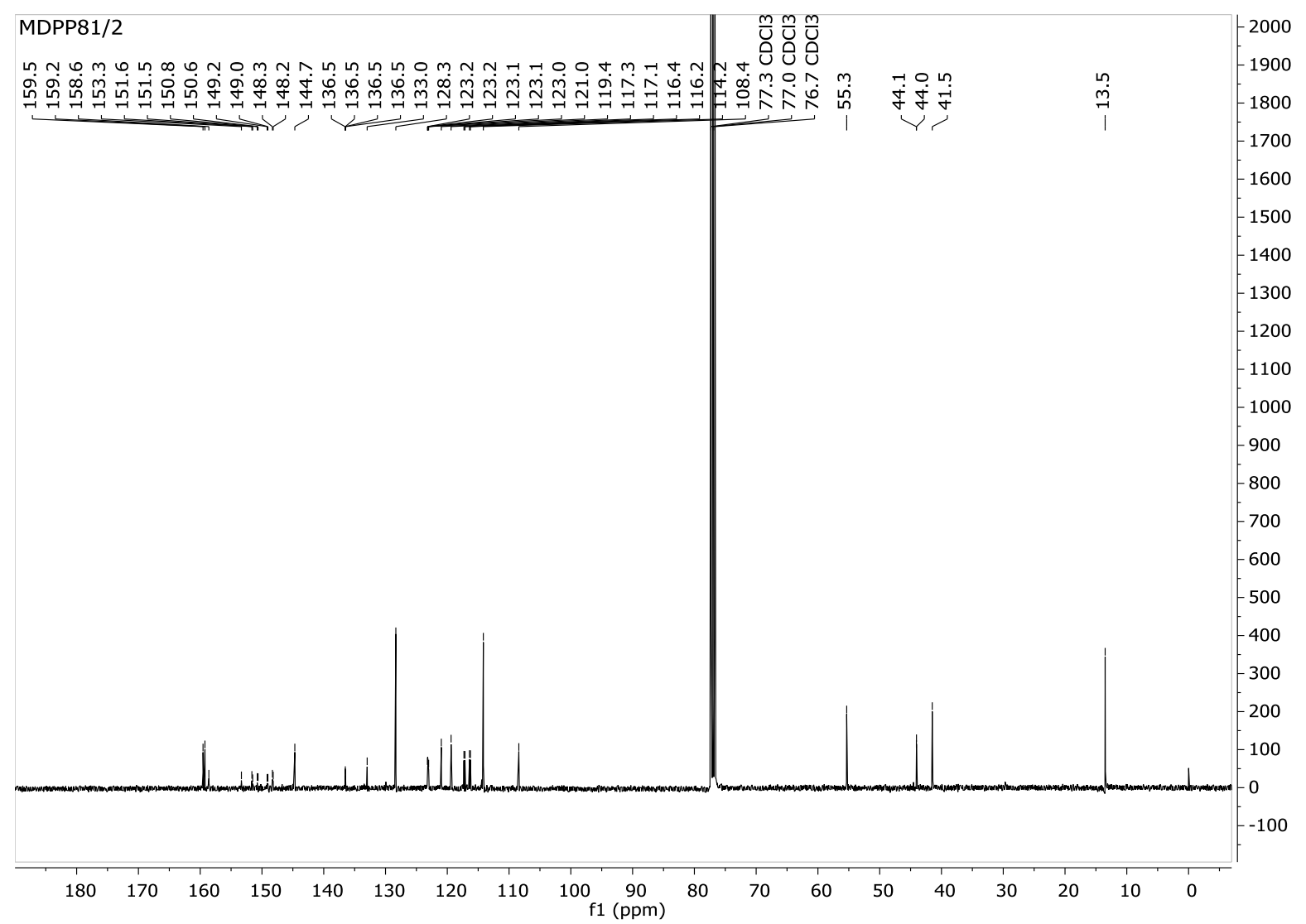

${ }^{13} \mathrm{C}$-NMR spectrum of compound $7 \mathrm{n}$ 


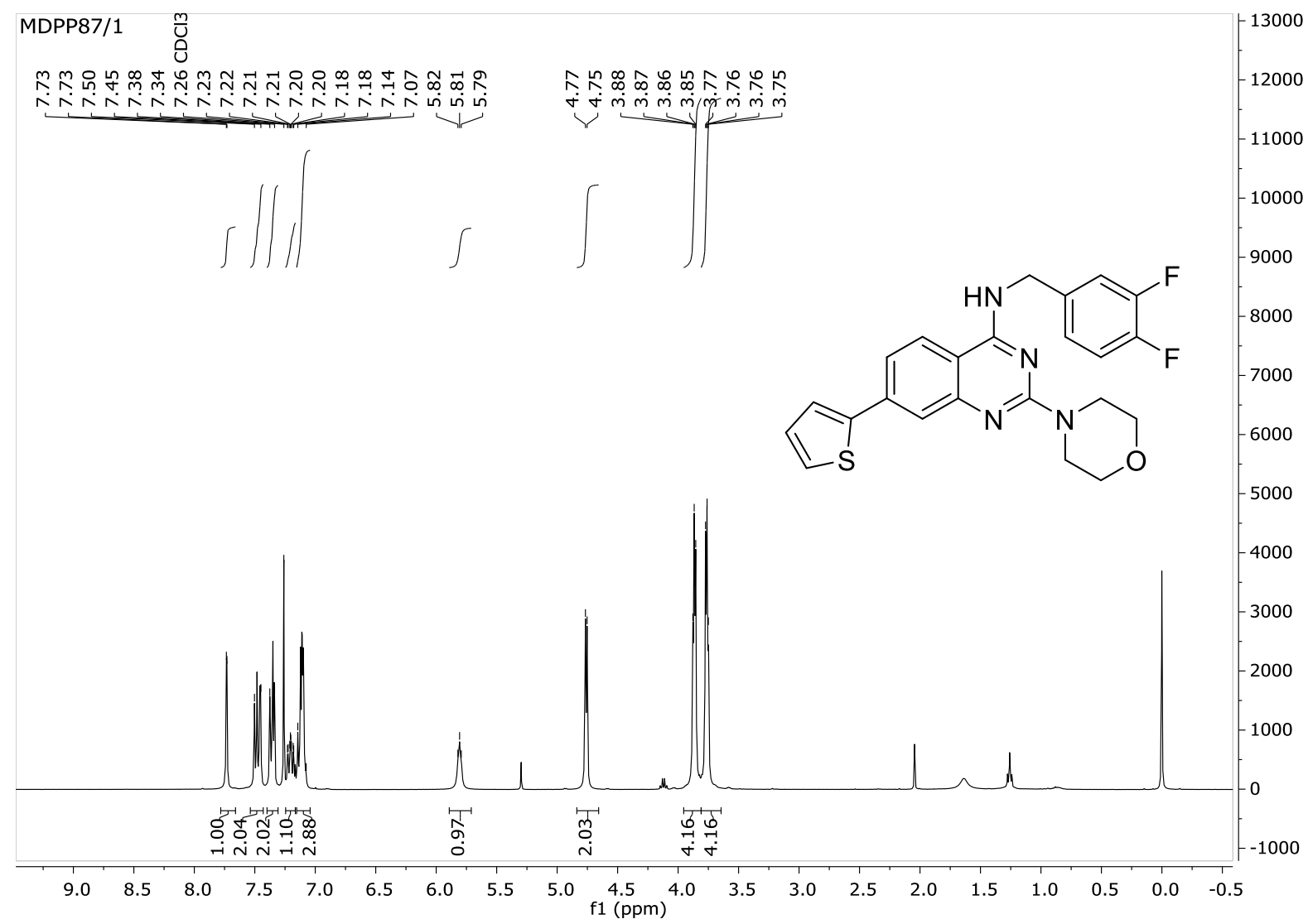

${ }^{1} \mathrm{H}-\mathrm{NMR}$ spectrum of compound $7 \mathrm{o}$

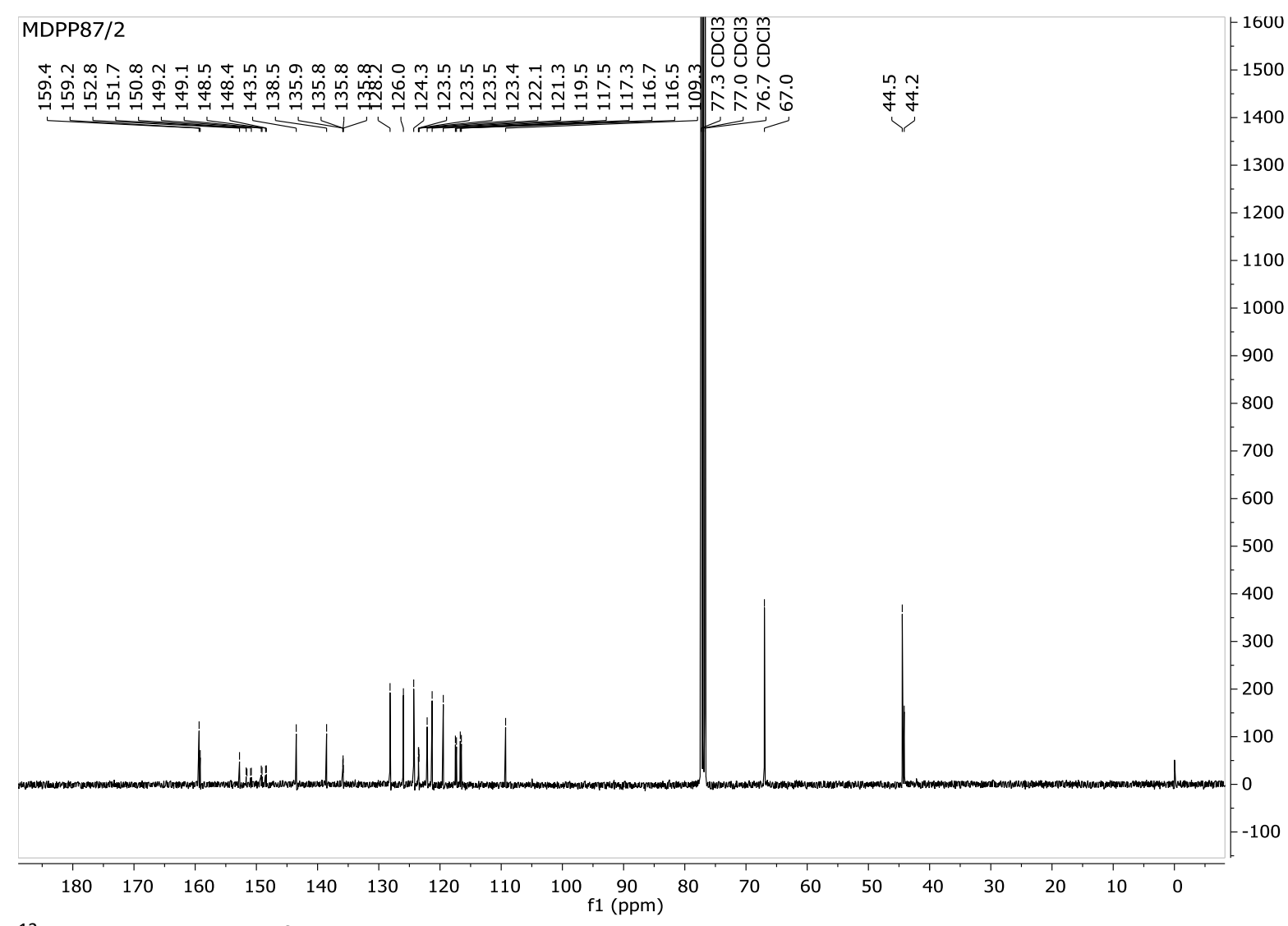

${ }^{13} \mathrm{C}-\mathrm{NMR}$ spectrum of compound $7 \mathrm{o}$ 


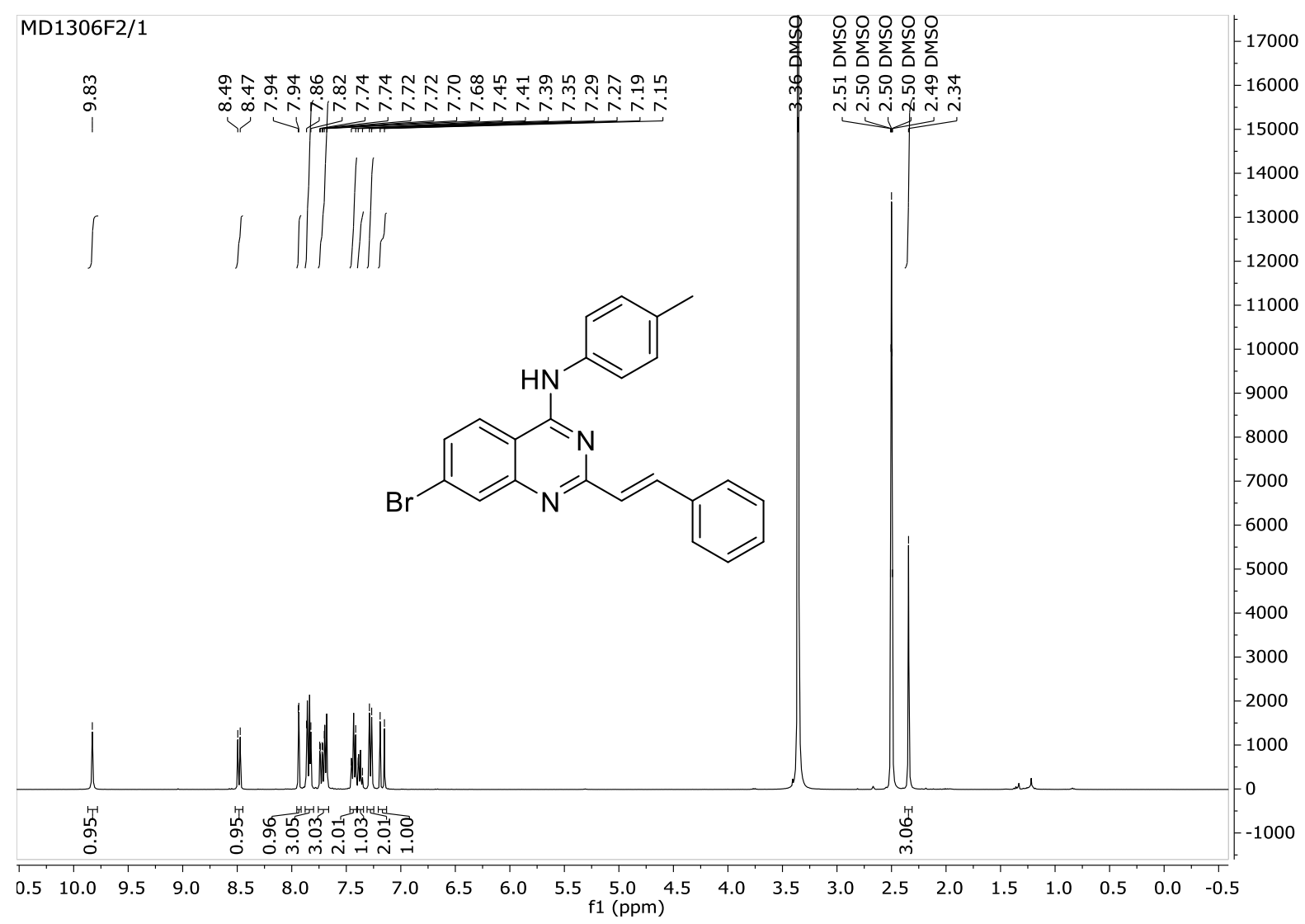

${ }^{1} \mathrm{H}-\mathrm{NMR}$ spectrum of compound $8 \mathrm{a}$

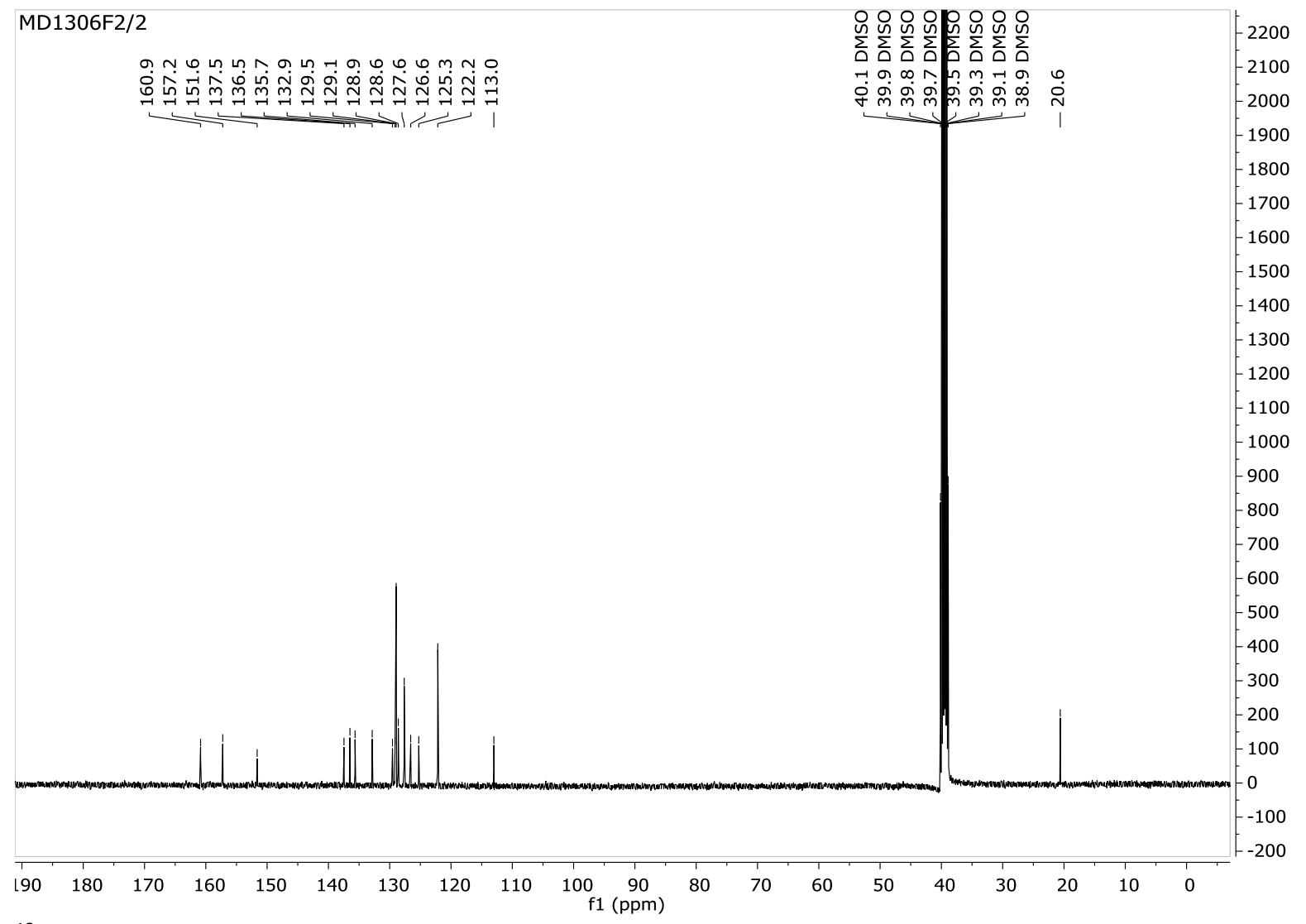

${ }^{13} \mathrm{C}-\mathrm{NMR}$ spectrum of compound $\mathbf{8 a}$ 


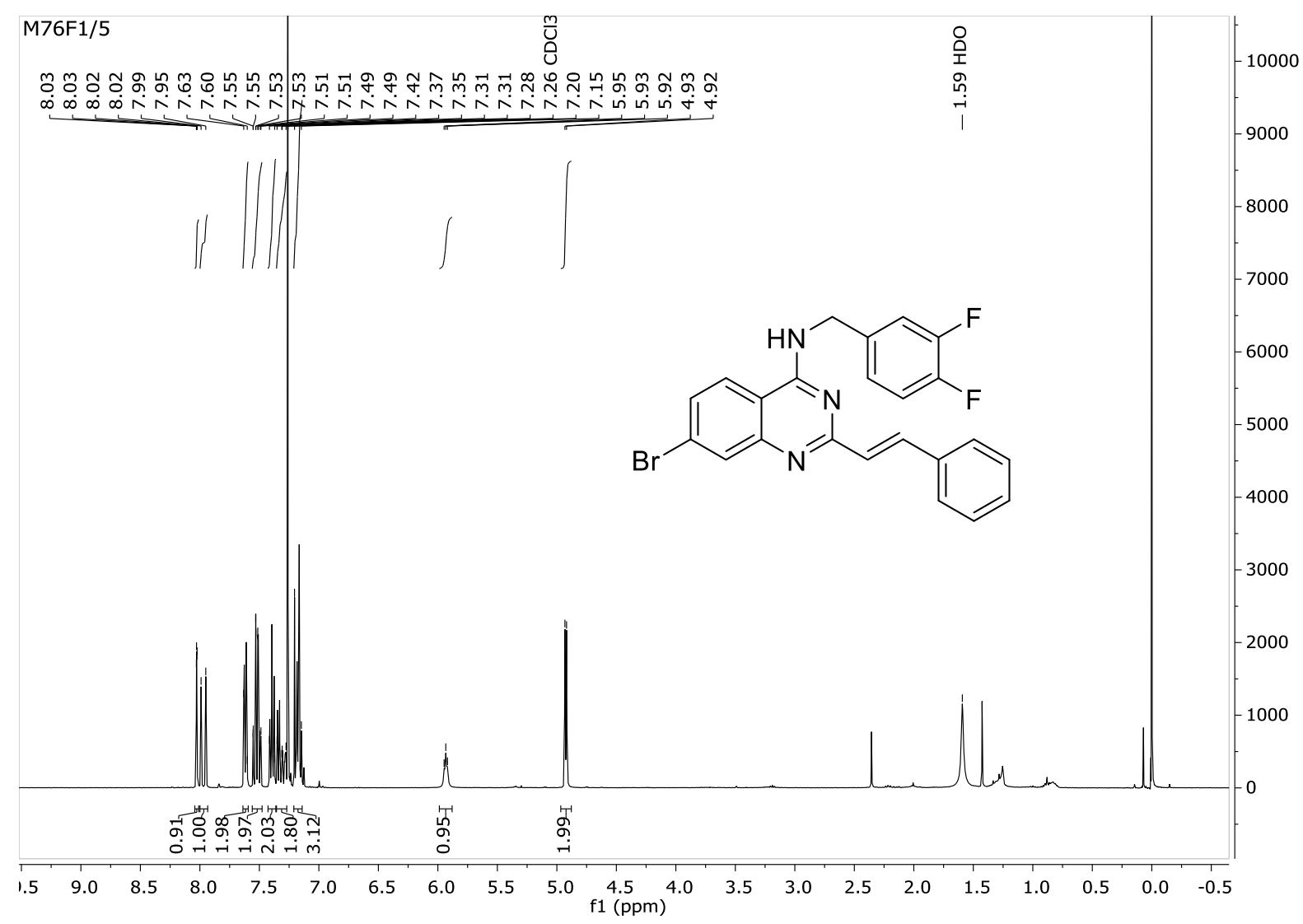

${ }^{1} \mathrm{H}-\mathrm{NMR}$ spectrum of compound $8 \mathrm{~b}$

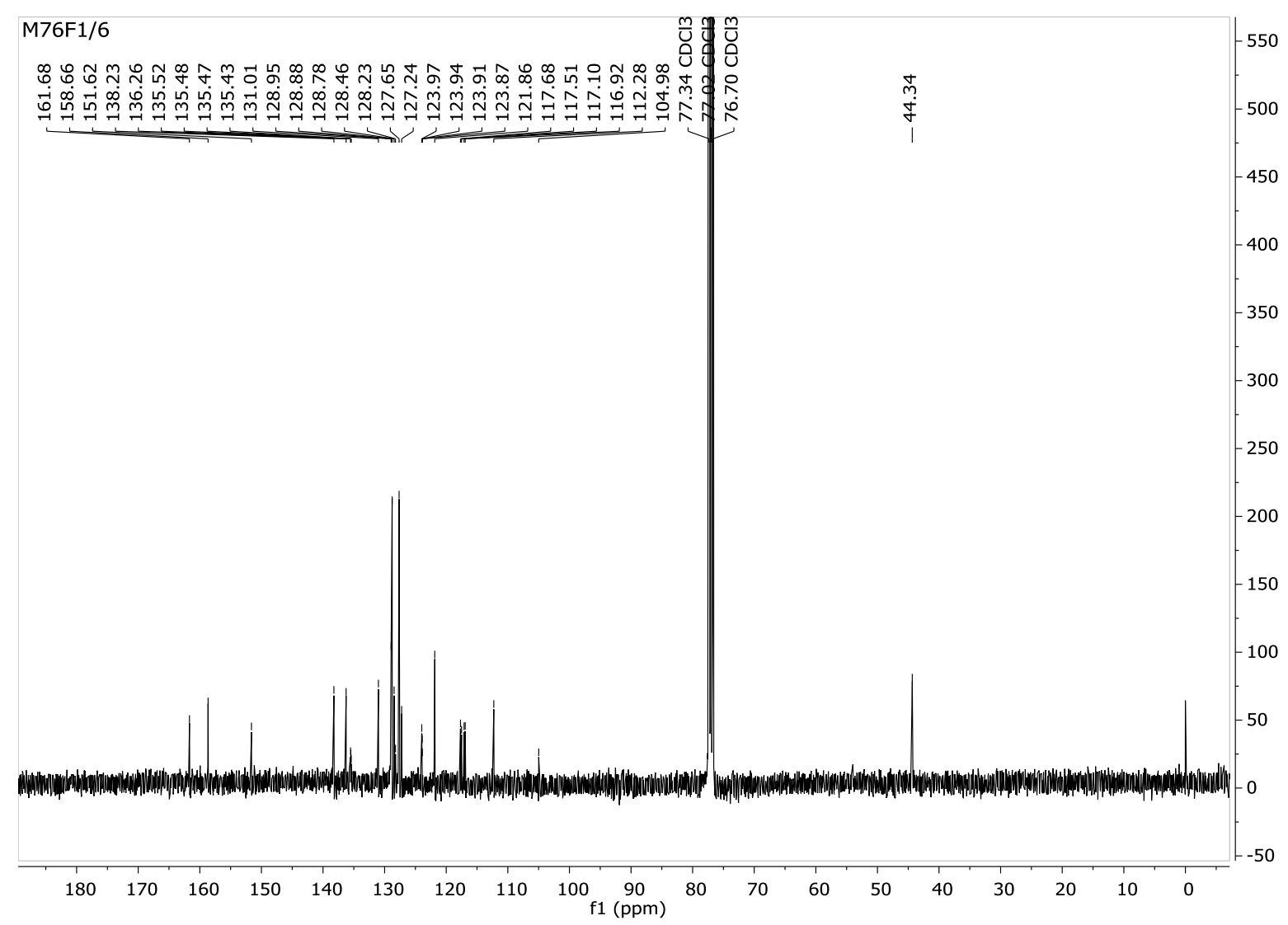

${ }^{13} \mathrm{C}-\mathrm{NMR}$ spectrum of compound $\mathbf{8 b}$ 


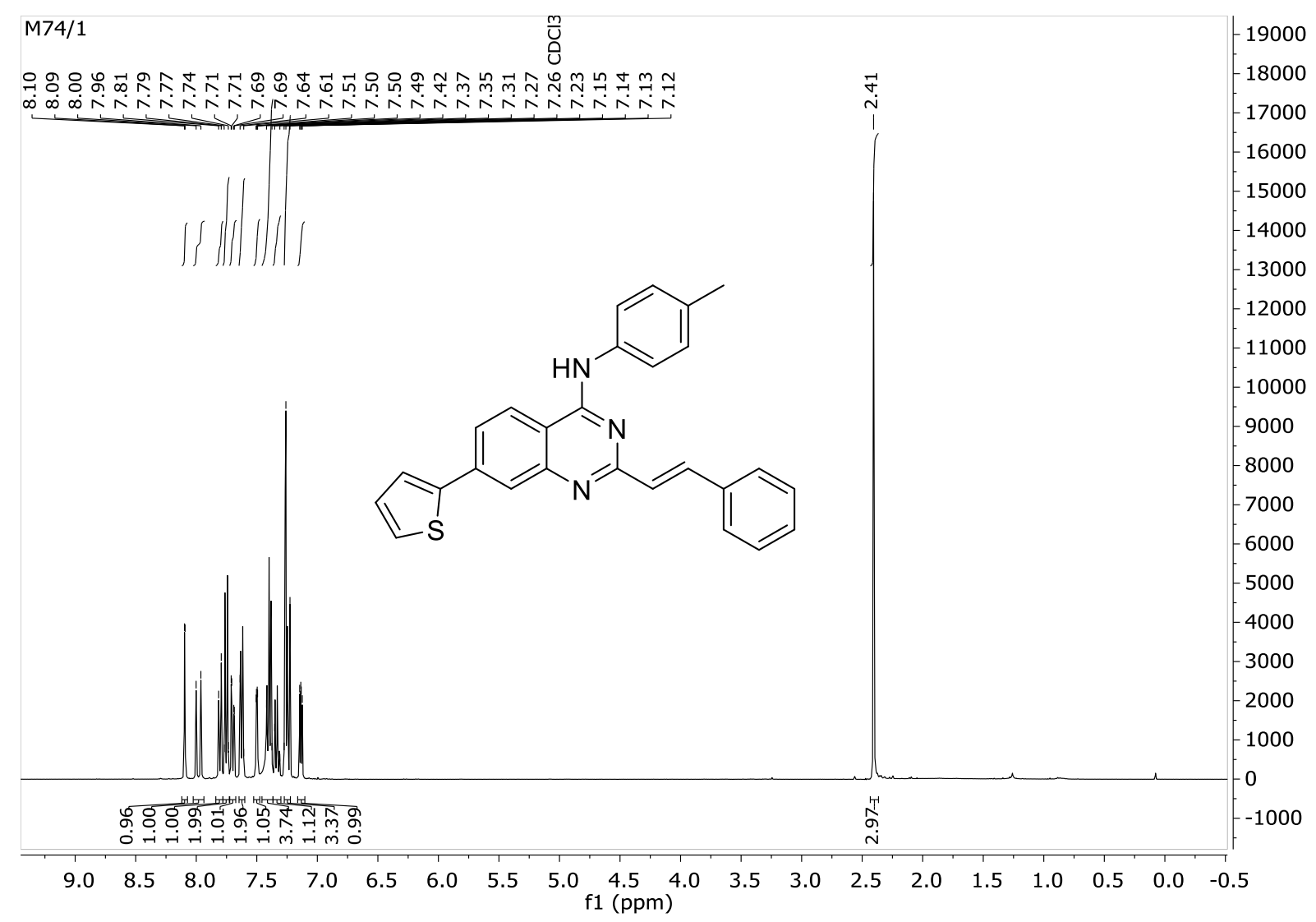

${ }^{1} \mathrm{H}-\mathrm{NMR}$ spectrum of compound $9 \mathrm{a}$

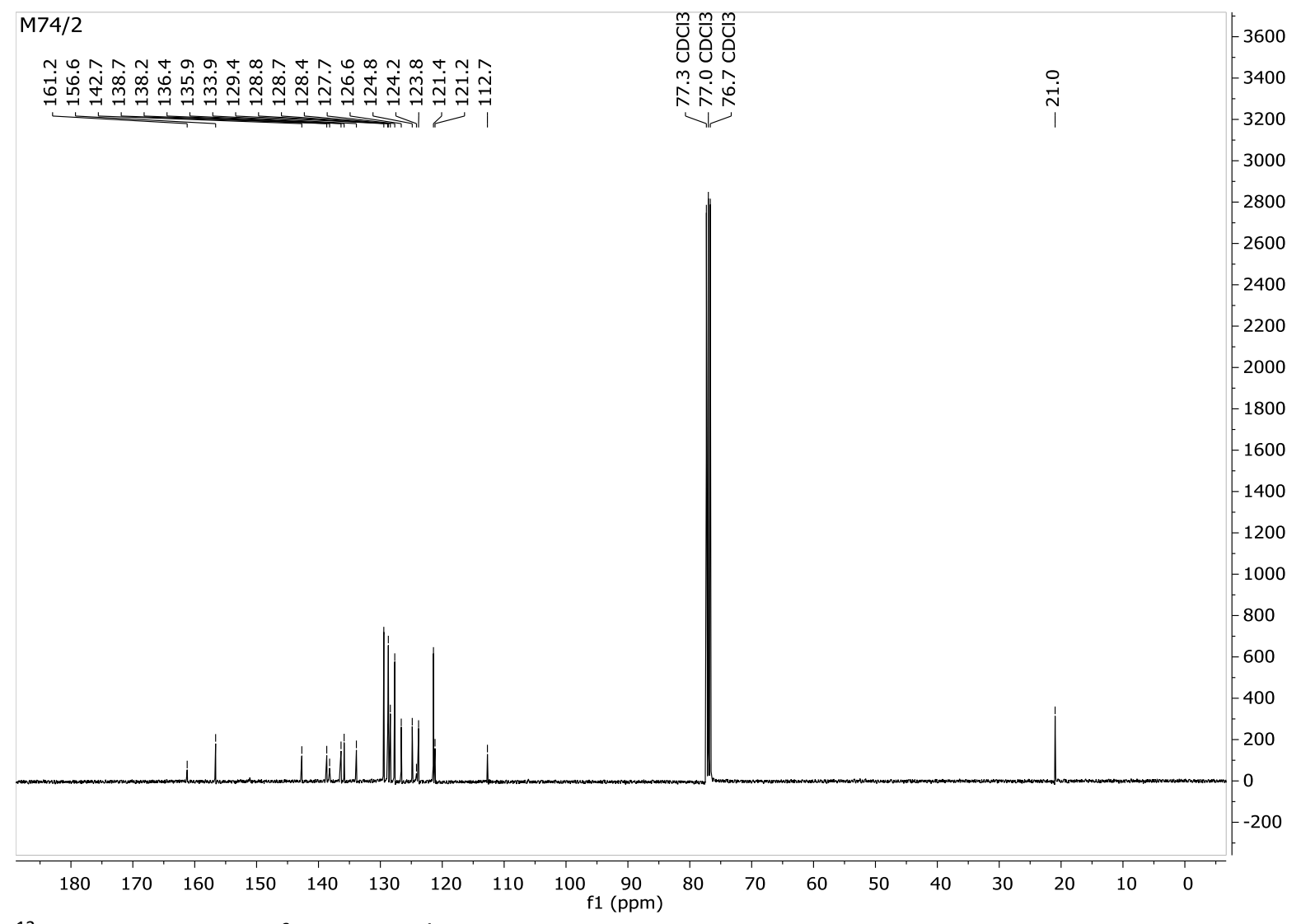

${ }^{13} \mathrm{C}-\mathrm{NMR}$ spectrum of compound $9 \mathrm{a}$ 


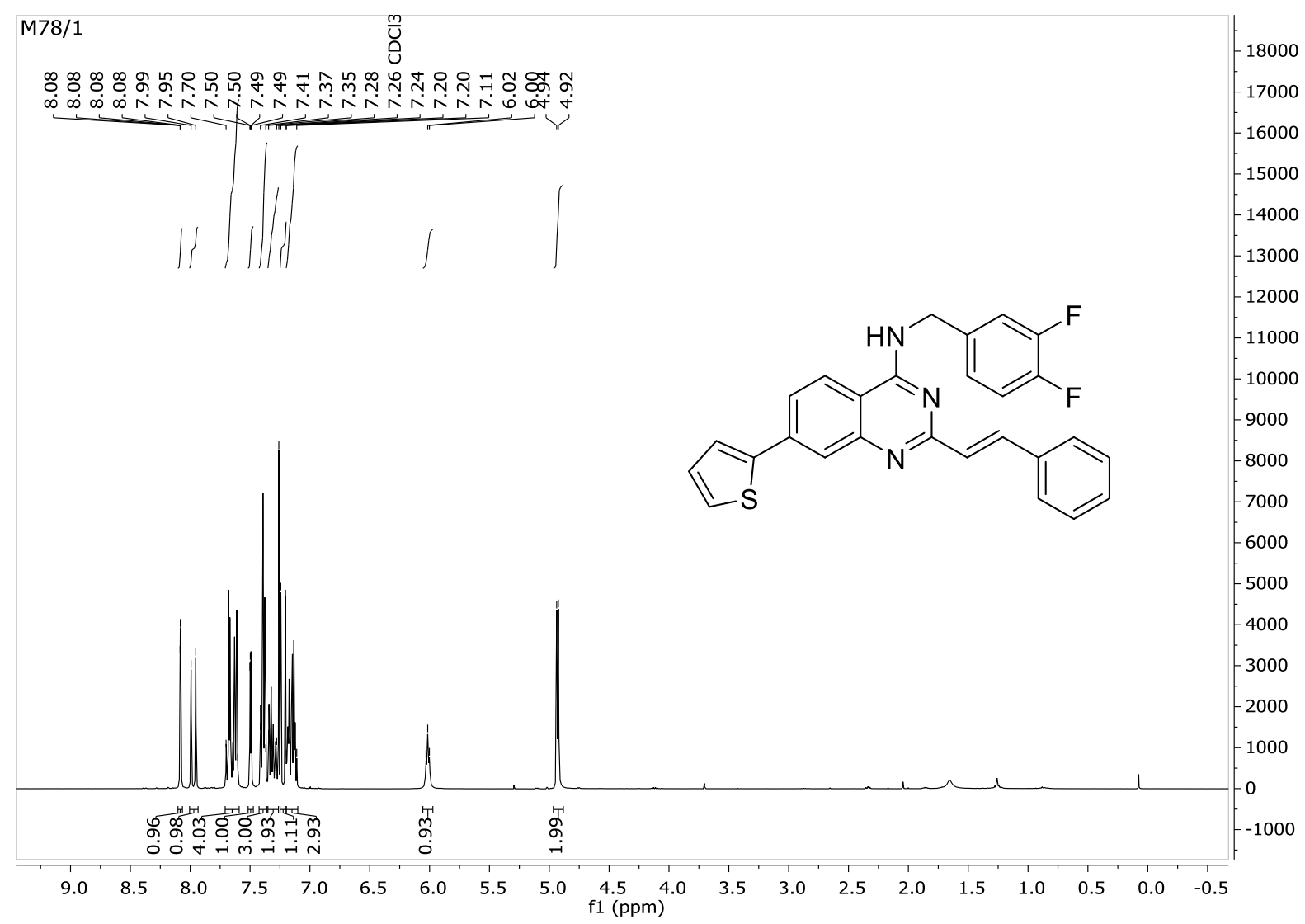

${ }^{1} \mathrm{H}-\mathrm{NMR}$ spectrum of compound $9 \mathrm{~b}$

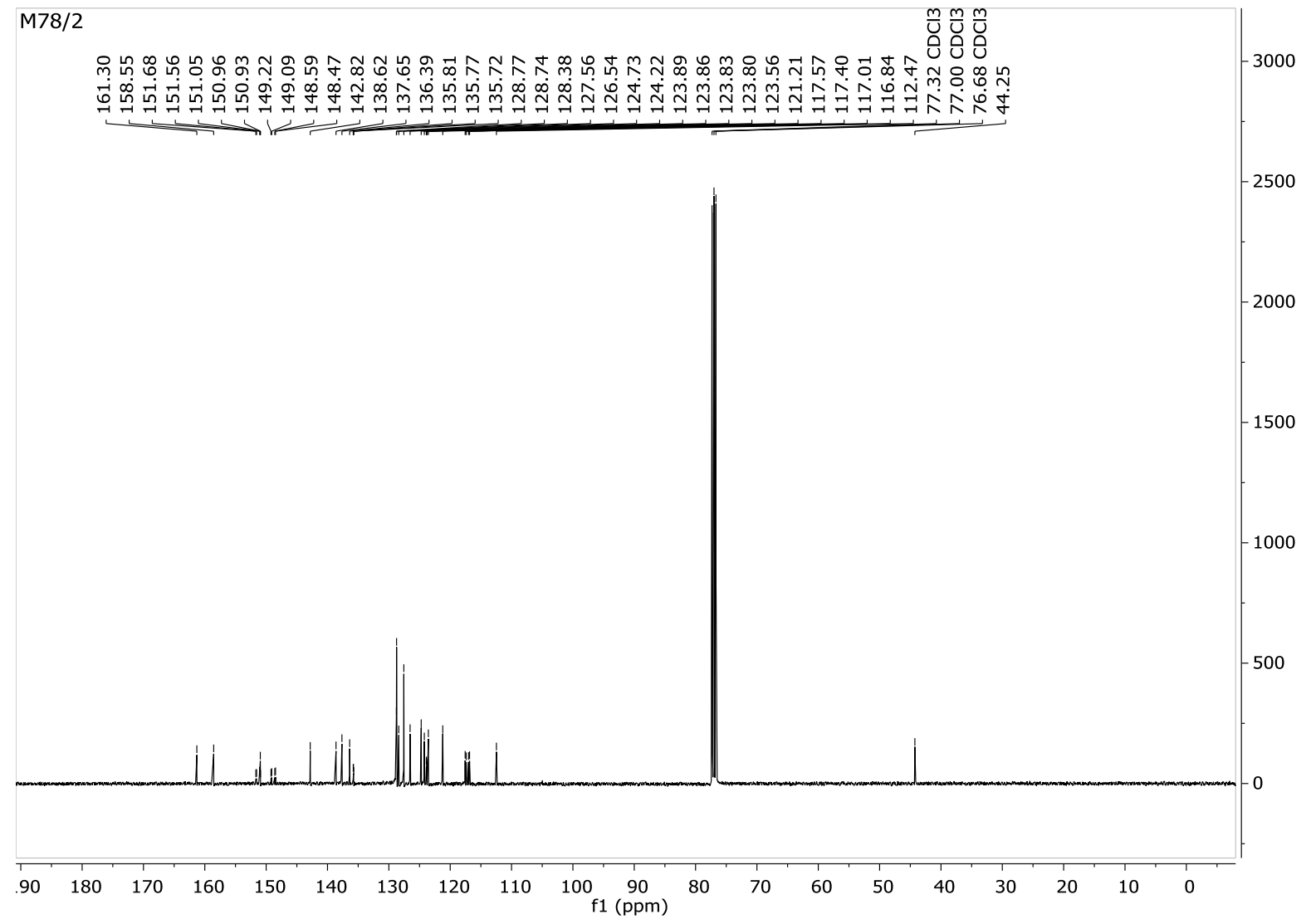

${ }^{13} \mathrm{C}-\mathrm{NMR}$ spectrum of compound $9 \mathrm{~b}$ 
Table 1S. Percentual inhibition of COX-1 and COX-2 isoenzymes, respectively, by tested compounds at $20 \mu \mathrm{M}$.

\begin{tabular}{|c|c|c|c|c|c|c|c|c|}
\hline \multirow{2}{*}{ Compound } & \multicolumn{2}{|c|}{ Inhibition \% } & \multirow{2}{*}{ Compound } & \multicolumn{2}{|c|}{ Inhibition \% } & \multirow{2}{*}{ Compound } & \multicolumn{2}{|c|}{ Inhibition \% } \\
\hline & cox-1 & cox-2 & & COX-1 & cox-2 & & cox-1 & cox-2 \\
\hline $3 a$ & 50.49 & -38.70 & $5 a$ & 48.80 & 22.69 & $8 a$ & 82.21 & 27.49 \\
\hline $3 b$ & 95.16 & 3.54 & $5 b$ & 30.38 & 30.65 & $8 b$ & 84.65 & 21.54 \\
\hline $3 c$ & 95.29 & 2.64 & & & & & & \\
\hline $3 d$ & 31.24 & -4.94 & $6 a$ & 34.09 & 7.04 & $9 a$ & 97.22 & 16.59 \\
\hline $3 e$ & 6.76 & -16.33 & $6 b$ & 26.57 & 27.64 & $9 b$ & 96.97 & 38.96 \\
\hline $3 f$ & 27.63 & -14.53 & $6 c$ & 92.40 & 32.29 & & & \\
\hline $3 g$ & 13.74 & -24.45 & $6 d$ & 31.62 & 26.49 & & & \\
\hline $3 h$ & 31.52 & 3.02 & $6 e$ & 96.48 & 39.92 & & & \\
\hline $3 \mathbf{i}$ & 17.70 & -11.07 & & & & & & \\
\hline $3 \mathbf{j}$ & 41.61 & 13.80 & $7 a$ & -3.35 & 0.80 & & & \\
\hline $3 k$ & 96.76 & 71.78 & $7 b$ & 6.91 & 19.38 & & & \\
\hline 31 & 46.16 & 14.95 & 7c & -16.49 & 24.18 & & & \\
\hline $3 m$ & 14.00 & 9.92 & $7 d$ & -10.92 & -1.39 & & & \\
\hline $3 n$ & 12.77 & 5.59 & $7 e$ & -5.92 & -7.39 & & & \\
\hline 30 & 7.33 & -4.79 & $7 f$ & 32.14 & 3.22 & & & \\
\hline $3 p$ & 37.96 & -22.92 & $7 g$ & -13.89 & -10.07 & & & \\
\hline $3 q$ & 24.91 & 12.61 & $7 \mathrm{~h}$ & -1.12 & 4.43 & & & \\
\hline $3 r$ & 30.65 & -1.77 & $7 i$ & 14.85 & -5.36 & & & \\
\hline $3 s$ & 23.09 & -14.13 & $7 \mathbf{j}$ & -38.13 & -2.17 & & & \\
\hline $3 t$ & 20.84 & 10.81 & $7 k$ & 6.66 & 7.98 & & & \\
\hline $3 u$ & 16.79 & 16.40 & 71 & -23.64 & 8.82 & & & \\
\hline \multirow[t]{3}{*}{$3 v$} & 94.26 & 3.50 & $7 m$ & -6.25 & 11.65 & & & \\
\hline & & & $7 n$ & 17.97 & 14.63 & & & \\
\hline & & & 70 & 66.00 & -3.62 & & & \\
\hline
\end{tabular}

Table 2 S. COX-1 inhibition by compound $\mathbf{9 b}$ and Ibuprofen at different substrate (arachidonic acid, AA) concentrations.

\begin{tabular}{cc} 
Compound (conc. AA) & \multicolumn{1}{c}{ IC $_{50}(\mu \mathrm{M})$} \\
\hline $\mathbf{9 b}(250 \mathrm{nM} \mathrm{AA})$ & $0.0211 \pm 0.0051$ \\
$\mathbf{9 b}(1250 \mathrm{nM} A \mathrm{~A})$ & $0.0728 \pm 0.0255$ \\
$\mathbf{9 b}(6250 \mathrm{nM} A \mathrm{~A})$ & $0.2536 \pm 0.0648$ \\
$\mathrm{IBU}(250 \mathrm{nM} \mathrm{AA})$ & $4.00 \pm 1.52$ \\
$\mathrm{IBU}(1250 \mathrm{nM} A \mathrm{~A})$ & $39.9 \pm 11.2$ \\
$\mathrm{IBU}(6250 \mathrm{nM} \mathrm{AA})$ & $70.1 \pm 0.32$ \\
\hline
\end{tabular}


Graph 1S. Percentual inhibition of COX-1 by active compounds at different concentrations depicted as \% inhibition vs. $\log$ (concentration) in $\mu \mathrm{M}$
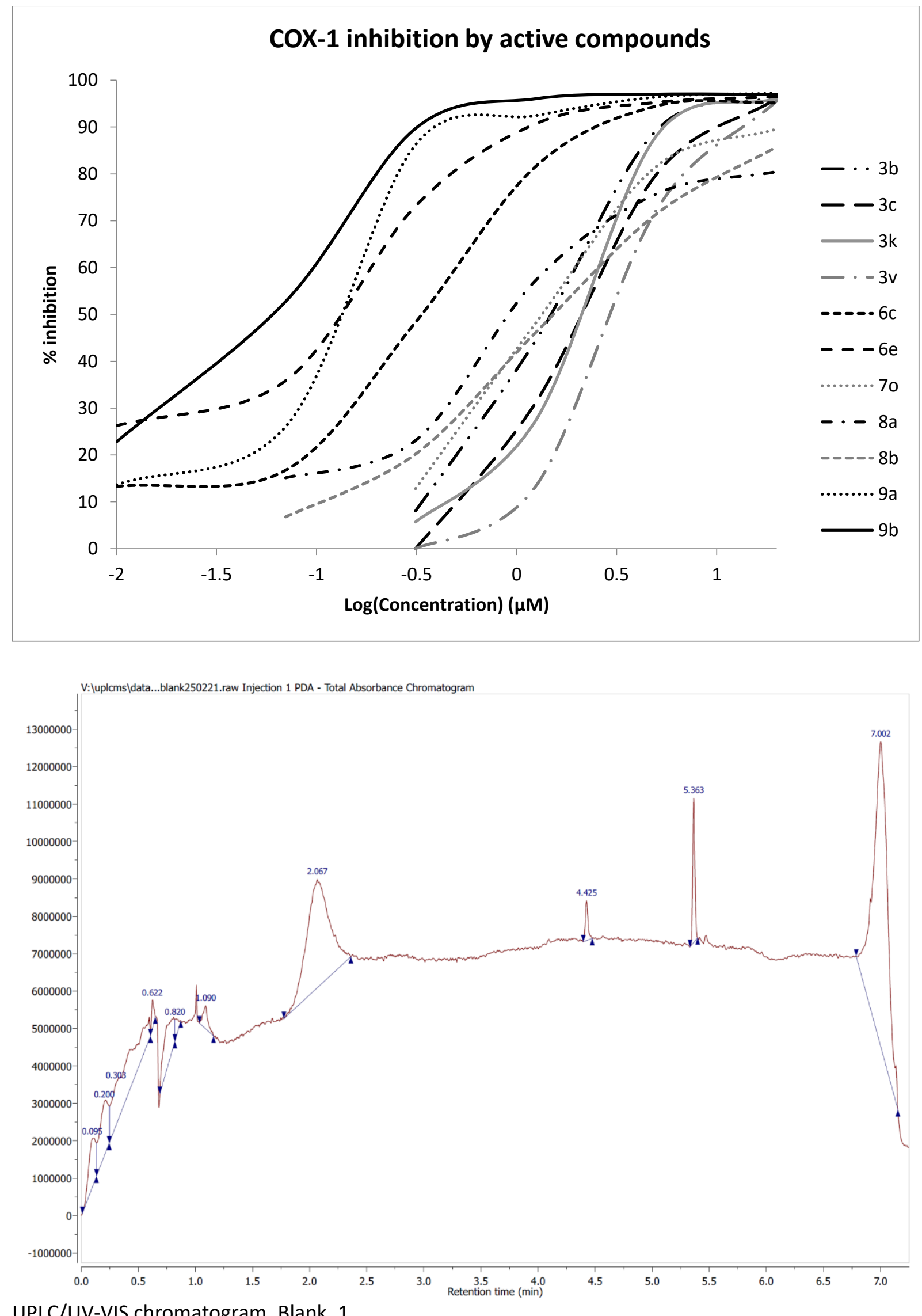


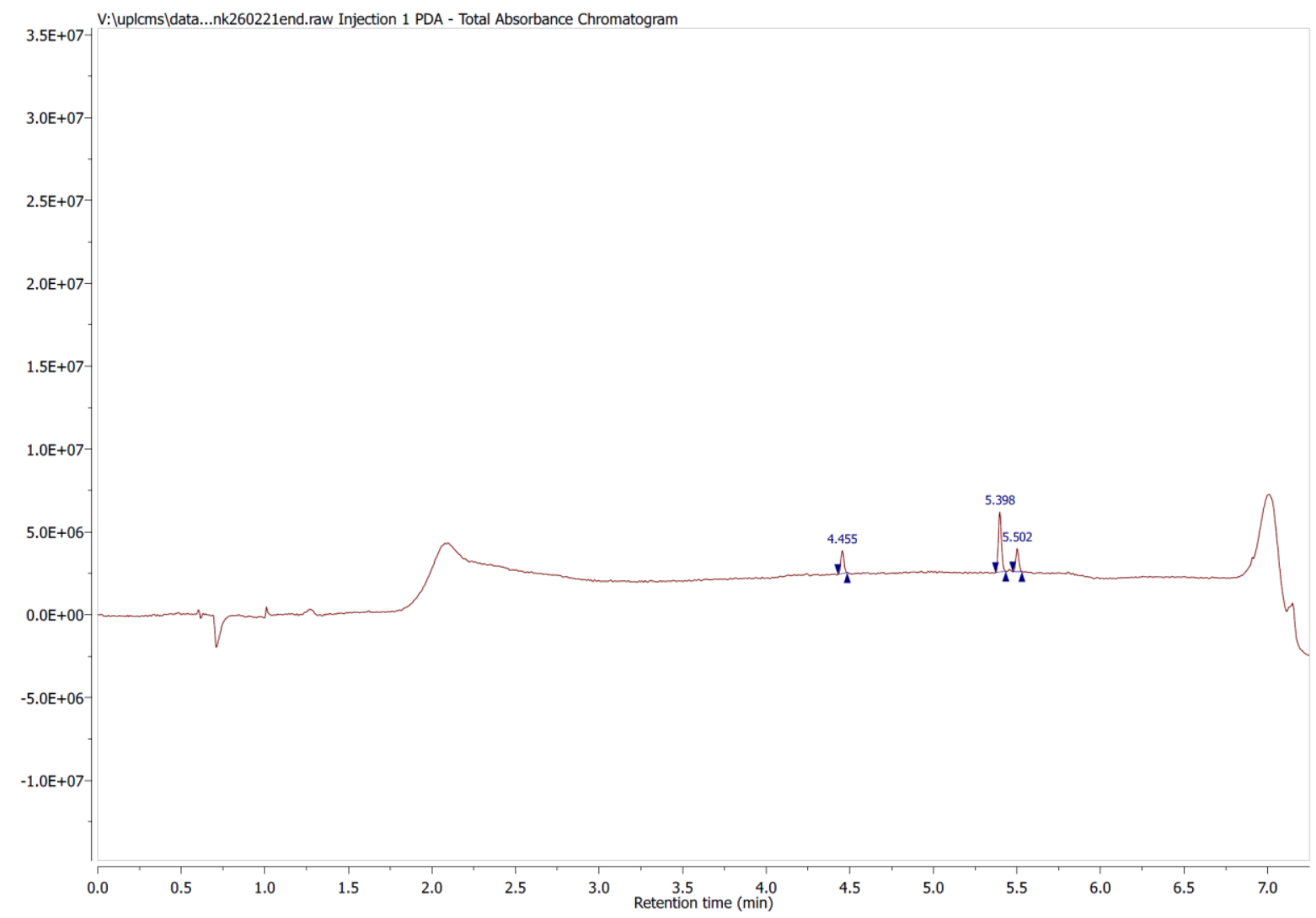

UPLC/UV-VIS chromatogram_Blank_2

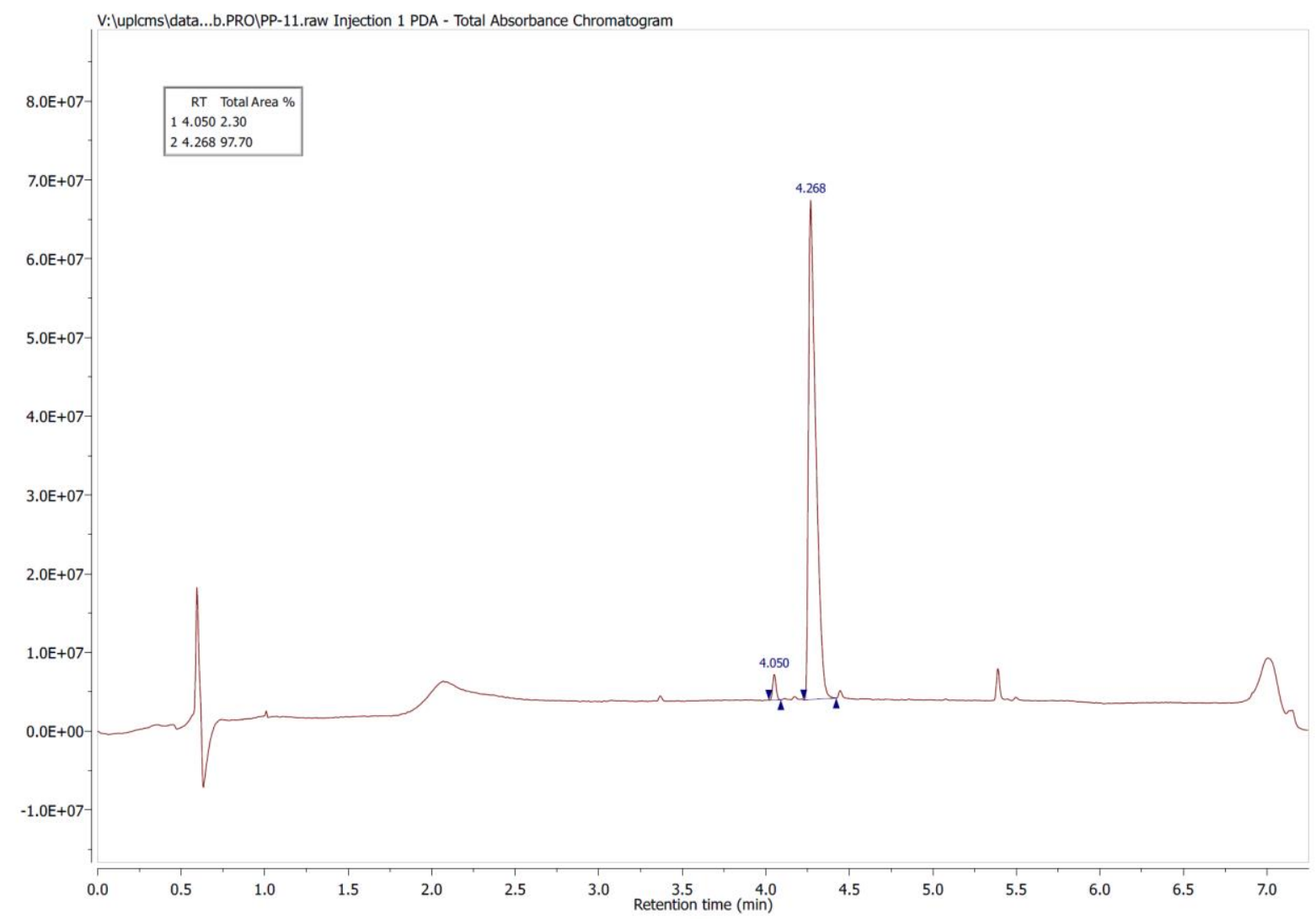

UPLC/UV-VIS chromatogram_Compound $\mathbf{3 b}$ 


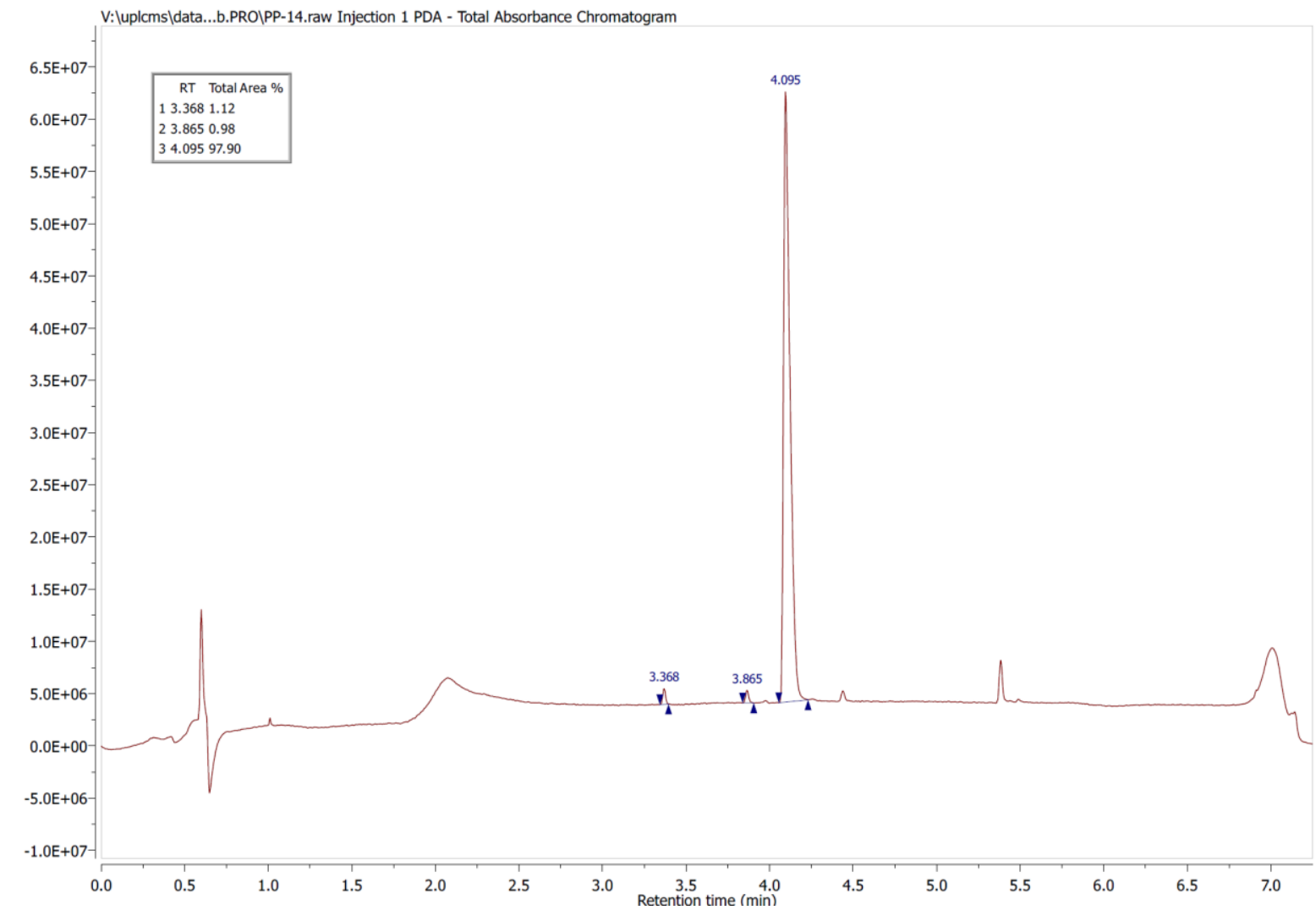

UPLC/UV-VIS chromatogram_Compound 3c

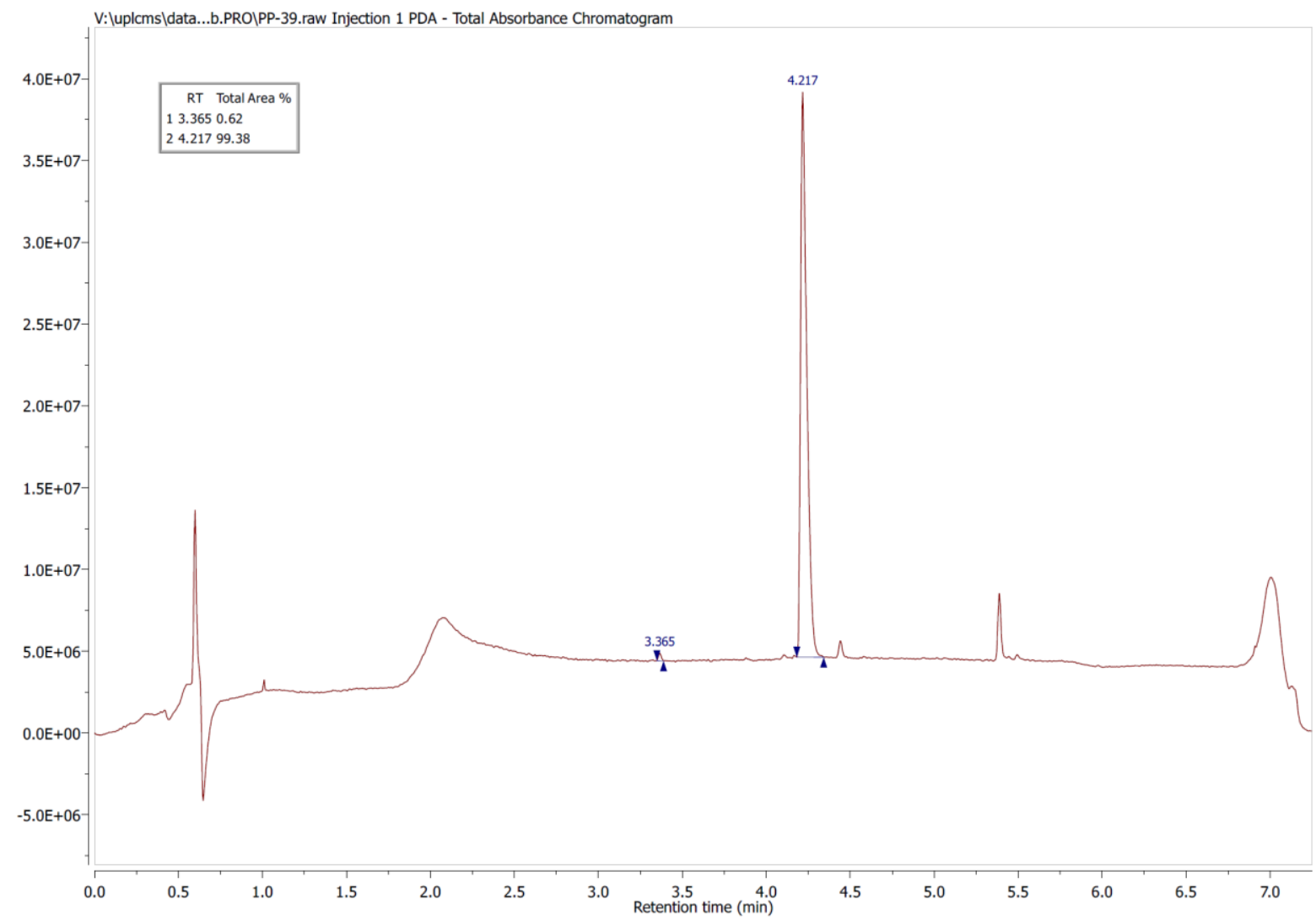

UPLC/UV-VIS chromatogram_Compound 3k 


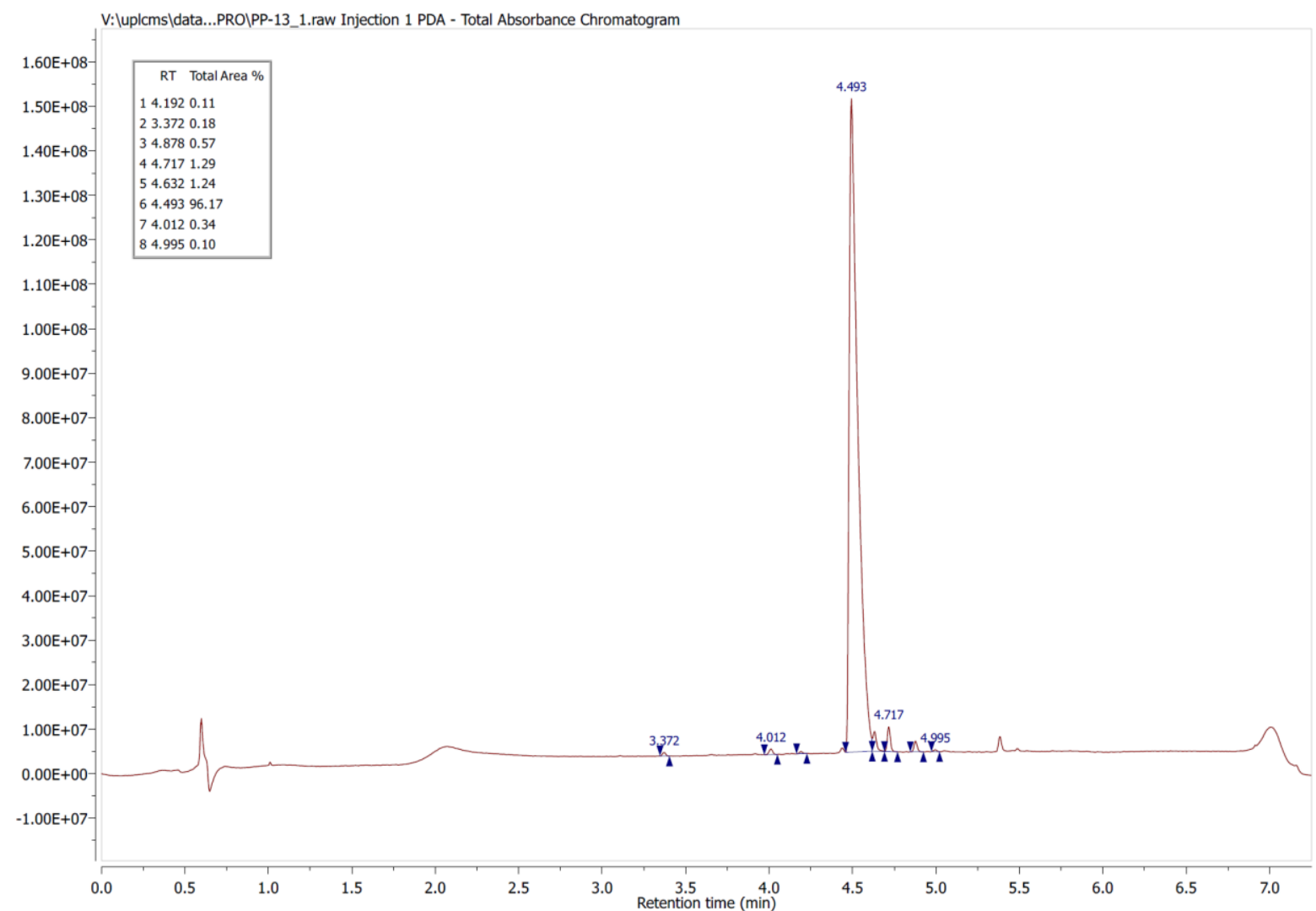

UPLC/UV-VIS chromatogram_Compound 3v

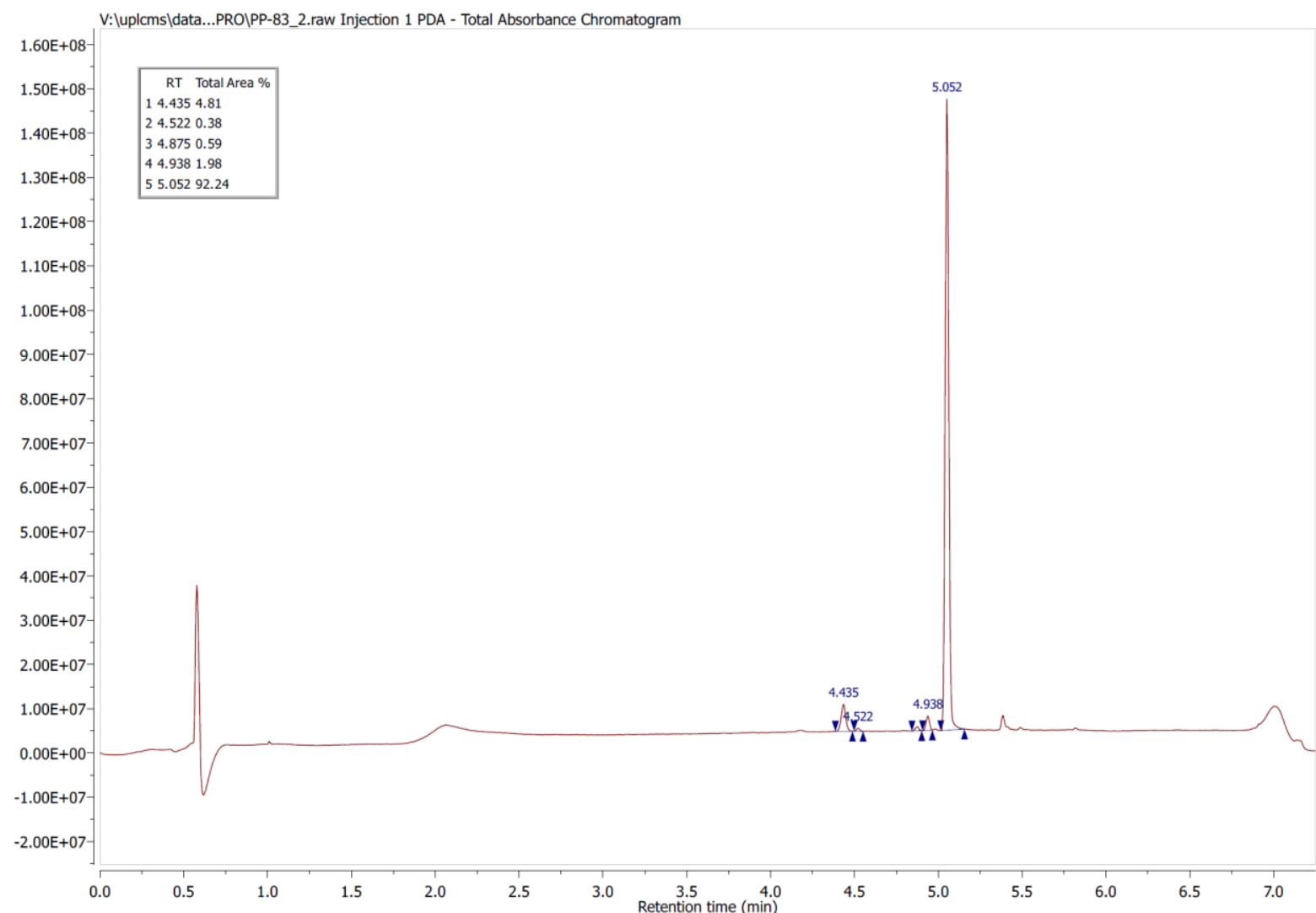

UPLC/UV-VIS chromatogram_Compound 6c 


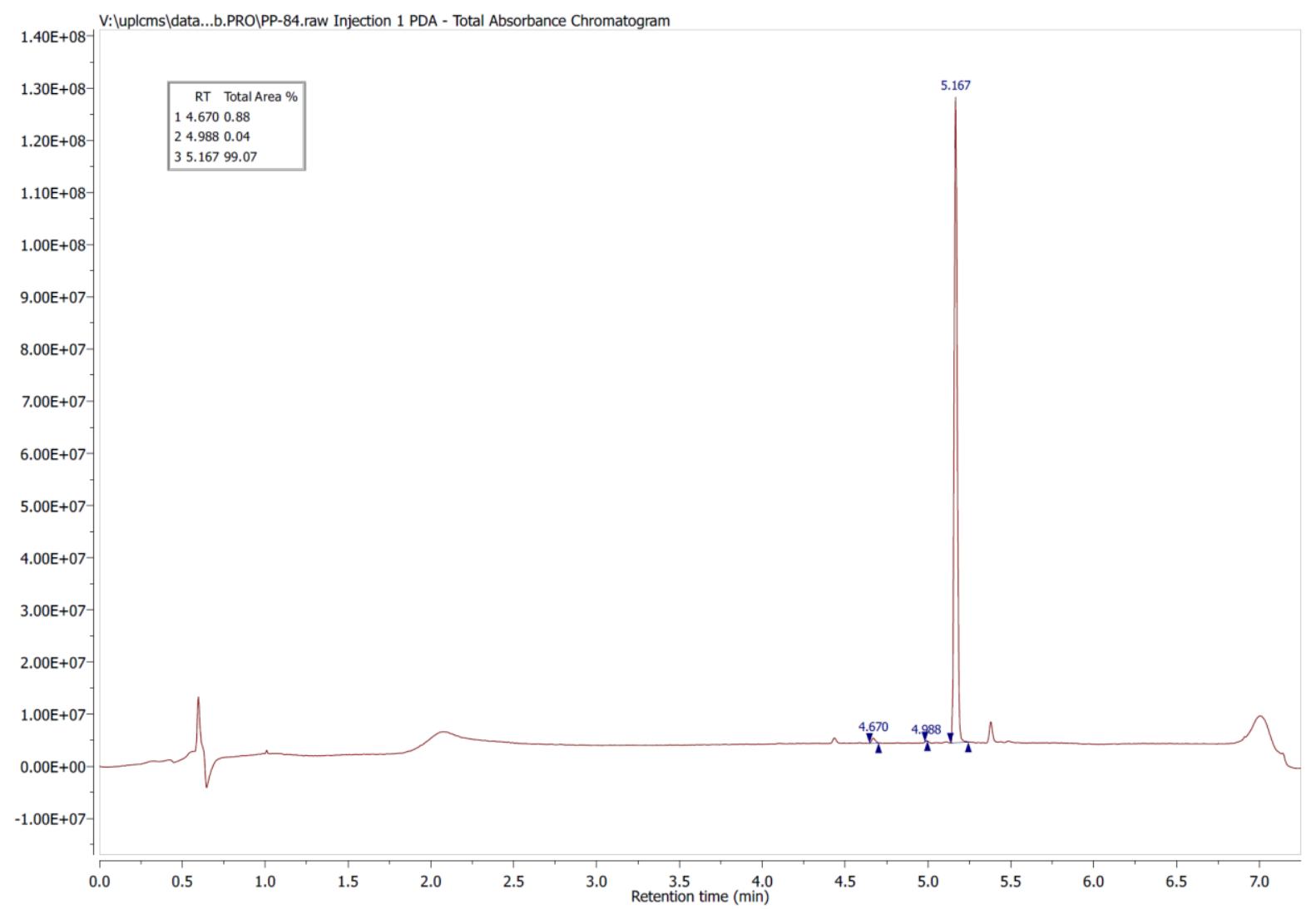

UPLC/UV-VIS chromatogram_Compound 6 e

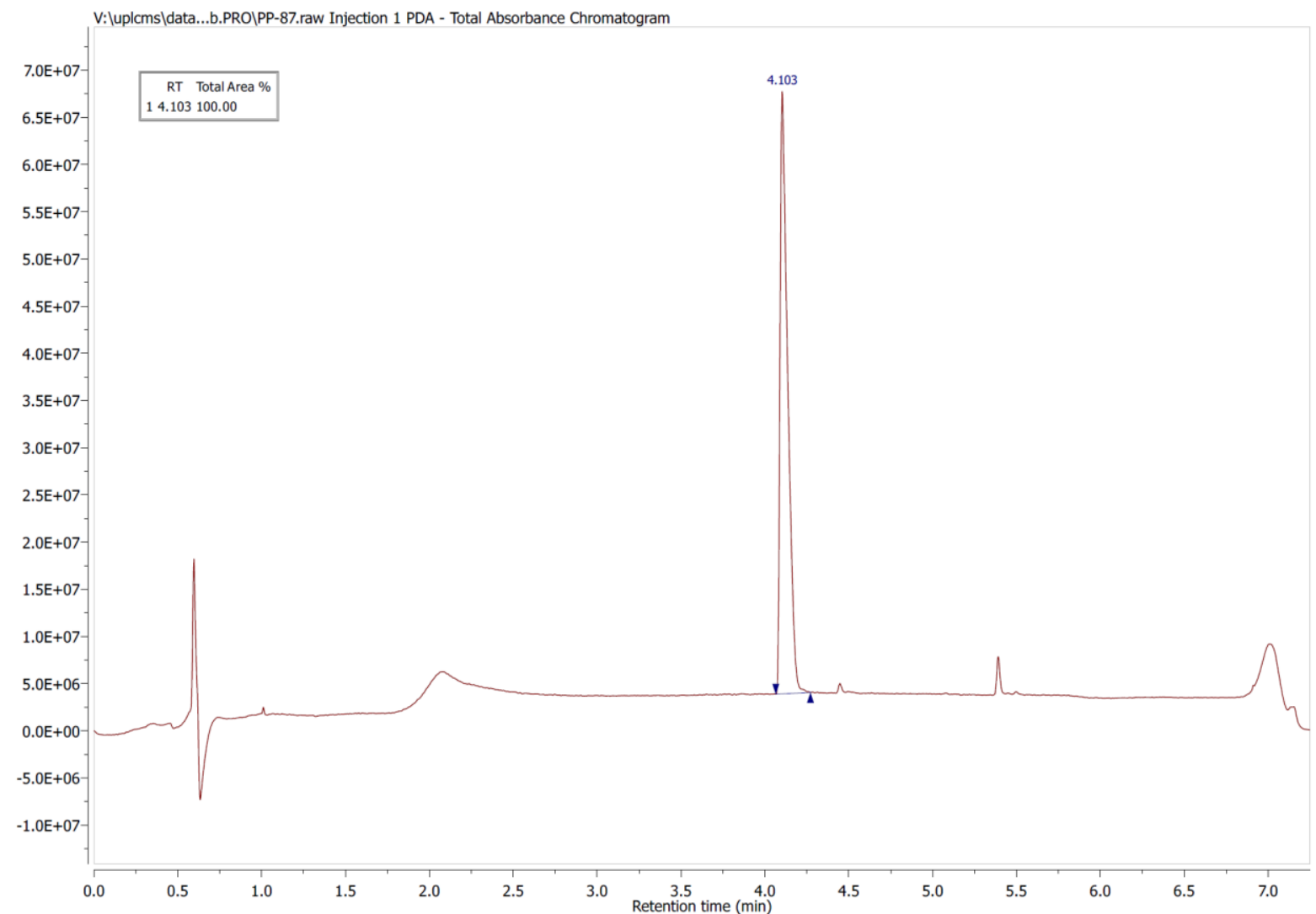

UPLC/UV-VIS chromatogram_Compound 70 


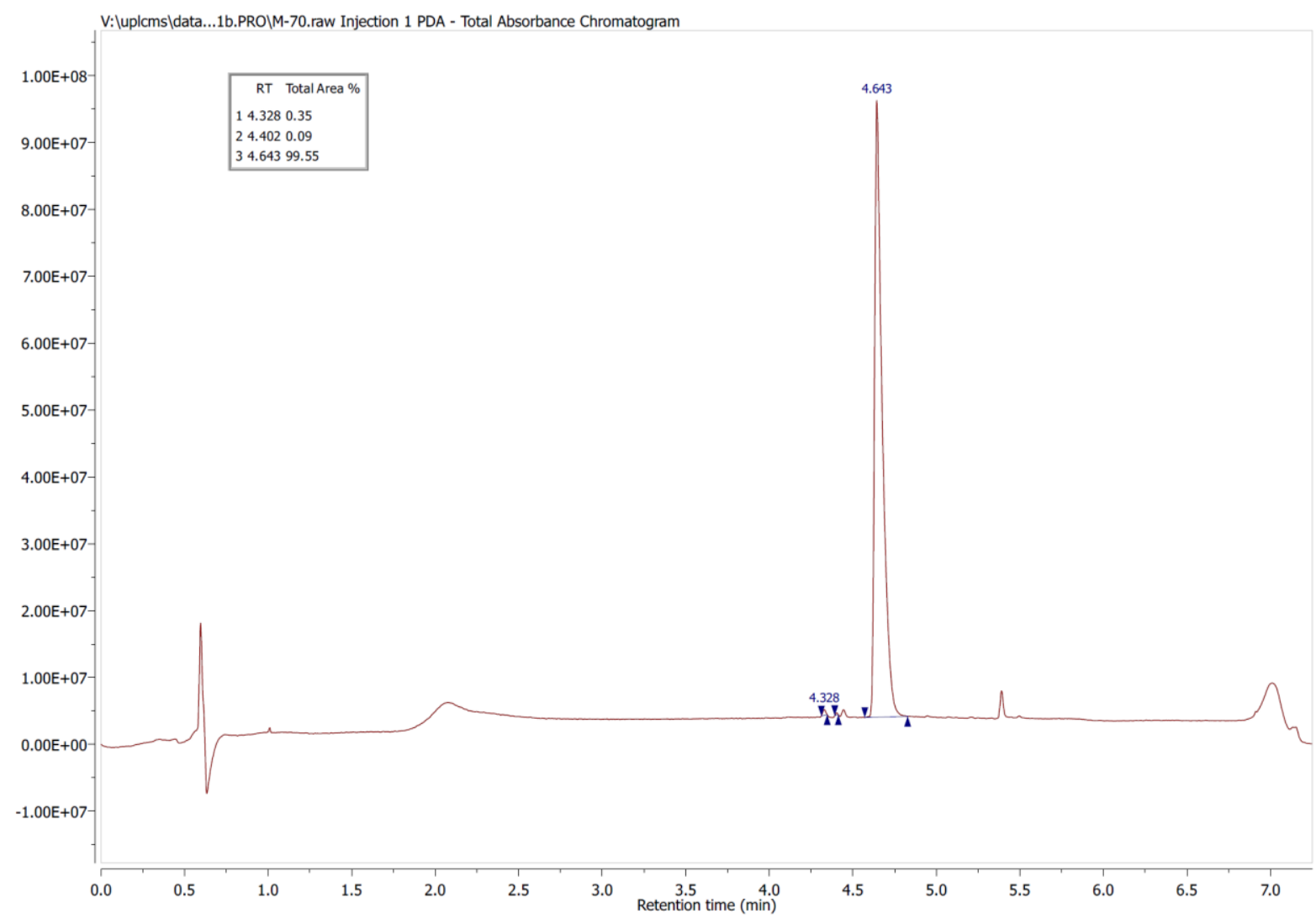

UPLC/UV-VIS chromatogram_Compound 8a

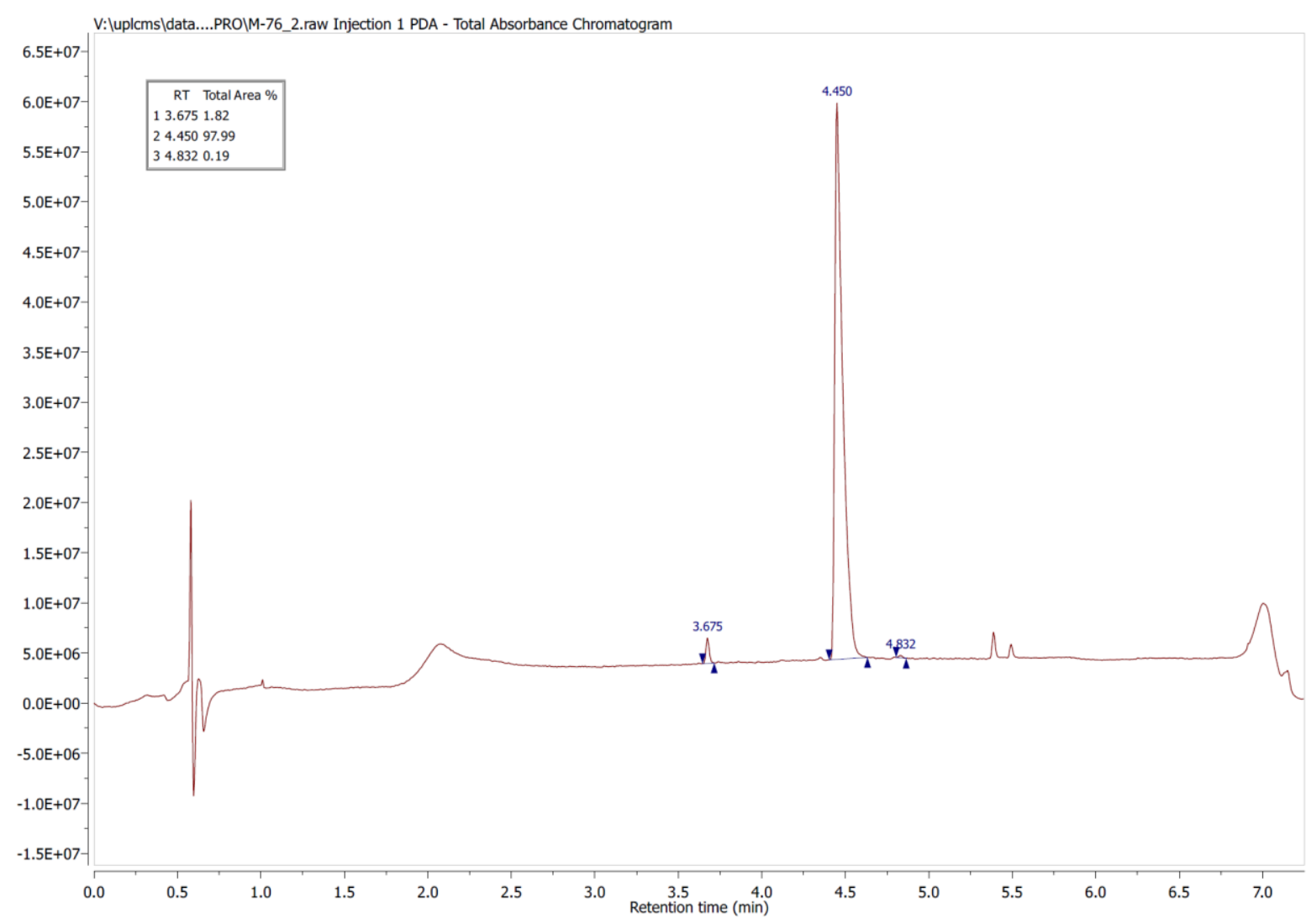

UPLC/UV-VIS chromatogram_Compound $8 \mathbf{b}$ 


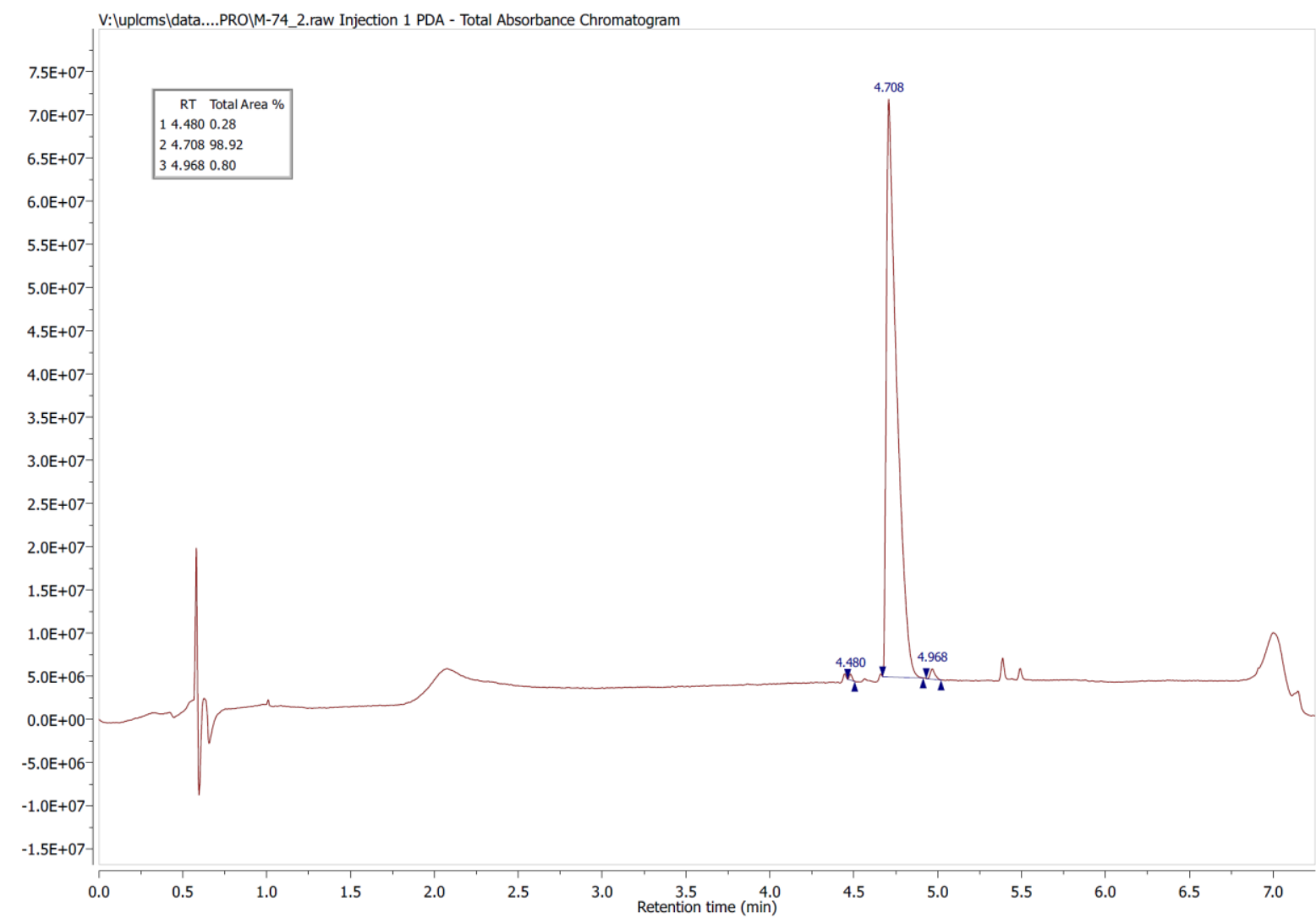

UPLC/UV-VIS chromatogram_Compound 9a

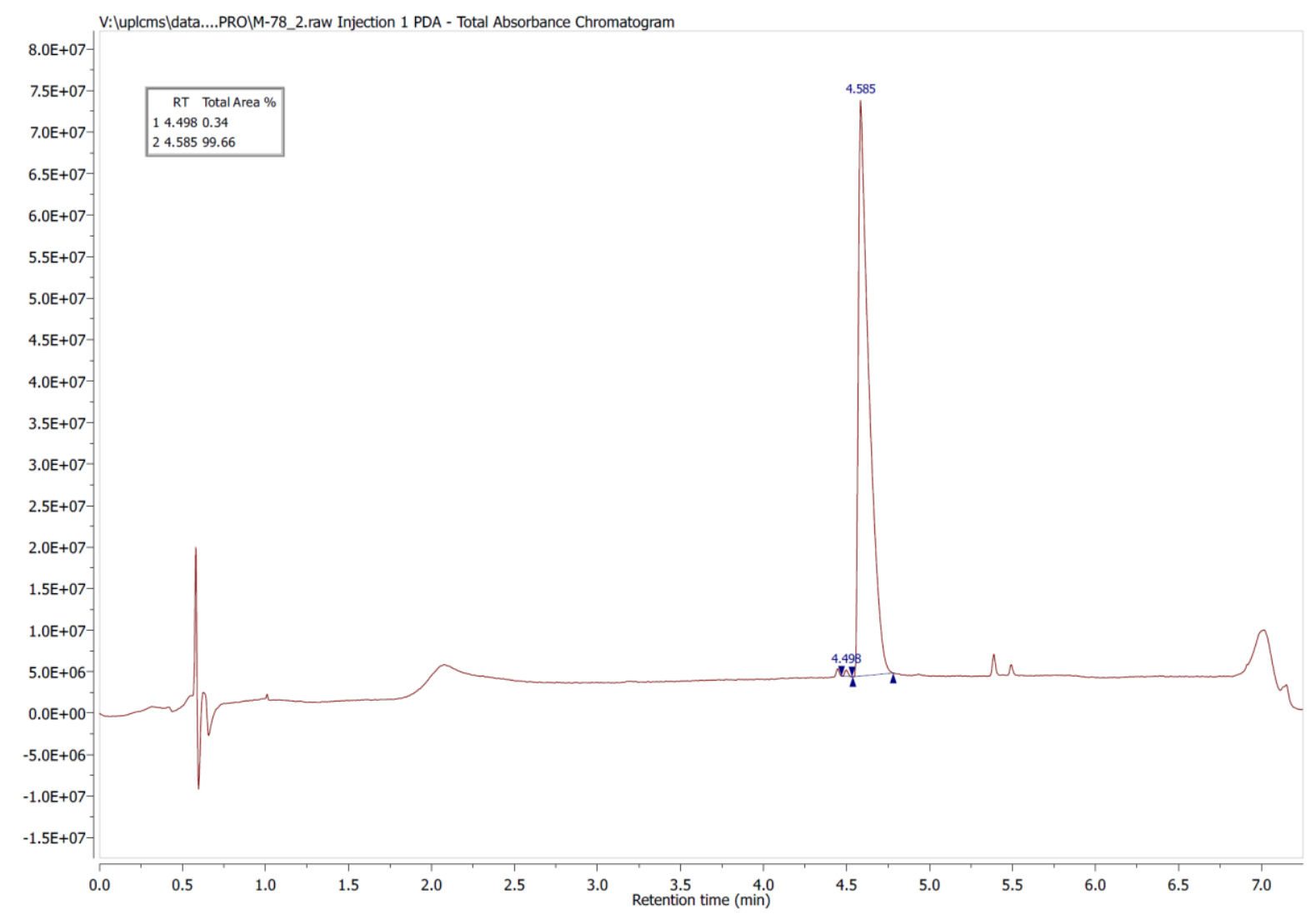

UPLC/UV-VIS chromatogram_Compound 9b 